\title{
WestVirginiaUniversity
}

THE RESEARCH REPOSITORY @ WVU

Graduate Theses, Dissertations, and Problem Reports

2010

\section{Mathematical modeling in understanding NFkB signaling pathway}

Huanling Liu

West Virginia University

Follow this and additional works at: https://researchrepository.wvu.edu/etd

\section{Recommended Citation}

Liu, Huanling, "Mathematical modeling in understanding NFkB signaling pathway" (2010). Graduate Theses, Dissertations, and Problem Reports. 4627.

https://researchrepository.wvu.edu/etd/4627

This Thesis is protected by copyright and/or related rights. It has been brought to you by the The Research Repository @ WVU with permission from the rights-holder(s). You are free to use this Thesis in any way that is permitted by the copyright and related rights legislation that applies to your use. For other uses you must obtain permission from the rights-holder(s) directly, unless additional rights are indicated by a Creative Commons license in the record and/ or on the work itself. This Thesis has been accepted for inclusion in WVU Graduate Theses, Dissertations, and Problem Reports collection by an authorized administrator of The Research Repository @ WVU. For more information, please contact researchrepository@mail.wvu.edu. 
Mathematical modeling in understanding NFkB signaling pathway

\title{
Huanling Liu
}

\author{
Thesis submitted to the \\ College of Engineering and Mineral Resources \\ at West Virginia University \\ in partial fulfillment of the requirements \\ for the degree of \\ Master of Science \\ in \\ Engineering
}

David J. Klinke, Ph.D., Chair

Charter D. Stinespring, Ph.D.

Robin Hissam, Ph.D.

Morgantown, West Virginia

2010

Keywords: 3,4-dichloropropionanilide, NFкB, Macrophages, Mathematical Modeling, Statistic Analysis 


\section{ABSTRACT Mathematical modeling in understanding NFкB signaling pathway Huanling Liu}

Chronic diseases, cancers and diabetes are associated with dysregulation of many biochemical cues. These biochemical cues are proteins that regulate cellular activity migration and death. The synthesis of these proteins is regulated by nuclear transcription factors. One of the most studied transcription factor is nuclear factor kappa B (NFкB). Many different proteins have been identified that regulate the activity of NFKB. Yet, how these proteins regulate $\mathrm{NF} \mathrm{K}$ is still unclear.

Understanding the regulation of $\mathrm{NF}_{\mathrm{K}} \mathrm{B}$ is important for developing drugs to treat these diseases. Our long term goal is to understand the mechanisms that regulate NFкB activity. The goal of this research is to identify how NFкB activity is regulated. As a model system, we will use LPS to stimulate macrophage cells with or without 3, 4dichloropropionanilide (DCPA) treatment. DCPA is a post-emergent herbicide used for controlling weeds in rice crops. Exposure to DCPA causes increases in liver and spleen weight demonstrated by toxicity study on rats. Previous study in our lab showed that DCPA could modulate NFKB activity. Our central hypothesis is that a mathematical model can be used to infer the regulation steps that are altered following DCPA treatment. To test our central hypothesis, we performed the following specific aim:

Establish that NFкB is differentially regulated by ІкВ $\alpha$ and ІкВ $\beta$ and that these proteins are in turn differentially regulated by DCPA. Moreover, a mathematical model was used to establish observed dynamics of $\mathrm{NF}_{\kappa} \mathrm{B}$ activities. Our working hypothesis is that an ordinary differential equation (ODE)-based model that includes $\mathrm{NF} \kappa \mathrm{B}$ regulation by ІкB $\alpha$ proteins can capture the observed dynamics. Furthermore, we used an empirical Bayesian approach to establish confidence in model parameters. Then, we included ІкВ $\beta$ in the model to more realistically describe the regulation of $\mathrm{NFK}_{\mathrm{B}}$ activity in macrophages. We expect that the results of this research will lead to greater understanding of the regulatory mechanism of $\mathrm{NFKB}$ signaling pathway in macrophages and have important implication for human health. This improved understanding may also inspire new ideas to treat these diseases. 


\section{DEDICATION}

To my husband, Mingyang Gong, and my parents 


\section{ACKNOWLEDGEMENTS}

I gratefully acknowledge the help and support of my advisor, Dr. David J Klinke. His knowledge, experience and enthusiasm gave me the possibility to complete this project. I thank Dr. John Barnett and his graduate student, Irina V. Ustyugova, for their work on experiments. I also would like to acknowledge support and help from all the faculty and graduate students in chemical engineering department. Lastly, I acknowledge my husband and my family for their supporting. 


\section{Table of Contents}

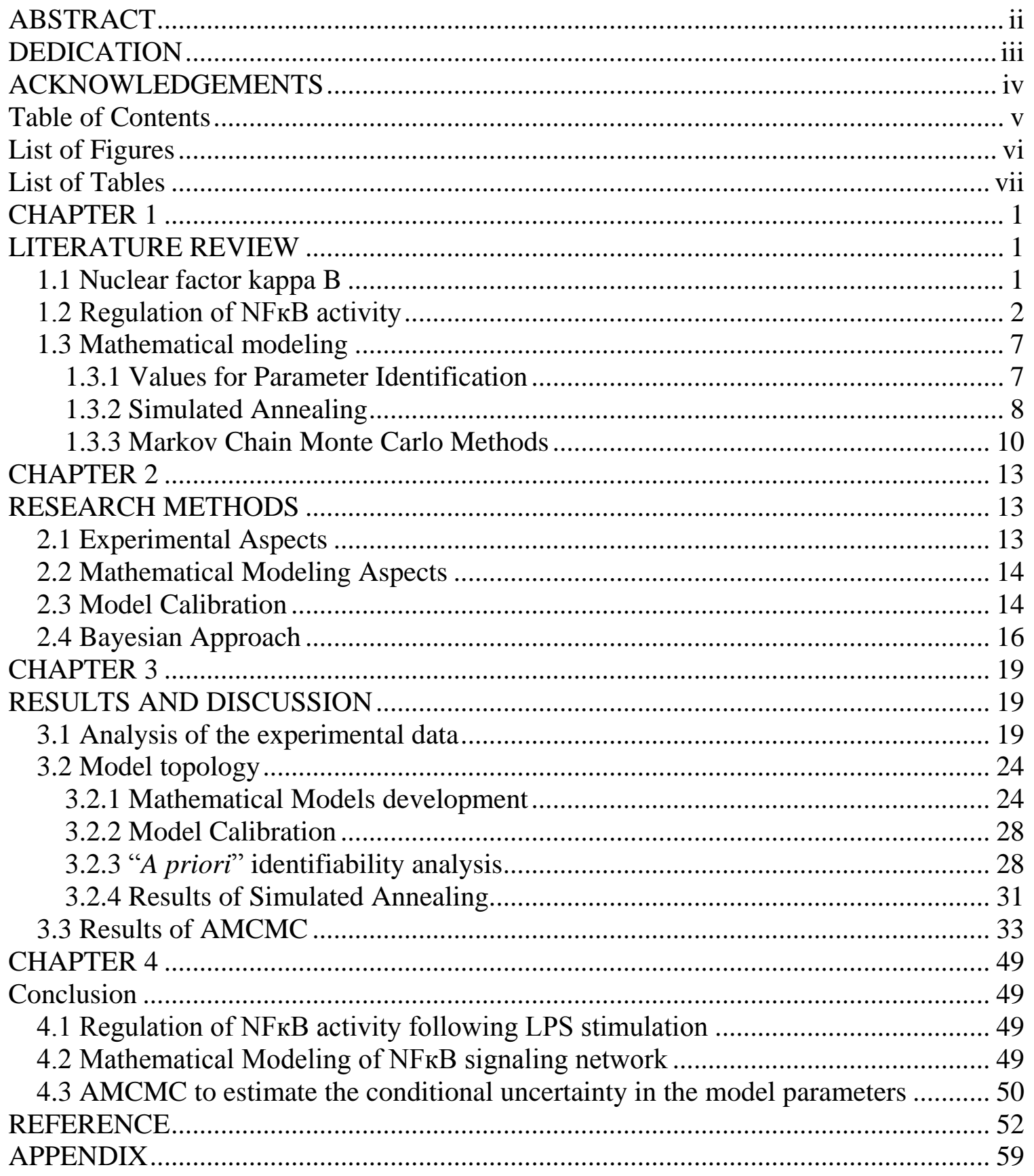




\section{List of Figures}

Figure 1 The dynamic activation of $\mathrm{NF}-\kappa \mathrm{B}$ in macrophages compared against prior

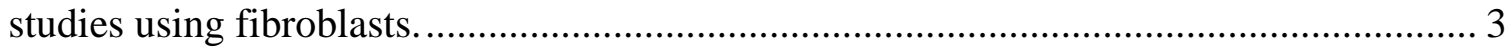

Figure 2 The I $\mathrm{B}$ family...................................................................................... 4

Figure 3 Schematic depiction of Lipniack's model (B) and Model predictions versus Hoffmann et al. (2002) measurements on wild-type cells (down) (A) NF-kB during persistent 6 h-long TNF stimulation [13]; (C) NF-kB at and after 15 min-long TNF

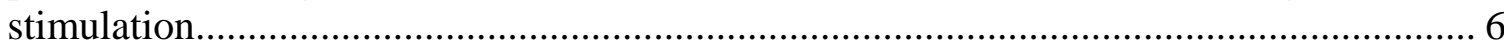

Figure 4 The structure of the simulated annealing algorithm....................................... 9

Figure 5 The AMCMC algorithm structure for our model .......................................... 17

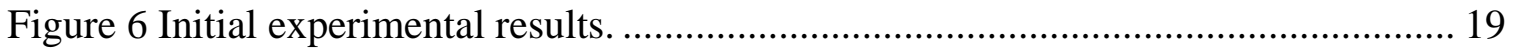

Figure 7 Summary of experimental data and normalized by the concentration before LPS

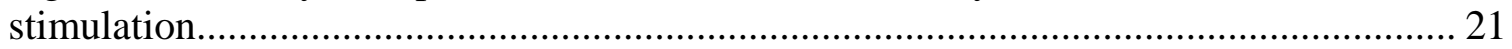

Figure 8 Schematic demonstration of the model 1 for $\mathrm{NF}$ KB signaling following the LPS

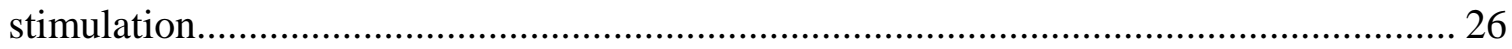

Figure 9 Schematic demonstration of the model 2 for NFкB signaling.. ...................... 27

Figure 10 Simulation results for model 1 compared with experimental data without

DCPA treatment using simulated annealing program............................................. 31

Figure 11 Simulation results for model 1 compared with experimental data with DCPA

treatment by simulated annealing program........................................................... 32

Figure 12 Evolution of the performance of the AMCMC algorithm............................. 34

Figure 13 Evolution in the likelihood, $\mathrm{P}(\mathrm{Y} \mid \Theta, \mathrm{M})$, as a function of AMCMC step......... 35

Figure 14 Gelman-Rubin assessment of the Convergence of AMCMC ......................... 36

Figure 15 The mathematical model 1 for early signaling events reproduces the early

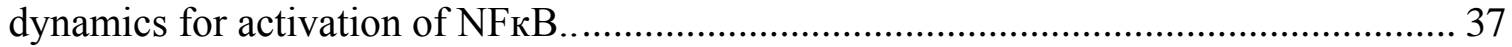

Figure 16 AMCMC summary plots for each of the model parameters for model 1 without

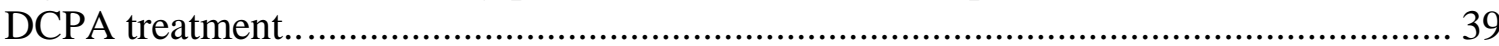

Figure 17 Normalized Distributions in Parameters for model 1 without DCPA treatment

Figure 18 Covariance structure of $\mathrm{P}(\Theta \mid \mathrm{Y})$ for model 1 without DCPA treatment. ......... 41

Figure 19 AMCMC summary plots for each of the model parameters for experimental

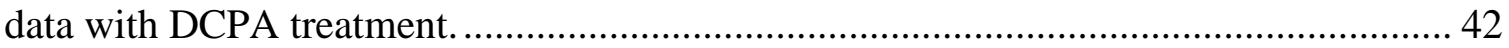

Figure 20 Normalized Distributions in Parameters for experimental data with DCPA

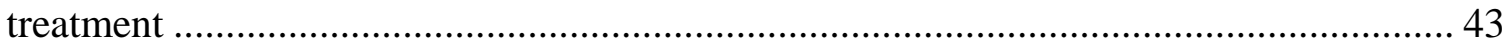

Figure 21 - Convergence of AMCMC . A contour plot of the Gelman-Rubin statistic of the model predictions as a function of time (i.e., the y-axis) calculated as a function of the cumulative chain up to a specific AMCMC step (i.e., the x-axis)................................ 44 Figure 22 The mathematical model 1 for early signaling events reproduces the early dynamics for activation of free $\mathrm{NF} \kappa \mathrm{B}$ expression $(\mathrm{A}, \mathrm{C})$ in the nucleus and $\mathrm{I}_{\kappa} \mathrm{B} \alpha(\mathrm{B}, \mathrm{D})$ in

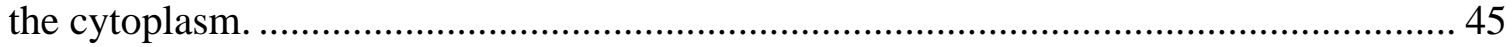

Figure 23 AMCMC summary plots for each of the model parameters for experimental

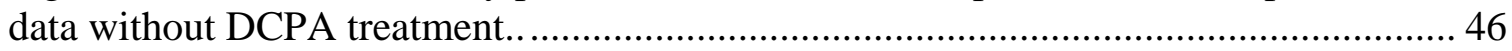


Figure 24 The mathematical model 2 for early signaling events reproduces the early

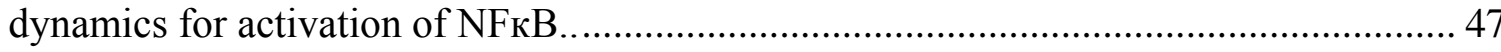

\section{List of Tables}

Table 3.1 Correlation analysis of unknown parameters in Model 1 .............................. 29

Table 3.2 Comparison of the parameter values fit to the two experimental conditions ... 30

Table A.1 List of Models Variables........................................................................... 59

Table A.2 Reaction rate equations of Model 1 and Model 2 for NFKB signaling pathway

Table A.3 Differential equations that define the mathematical model 1 for NFkB signaling pathway 65

Table A.4 Differential equations that define the mathematical model 2 for NFkB signaling pathway 66

Table A.5 List of parameters and corresponding values model 1 and model 2. 


\section{CHAPTER 1}

\section{LITERATURE REVIEW}

\subsection{Nuclear factor kappa B}

Chronic diseases, cancers and diabetes are associated with dysregulation of many biochemical cues $[1,2]$. These biochemical cues are proteins that regulate cellular activity migration and death. The synthesis of these proteins is regulated by nuclear transcription factors. One of the most studied transcription factors is nuclear factor kappa $\mathrm{B}(\mathrm{NF} \mathrm{K})$, which plays an important role in regulating the expression of various inflammatory mediators $[3,4,5]$. Inflammatory mediators are released by immune cells during times when harmful agents invade our body. Immune cells like macrophages can recognize the bacterial cell wall components, such as lipopolysaccharide (LPS), and secret inflammatory mediators like TNF $\alpha$ and IL-1. In rheumatoid arthritis patients, inflammatory mediators like TNF $\alpha$ and IL-1 are secreted by primarily macrophages and also upregulated by NFкB. Then TNF $\alpha$ and IL-1 activate NFкB in a wide variety of cells to produce more inflammatory mediators inducing cytokines [41]. Roy L and co-workers [42] observed that pro-arthritic mice had significant increase in breast cancer-associated secondary metastasis compared to non-arthritic mice. Increased inflammatory mediators like IL-6, TNF $\alpha$ and IL-17 were measured on arthritic mice and were suggested as the underlying factors that are responsible for the increased metastasis in the arthritic mice. NFкB was also observed constitutively active in mononuclear cells from patients with type 1 diabetes and some cancers [1,4]. For inflammation-associated cancers, activity of NFкB was proposed to enhance tumor development by promoting inflammation.

Therefore, understanding the regulatory mechanisms for NFкB activity is important for treating these diseases [6].

3,4-dichloropropionanilide (DCPA), which is also known as propanil, is a common herbicide for control of weeds on commercial rice crops worldwide. DCPA has been demonstrated suppressing inflammatory mediator TNF $\alpha$ production by macrophage following the LPS stimulation on both mRNA and protein levels [27]. Further study on 
the mechanism of DCPA suppressing macrophage functions by Frost and coworkers [29] demonstrated that DCPA treatment decreases NFKB nuclear localization and DNA binding in IC-21 cells following $10 \mu \mathrm{g} / \mathrm{ml}$ LPS stimulation. A simple mathematical model was built to display the effect of DCPA on NFKB activity [28]. DCPA treatment resulted in a potentiation of early LPS-induced NFKB activation and could be a tool to probe the fundamental aspects of NFKB signaling. However, the mechanism of DCPA modulating NFKB is still not clear. Our current research aims to expand this model to incorporate mechanisms by which NFKB is regulated in macrophages. Furthermore, an empirical Bayesian approach will be used to establish confidence in model parameters and the special aspects affected by DCPA treatment.

\subsection{Regulation of NFrB activity}

Many different proteins have been identified having ability to regulate NFKB activity. Besides those proteins in the signaling process indentified as inhibitors of NFKB, a lot of other compounds like small molecules are found to modulate NFKB activity [25,26,29]. DCPA has also been shown to alter NFKB activity [28]. Yet, how these proteins and compounds regulate $\mathrm{NF \kappa B}$ is still unclear $[7,8]$. Moreover, the regulatory mechanisms may be different in different cell types. In Figure 1 which is summarized Klinke [28], we can see that NFKB is activated more rapidly in macrophages than in Fibroblasts following LPS stimulations.[28] The different dynamics of NFKB activity may be caused by different signaling pathways. Different cells have different functions in the immune system. Macrophages are important and essential to the regulation of immune response and the development of inflammation. Therefore, it is meaningful to Figure out the mechanism of NFKB activity in macrophages.

IкB proteins is a family of similar proteins, including $\mathrm{I \kappa B} \alpha, \operatorname{I\kappa B} \beta$ and $\mathrm{I \kappa B} \varepsilon$ that has been identified as major inhibitors of NFкB activity in different kinds of cells [5,7]. ІкB $\alpha$, ІкВ $\beta$ and ІкВ $\varepsilon$ proteins have several structural motifs in common, including six ankyrin repeats and $\mathrm{N}$-terminal regulatory regions (shown as Figure 2). The similarity in structure also correlates to similar functions: they bind to $\mathrm{NF \kappa B}$, and mask the nuclear localization sequence (NLS) of NFKB. In addition, phosphorylation of IкB proteins by IкB kinase 
(IKK) liberates NFкB [9]. The slight differences in structure lead to differential functions or mechanisms in regulating NFкB $[10,11,34]$. For instance, different dynamics of NFкB activity in embryonic fibroblasts were observed in $\alpha-/-\beta-/-$ cells, $\alpha-/-\varepsilon-/-$ cells, and $\beta-/-\varepsilon-/-$ cells [11]. Mathematical models have been used to explain the discrete functions

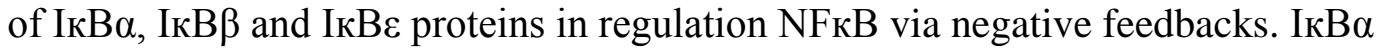
proteins are rapidly synthesized in response to NFKB and are suggested to provide strong negative feedback leading to oscillations in NFкB activity. In contrast, ІкB $\beta$ and ІкB $\varepsilon$ proteins dampen the long-term oscillatory activity of NFKB. Sparked by this work, several other models has been built to help understanding the mechanism of different proteins regulating $\mathrm{NF} \mathrm{B}$ activity following extracellular stimulations as reviewed in [12].

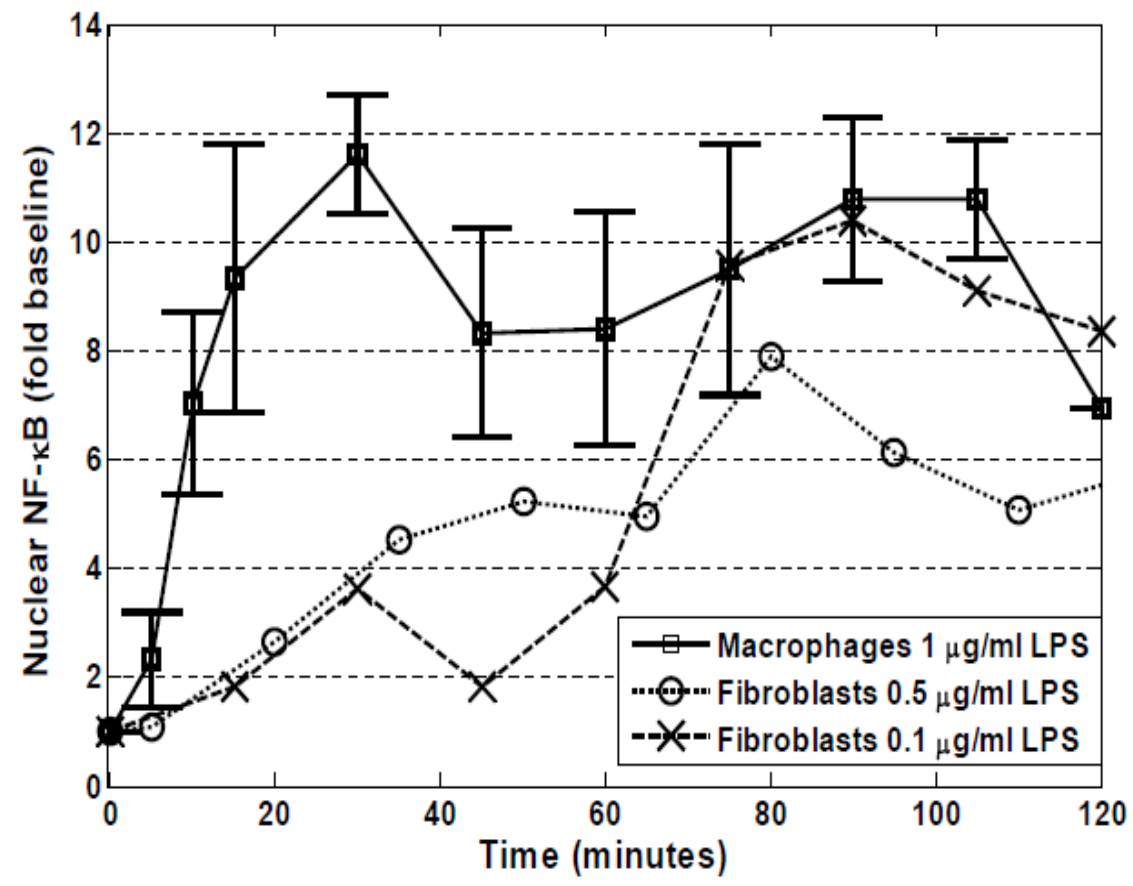

Figure 1 The dynamic activation of NF- $\kappa \mathrm{B}$ in macrophages compared against prior studies using fibroblasts. Nuclear NF- $\mathrm{BB}$ was assayed by EMSA at the indicated times after persistent stimulation with $1 \mu \mathrm{g} / \mathrm{ml}$ LPS in macrophages (in Klinke 2008, $\mathrm{n}=8$, values reported as average $\pm 95 \%$ confidence interval), 0.5 $\mu \mathrm{g} / \mathrm{ml}$ LPS in fibroblasts demonstrated by Covert et al. (30) (०), and $0.1 \mu \mathrm{g} / \mathrm{ml}$ LPS in fibroblasts demonstrated by Werner et al. (46) (x). 

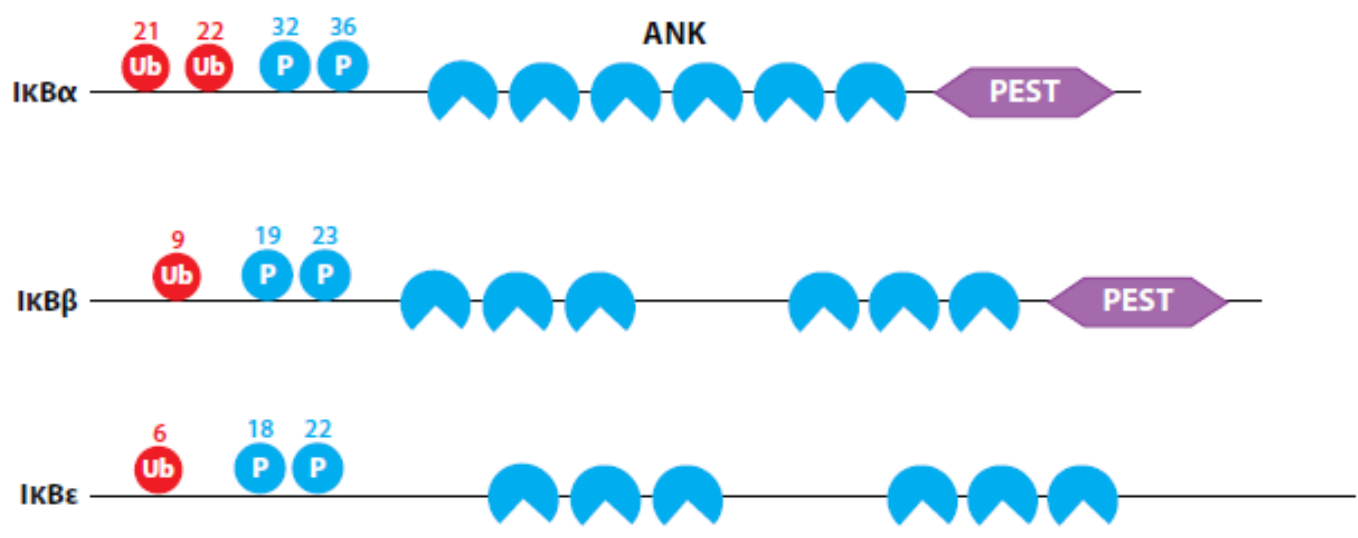

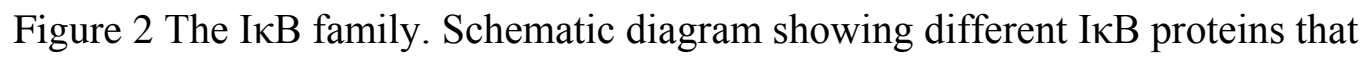
contain several ankyrin repeats (ANK). Phosphorylation and ubiquitination at specific amino acid residues are indicated. Proline $(\mathrm{P})$, glutamic acid $(\mathrm{E})$, serine (S), and threonine (T) domains are indicated as PEST.

Besides ІкB $\alpha$, ІкB $\beta$ and Ік $B \varepsilon$ proteins, $A 20$ is suggested as an important inhibitor of NFKB activation by deactivating IKK [13] or by blocking the upstream activator of IKK [14]. Prolonged NFKB activity was observed not only in A20-deficient fibroblasts following TNF stimulation [15] but also in macrophages following LPS stimulation [16]. Persistent phosphorylation of ІкВ $\alpha$ proteins in A20-deficient cells following the stimulation suggests that prolonged IKK activity results in persistent NFKB activity. Although A20 is essential in regulating NFкB activity following extracellular stimuli, the molecular mechanism of this regulation is still unknown. Ubiquitination (or ubiquitylation) refers to the post-translational modification of a protein by the covalent attachment (via an isopeptide bond) of one or more ubiquitin monomers. A20 has both de-ubiquitination and ubiquitin ligase domains which label proteins for proteasomal degradation. Wert and coworkers established receptor interacting protein (RIP) as an A20 substrate by analyzing possible ubiquitination in the TNF-induced NFKB signaling pathway and found that A20 directly ubiquitinated RIP, which is essential for TNFinduced signaling [17]. 
The expression of most of these important regulators of $\mathrm{NF}_{\kappa} \mathrm{B}$ is also regulated by $\mathrm{NF \kappa B}$ activity [18]. For instance, NFкB directly promotes ІкB $\alpha$ transcription [19]. NFкB binding with $\mathrm{I}_{\kappa} \mathrm{B} \alpha$ results in a slower bound Iк $\mathrm{B} \alpha$ degradation rate compared to free Iк $\mathrm{B} \alpha$ $[20,21]$, but increases phosphorylation of ІкB $\alpha$ by IKK [22]. Thereby, NFкB is not only responsible for the production but also stability of ІкB $\alpha$. For IкB $\beta$ and ІкB $\varepsilon$, less is known about their regulation by NFкB. Kearns and coworkers studied the gene expression of ІкB $\alpha$, ІкВ $\beta$ and ІкB $\varepsilon$ in wild-type murine embryonic fibroblasts (MEFs) and NFкB-deficient MEFs following TNF stimulation [23]. Gene expression of ІкВ $\alpha$, ІкВ $\beta$ and ІкВ $\varepsilon$ was observed increasing in wild-type cells following the stimulation, but

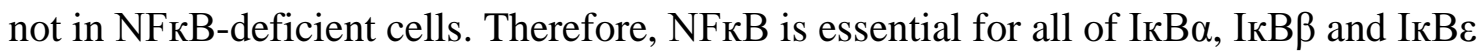
gene expression in MEFs following TNF stimulation. However, the dynamics of expression in response to $\mathrm{NF} \kappa \mathrm{B}$ for these species are different. In particular, ІкB $\beta$ and ІкВ $\varepsilon$ had a 45 minutes transcription delay comparing to ІкB $\alpha$ in wild-type MEFs following TNF stimulation [23]. Although some intermediate transcription factors, like Foxj1, which was demonstrated to have the ability to regulate ІкВ $\beta$ by Lin [24], may cause the time delay, the mechanisms of these different promotions by NFкB are still unknown. Similar to ІкB $\alpha$, rapid A20 gene expression was observed following NFкB activation in wild-type MEFs and also in bone marrow-derived macrophages (BMDMs) $[15,16]$. NFKB controls gene expression of its inhibitors which forms auto-regulatory feedback loops to terminate the NFкB response.

As illustrated by the regulation of A20 and ІкBs on NFKB, these auto-feedback loops play different roles in regulating NFKB dynamics. Given the reciprocal nature of $\mathrm{NF} \mathrm{B} / \mathrm{I} \kappa \mathrm{B}$ regulation, mathematical models integrated with biochemical studies have been an instrumental tool to understand the regulation of NFKB [31]. Most of the models focused on TNF-induced or LPS-induced NFKB activity in MEFs [13, 23, 30]. Biological events were assembled into a biochemical reaction network and modeled using non-linear ordinary differential equations. Parameters were refit to reproduce experimental data under different conditions and assumptions [12], as shown in Figure 3. Figure 3-A reproduced $\mathrm{NFK}_{\mathrm{B}}$ activity measured in wild-type MEFs following during persistent $6 \mathrm{~h}$ - 
long TNF stimulation, while Figure 3-C reproduced that after 15 min-long TNF stimulation. Through this mathematical model which could reproduce some
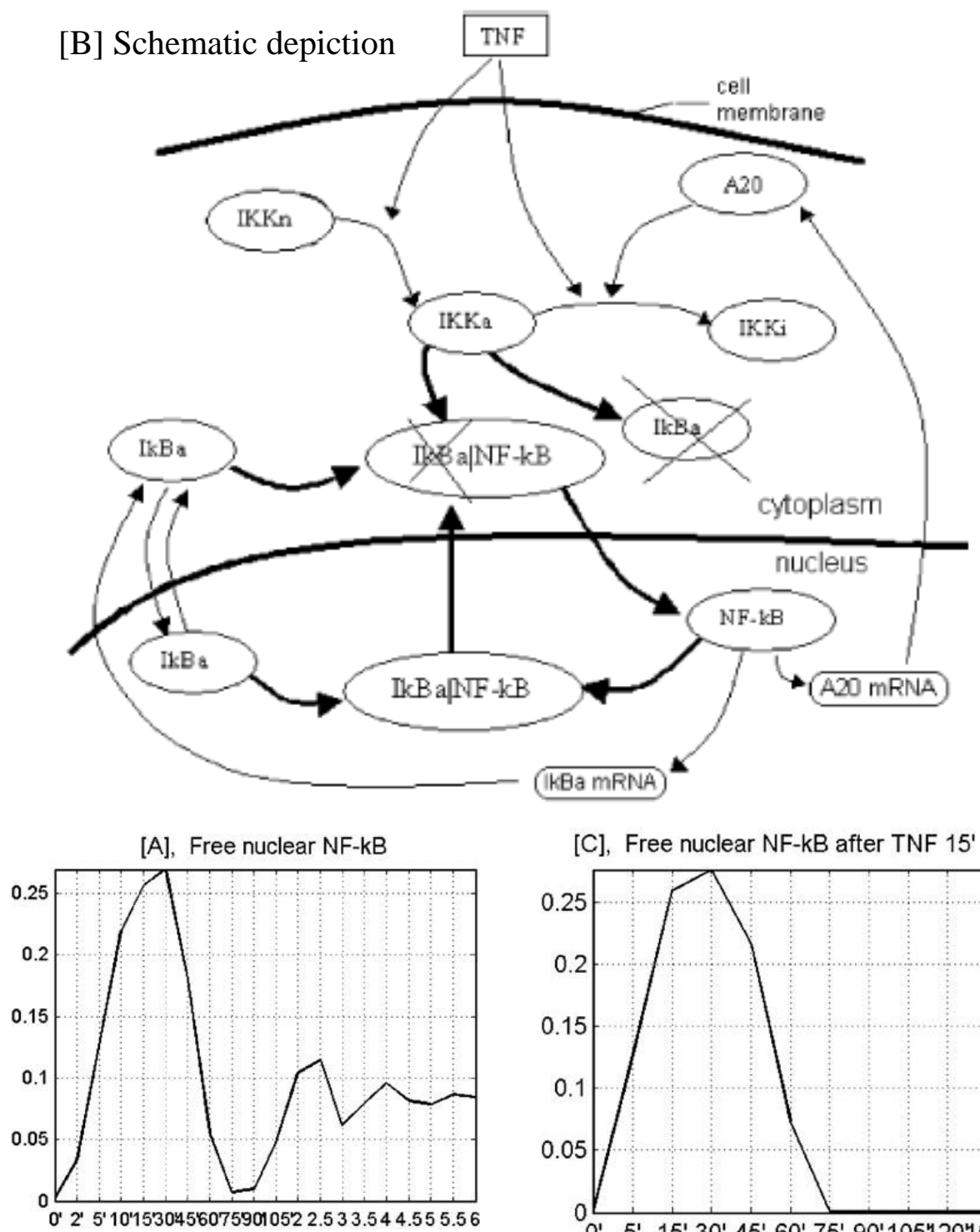

[C], Free nuclear NF-kB after TNF 15' pulse
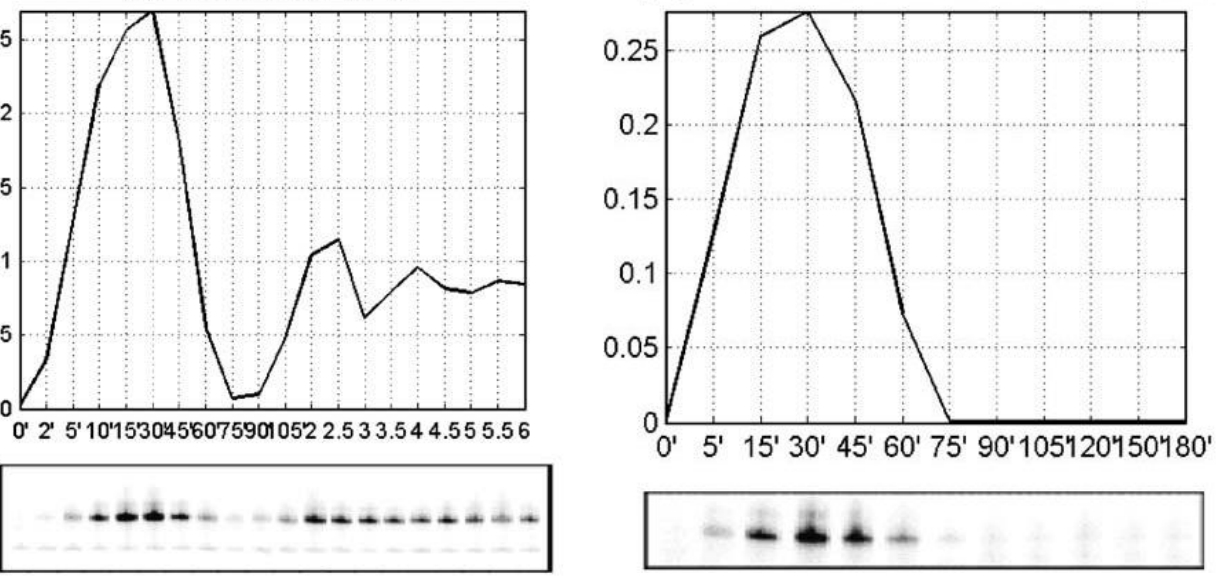

Figure 3 Schematic depiction of Lipniack's model (B) and Model predictions versus Hoffmann et al. (2002) measurements on wild-type cells (down) (A) NFkB during persistent 6 h-long TNF stimulation [13]; (C) NF-kB at and after 15 min-long TNF stimulation. 
experimental data measured under different conditions, the mechanism of $\mathrm{NFKB}$ regulation by $\mathrm{A} 20$ and ІкB $\alpha$ was proposed that $\mathrm{A} 20$ regulates $\mathrm{NF \kappa B}$ activity through inhibiting IKK activity while ІкB $\alpha$ through binding with NFкB and keeping it in the cytoplasm. Through mathematical modeling, the distinct function of other inhibitors in controlling NFкB activity was also demonstrated [23, 32].

\subsection{Mathematical modeling}

Mathematical modeling has been demonstrated as an instrumental tool in understanding signaling mechanisms in biological system [11-13]. Common modeling approaches give the maximum likelihood estimate of some unknown parameters by comparing the simulation results and experimental data[11,13, 45]. However, in biological systems, a signaling network involves tens of or even hundreds of biological events like proteinprotein interaction, mRNA transcription and translation. Not all of these events are currently measurable. Most of the time, only some of the parameters associated with certain events can be measured. For other parameters, a slight change in value may not influence the production or affect system results in ways that are difficult to separate from other parameters. These parameters are called unidentifiable or inestimable. Like experimental studies, we need to establish a level of confidence associate with how well the mathematical model describes a system.

\subsubsection{Values for Parameter Identification}

Parameters associated with biological events can be measured directly by experiment or estimated by analysis data using a mathematical method. For parameters that can't be measured currently, A priori identifiability approach was developed by Jacquez [52]. A priori identifiability is used to check whether the values of the parameters at a point in parameter space can be estimated independently for models described by systems of ordinary differential equations. Klinke [28] used the approach to demonstrate that estimates of the strength parameter of effect DCPA on NFкB activation could be uniquely determined from the data. The sensitivity function is defined as

$\mathrm{S}_{i j}(t)=\left(\partial y_{j}(t) / \partial k_{i}\right) \cdot k_{\mathrm{i}} \operatorname{MAX}\left(y_{j},(t)\right)$ 
where $y_{j}$ represents model variables, $k_{i}$ denotes model parameters around a local optimum, and the partial derivative values are scaled by the parameter value and the maximum value of the model variable during the simulation. The sensitivity function is practically approximated by obtaining the sensitivity measure $S_{i j}$ at a set of dicrete time points, $t_{k}$, and experimental conditions, $[\mathrm{Cn}]_{n}$. Then a reduced sensitivity matrix (M) is constructed as

$\mathrm{M}=\left[\mathrm{S}_{i j}\left(\mathrm{t}_{1}, C n_{0}\right), \ldots, \mathrm{S}_{i j}\left(t_{k}, C n_{0}\right), \ldots, \mathrm{S}_{i j}\left(t_{1}, C n_{n}\right), \ldots, \mathrm{S}_{i j}\left(t_{k}, C n_{n}\right)\right]^{\mathrm{T}}$

A set of correlation coefficients between model parameters is calculated from M.

Parameters that are locally identifiable have correlations with all other parameters between in practical -0.99 and +0.99 . Parameters that are not locally identifiable, termed a proiori unidentifiable, have correlations of greater than 0.95 and less than -0.95 with at least one other parameter.

\subsubsection{Simulated Annealing}

Simulated Annealing (SA) is a random searching technique, developed in 1983 to deal with highly nonlinear problems. The principle and advantages of SA was reviewed by Busetti[56]. SA exploits an analogy between the way in which a metal cools and freezes into a minimum energy crystalline structure (the annealing process) and the search for a minimum in a more general system. The principle of SA approaching the global maximization is similarly to using a bouncing ball which can bounce over mountains from valley to valley. At the beginning, it starts from a "high temperature" bounce with high energy to access any valley, and then finally get into a small range of valleys. The SA method needs a generating distribution that generates possible valleys or states to be explored and an acceptance distribution which depends on the difference between the function value of the present generated valley to be explored and the last saved lowest valley. The acceptance distribution decides probabilistically whether to stay in a new lower valley or to bounce out of it. All generating and acceptance distributions depend on the temperature. The structure of the simulated annealing algorithm is shown as Figure 4. 


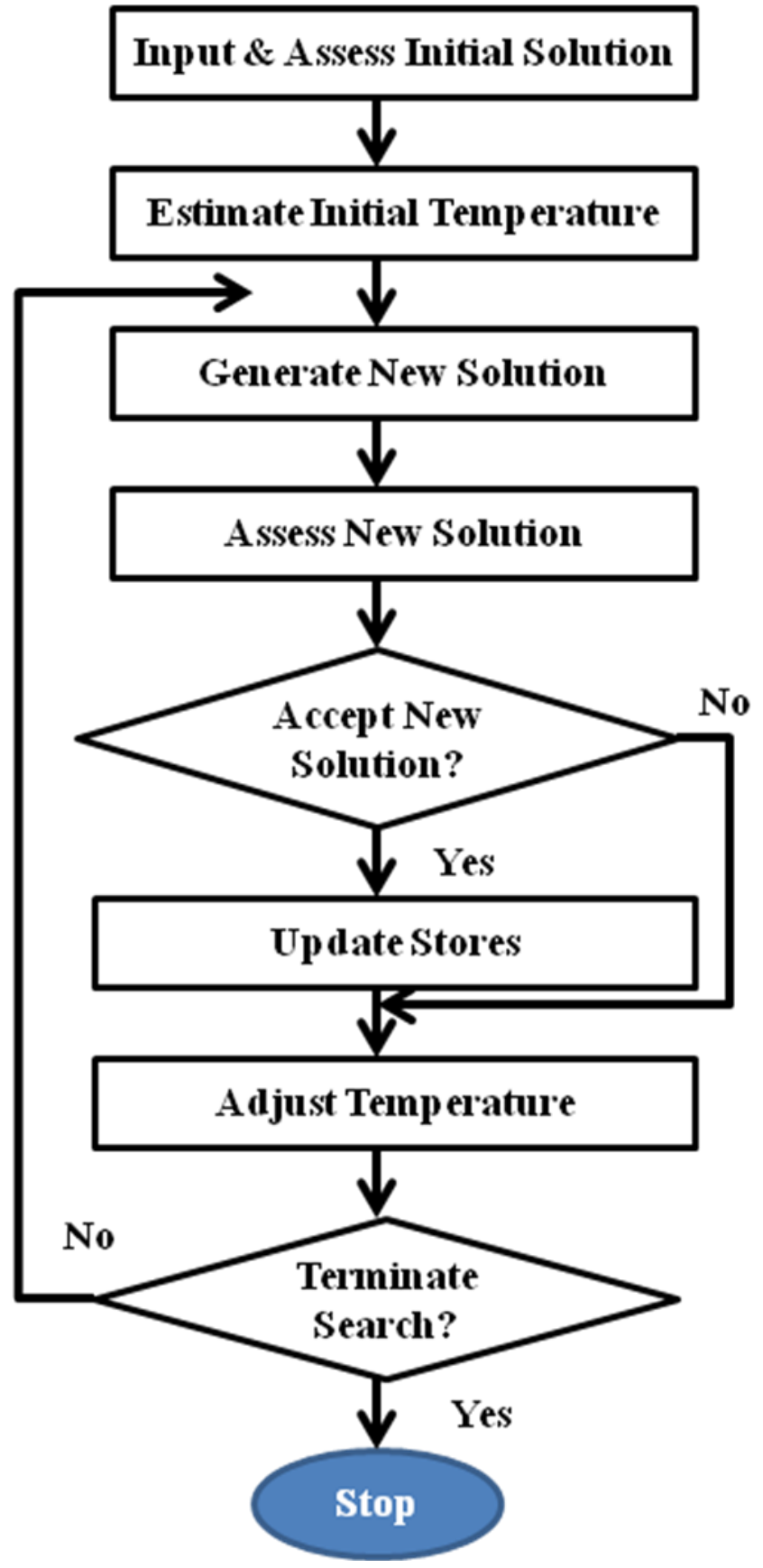

Figure 4 The structure of the simulated annealing algorithm.[56]

The major advantage SA over other methods is an ability to avoid becoming trapped in local minima. It is flexible and able to approach global optimality. Carefully controlling the rate of cooling of the temperature, SA can find the global optimum. However, this 
requires infinite time. Also, the evaluation of the problem functions is essentially a "black box" operation as far as the optimization algorithm is concerned, because the SA algorithm does not require or deduce derivative information. However, for many applications, the computational efficiency is important. The standard implementation of SA algorithm is one in which a collection Markov chain of finite length are generated at decreasing temperatures.

\subsubsection{Markov Chain Monte Carlo Methods}

A Markov chain is a mathematical tool for statistical modeling in modern applied mathematics. In a Markov chain, the next state depends only on the current state, with the state changing randomly between steps. After sufficient amount of steps, the chain may reach a stationary distribution where the probability values are independent of the actual starting value. Since the system changes randomly, it is generally impossible to predict the exact state of the system in the future. However, the statistical properties of the system's future can be predicted. In many applications, these statistical properties are important.

Markov chain Monte Carlo (MCMC) methods are a class of algorithms for empirically creating a probability distribution by constructing a Markov chain that has the desired distribution as its equilibrium distribution. MCMC techniques provide random walks in parameter space whereby successive steps are weighted by the likelihood of observing data given the corresponding parameter values. They are widely used in the field of Bayesian statistics where they provide an attractive option for assessing the uncertainty in the model parameters given the calibration data.[51,53] One of the big challenge in the application of Bayesian approach to more realistic problems, such as modeling biological system networks, is computational efficiency. The computational efficiency of a MCMC algorithm depends highly on the structure of the proposal distribution. One recent advance in MCMC algorithms has been to improve the computational efficiency by dynamically adjusting the proposal distribution from a non-informative prior distribution at the start of the simulation to a proposal distribution that reflects the structure in the cumulative Markov chain. These are called Adaptive MCMC methods. Klinke developed 
and applied an empirical Bayesian approach to establish the confidence that one particular mathematical model can describe signal transduction mechanisms in biological signaling networks, given the available data [37]. In the study, an Adaptive Markov Chain Monte Carlo (MCMC) techniques was used to assess the uncertainty in the model parameters given the calibration data for the mathematical model by providing random walks in parameter space whereby successive steps are weighted by the likelihood of observing data given the corresponding parameter values. Bayesian approach has been used to infer confidence of models for transcription factor activity and cellular signaling networks. Monte Carlo integration was used to approximate posterior distribution required for a Bayesian analysis. A Markov chain was generated, using the previous sample values to randomly generate the next sample. Metropolis-Hasting algorithm can be used to generate a Markov chain by random sampling. Typically the first 100000 to 500000 elements are in the burn-in or "learning" period. A poor choice of staring values can greatly increase the required burn-in time. The values obtained by simulated annealing were used as a starting point to generate Markov chains.

Sequential steps in a generated Markov Chain exhibit autocorrelation. To minimize the effect of autocorrelation, a technique called "thinning" was used by selecting values from the Markov Chain at every nth iteration [37]. Recursive calculation of the proposal covariance of the Markov Chain during the MCMC run is improved by thinning. The expected value for some property of a model can be calculated from the following integral:

$$
E[f(\Theta) \mid M, Y]=\int_{\Theta_{M i n}}^{\Theta_{M a z}} f(\Theta) \cdot P(\Theta \mid M, Y) d \Theta,
$$

where $f(\Theta)$ is a generic function of the model parameters. In this case $f(\Theta)$ is a deterministic function that provides a prediction of the dynamic trajectory of the system in response to a stimuli, given a set of parameter values. This equation used in conjunction with the posterior distribution in the model parameter provides an estimate of the uncertainty in the model prediction, given a model of particular calibration data. 
The expected value is dependent on the particular formulation of the model, $\mathrm{M}$, and the data used in calibrating the model, Y. As not all combinations of parameters provide realistic simulations, values for $\mathrm{f}(\Theta)$ are weighted by distribution of parameters given $M$ and Y (i.e., the posterior distribution $\mathrm{P}(\Theta \mid \mathrm{M}, \mathrm{Y}))$ ). A Bayesian estimate of $\mathrm{P}(\Theta \mid \mathrm{M}, \mathrm{Y}))$ could be provided by computer-intensive methods like Monte Carlo algorithms. Markov chain represents a random walk within parameter space. Recently developed AMCMC can dynamically adjust the structure of the proposal distribution based upon the prior steps of an evolving Markov chain. The prior distribution used in this study was the same for all parameters, proper, normally distributed, and used to specify the initial proposal distribution. Following a specified "learning" period, the proposal distribution was adjusted to reflect the structure in the cumulative Markov chain.

However, deciding when the cumulative Markov chain is a representative sample drawn from the underlying stationary distribution is still a big challenge with implementing a MCMC approach for Bayesian inference. Convergence is a criteria used to evaluate how long of a chain is necessary to traverse a representative sample of parameter space. Most of algorithms developed diagnose the convergence of a Markov chain by focusing on the model parameters. Klinke instead focused on the the predictions of the model to assess convergence of Markov chains using Gelman-Rubin method. The Gelman-Rubin method is based upon the concept that convergence has been achieved when the variance among chains is less than within single chains. 


\title{
CHAPTER 2
}

\section{RESEARCH METHODS}

\subsection{Experimental Aspects}

\author{
All biological experiments were done by Irina V. Ustyugova who was a graduate \\ student in John Barnet's lab, Department of Microbiology, Immunology \& Cell \\ Biology, West Virginia University, Morgantown, WV, USA
}

Cell culture, stimulation and DCPA treatment The murine peritoneal macrophage cell line, IC-21, was cultured to $80 \%$ confluency in complete RPMI (cRPMI) Cells were treated with $99 \%$ pure DCPA and simultaneously stimulated with $1 \mu \mathrm{g} / \mathrm{ml}$ LPS phenol extracted for various times. $100 \mu \mathrm{M}$ of DCPA were dissolved in 100\% ethanol and added to cells. The final ethanol concentration added to all cultures was $0.1 \%$; control cultures received equal concentrations of ethanol.

\section{Nuclear Extracts}

Cells were then treated with either $0.1 \%$ ethanol or $100 \mu \mathrm{M} \mathrm{DCPA}$, then stimulated with $1 \mu \mathrm{g} / \mathrm{ml}$ LPS. Cells were washed. A total protein concentration for nuclear extracts was determined with Coomassie Plus Protein Assay Reagent, as described by manufacturer (Pierce, Rockford, IL).

\section{Electrophoretic mobility shift assay (EMSA)}

NF- $\mathrm{KB}$ consensus oligonucleotides were labeled with $\gamma$-32P-ATP using Ready-ToGoTM T4 polynucleotide kinase kit. Nuclear extracts, $5 \mu \mathrm{g}$ per sample, were incubated with 50,000 cpm of labeled probe and $1 \mathrm{~g} / \mathrm{ml} \mathrm{dI}: \mathrm{dC}$ to allow formation of band shift complexes and electrophoresed. The EMSA experimental results are reported as the ratio of the intensity measured for a particular condition (i.e. time $>0$ ) relative to the intensity of nuclear NF- $\mathrm{KB}$ prior to treatment (i.e. time $=0$ ). 


\section{Western Blotting of ІкB $\alpha$ and ІкBß}

After the nuclear extracts, IC-21 cells were treated as indicated, collected by centrifugation, and washed two times with cold phosphate-buffered saline. Western blot analysis was performed using the indicated antibodies of ІкB $\alpha$ and ІкB $\beta$.

\subsection{Mathematical Modeling Aspects}

The application of mathematical models to describe NFкB-ІкBs signaling mechanism was pioneered by Hoffmann A [11], and extended by many others [13, 23]. This model builds upon prior modeling studies by Lipniacki [13] but incorporates two key changes. First, the reactions were grouped into reaction classes that are defined based upon peptide motif-motif interactions [35]. Equal parameters are assigned to reactions in the same class. Additional effect factors to some complexes reactions in the presence of NFкB are considered, according published experimental data [36]. Second, dynamic equilibrium is considered between protein-protein interactions. NFKB is considered as a single protein. The interaction between IKK and ІкB $\alpha$ as well as IкB $\alpha$ NFкB complex in the cytoplasm effectively proceeded as a single enzymatic degradation reaction scheme:

$$
\mathrm{E}+\mathrm{S} \rightarrow \mathrm{ES} \rightarrow \mathrm{E}
$$

where $\mathrm{E}$ is the enzyme, IKKa (IKK in active status), $\mathrm{S}$ is the substrate (IкB $\alpha$ or ІкB $\alpha \mathrm{NF}_{\kappa} \mathrm{B}$ ) and $\mathrm{ES}$ is the enzyme-substrate complex (IKКаІкB $\alpha$ or IKКаІкB $\alpha \mathrm{NF} \kappa \mathrm{B}$ complex). Three parameters are used to describe this process, including association rate, a2, dissociation rate, $\mathrm{d} 2$ and catalytic rate, kcat. After this enzymatic process, IKKa is regained but ІкB $\alpha$ is lost while $\mathrm{NF}_{\kappa} \mathrm{B}$ is released. The interaction between ІкB $\alpha$ and NFкB also consists in the forward and reverse reactions with rate a1 and d1. Dynamics of IKK is represented as a module, where details of upstream signaling interaction are not represented in detail. The description of all reactions is shown in supplement material 1.

\subsection{Model Calibration}

The reactions between all components associated with parameters were converted to a set of non-linear ordinary differential equations. For the values of the parameters, some of 
them are from literature published before, while a subset of parameters will be determined from the experimental data. As many of the parameters are correlated, a parameter identifiablity analysis described by Klinke [28] was used to establish the parameters which can be uniquely determined, given unlimited information about the model. Parameters that are not locally identifiable, termed a priori unidentifiable, have correlation values less than -0.985 or greater than 0.985 with at least one other parameter.

Two models were built. Model 1 was built to describe the system by fitting experimental data from IкB $\alpha$ and NFKB measured in IC-21 cells with and without DCPA treatment following LPS stimulation. To further study the signaling mechanism, model 2 was built to include also fitting IкB $\beta$ experimental data. Initial concentrations of the components are needed to simulate the response. The initial concentration of $\mathrm{NF \kappa B}$ is assumed as 0.06 $\mu \mathrm{M}$ in the cytoplasm [36]. All of NFKB is assumed to exist as ІкB $\alpha \mathrm{NF \kappa B}$ for model 1 in the cytoplasm. For model 2, the initial concentration of NFKB is assumed as $0.03 \mu \mathrm{M}$ $\kappa \mathrm{B} \alpha \mathrm{NF \kappa} \mathrm{B}$ and $0.03 \mu \mathrm{M}$ ІкB $\beta \mathrm{NF \kappa} \mathrm{B}$ in the cytoplasm; the initial concentration of NFX is assumed as $0.02 \mu \mathrm{M}$ in the cytoplasm. All other components are assumed as zero. A 2000 minute period is simulated to get the equilibrium concentrations of all the variables before the stimulation and DCPA treatment.

Unknown parameters obtained from the first model were used as a starting point to simulate the second model. Experimental data of NFкB in the nucleus, ІкB $\alpha$ in the cytoplasm and ІкB $\beta$ in the cytoplasm, measured previously in our lab, were used to calibrate the model. More unknown parameters were identified by the simulated annealing program. Simulated annealing is a robust and general technique to deal with highly nonlinear models. The greatest advantage of this technique is the ability to approach global optimality. The model equations are encoded and evaluated in MATLAB V7.1 (The MathWorks, Natick, MA). Summed squared error between experimental data measured previously in our lab and simulated measurements was used to determine goodness-of-fit. The optimum values obtained from the simulated annealing were used as a starting point for the Markov Chain [37]. 


\subsection{Bayesian Approach}

After parameter identifiablity analysis, Simulated Annealing was used to find the optimum fitness of the given experimental data for of NFKB in the nucleus and IкB $\alpha$ in the cytoplasm. Metropolis-Hasting algorithm was used to generate possible states to be explored in the parameter space. An acceptance distribution depends on the difference between the function value of the present state to be explored and the last saved lowest state. The acceptance distribution decides probability whether to stay in a new state or to bounce out of it. The Simulated annealing program was used to produce the initial values for the AMCMC algorithm, shown as Figure 5.

Using the results from Simulated Annealing program as the start point to generate a Markov chain by An empirical Bayesian approach using Adaptive Markov Chain Monet Carlo (AMCMC) algorithms, as described by Klinke [37]. The generated Chain by Metropolis-Hasting algorithm is autocorrelative. To minimize the effect of autocorrelation, a technique called "thinning" was used by selecting values from the Markov Chain at every nth iteration. Recursive calculation of the proposal covariance of the Markov Chain during the MCMC run was improved by thinning. The thinning value used to estimate the covariance recursively from the evolving Markov chain is 40. To obtain $\mathrm{P}(\Theta \mid \mathrm{Y}, \mathrm{M})$ from the final Markov chains, a thinning value of 20 was used.

The prior distribution used in this study was the same for all parameters, proper, normally distributed, and used to specify the initial proposal distribution. Following a specified "learning" period, the proposal distribution was adjusted to reflect the structure in the cumulative Markov chain. How a Monte Carlo Markov chain is generated is as same as description by Klinke [37]. The Gelman-Rubin method is then used to analyze the convergence of the model using two parallel chains. The first $\mathrm{N}$ steps, called "learning period" or "burn-in period", are discarded as they are assumed to be drawn from tails of the stationary distributions. The remainder of the parallel chains was used to estimate the convergence of the predictions to a stationary distribution. Two parallel Markov chains were calculated each containing 900,000 steps. The simulation of each chain took 
approximately 500 hours on a single core of a $2.66 \mathrm{GHz}$ Dual-Core Intel Xeon 64-bit processor with 8 GB RAM.

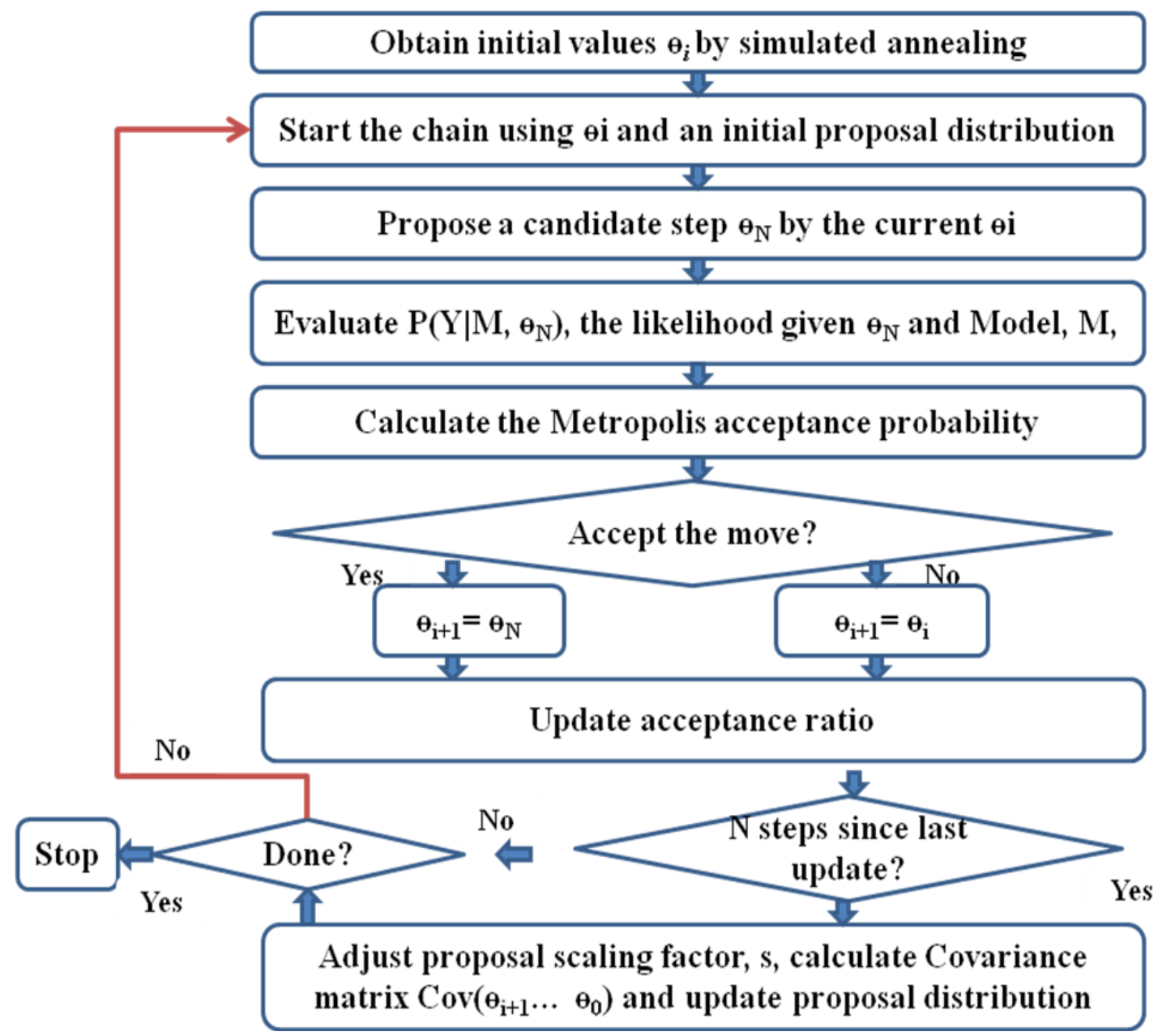

Figure 5 The AMCMC algorithm structure for our model

The parameter values obtained using simulated annealing provided the starting point for these chains. A "learning" (a.k.a. "burn-in") period of 250,000 steps was specified a priori to provide an initial estimate for the proposal covariance.

To estimate convergence, the prediction $\mathrm{PY}_{i j}$ obtained from a single draw from $\mathrm{J}$ parallel MCMC samples of length $\mathrm{N}$, where $j \in \mathrm{N}$ and $i \in \mathrm{N}$. The overall variance of prediction, $\operatorname{Var}(\mathrm{PY})$, derived from the target distribution is estimated from the between-sequence (B) and the within-sequence (W) variances. The Gelman-Rubin Method diagnoses convergence from the potential scale reduction factor is calculated as follows: 
$\mathrm{R}=\mathrm{V} \operatorname{ar}(\mathrm{PY}) / \mathrm{W}$

where parallel chains of length $\mathrm{N}$ should be increased until $\mathrm{R}$ is less than 1.2. 


\section{CHAPTER 3}

\section{RESULTS AND DISCUSSION}

\subsection{Analysis of the experimental data}

Experimental results (measured previously in our lab by Irina V. Ustyugova)

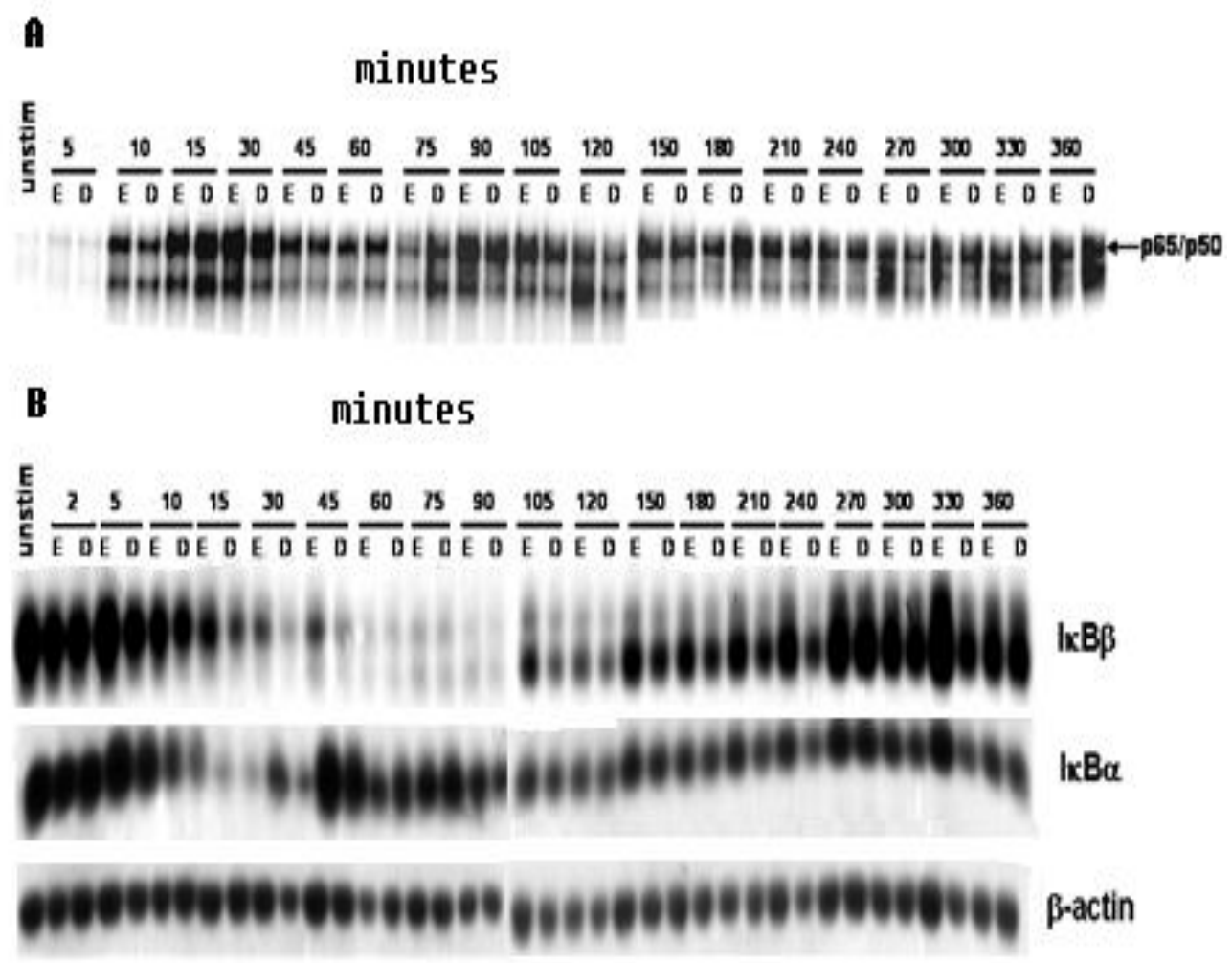

Figure 6 Initial experimental results. (A) NFкB in the nucleus measured by Electrophoretic mobility Shift Assay (EMSA); (B) ІкВ $\alpha$, ІкВ $\beta$ and $\beta$-actin which was used to normalize ІкВ $\alpha$ and ІкВ $\beta$, in the cytoplasm measured by western blotting. E represents ethanol treatment while D represents DCPA treatment.

The changes of NFKB concentration in the nucleus of IC-21 macrophages were measured following LPS stimulation or LPS stimulation and DCPA treatment for period of 6 hours using electrophoretic mobility shift assay, shown as in Figure 6 (A). The 
concentration change of IкB $\alpha$ and IкB $\beta$ proteins in the cytoplasm of IC-21 cells were also measured by western blot, shown as B in Figure 6. Ethanol treatment following LPS stimulation was used as control experiments. $100 \mu \mathrm{L}$ DCPA was used to test the effect of DCPA on NFKB activity in macrophages.

Differential dynamics of ІкB $\alpha$ and ІкB $\beta$ were observed following LPS stimulation for both ethanol and DCPA treated IC-21 cells. From Figure 6, we can see that following LPS stimulation with or without DCPA treatment (both of LPS and DCPA or ethanol were added at time 0$),$ ІкВ $\alpha$ (middle band) concentration decreased and then rebounded more rapid than IкB $\beta$ (top band). All these experimental data are numerically summarized as Figure 7. From Figure 7, we can see clearly that the increase of free nuclear NFKB concentration starts after 5 minutes, which is following the decrease in ІкВ $\alpha$. The cytoplasmic ІкВ $\alpha$ reaches the lowest concentration earlier than free nuclear $\mathrm{NF} \kappa \mathrm{B}$ reaches its highest concentration. Following free nuclear NFкB, which is thought to be the active form with the ability to promote the productions of other proteins, cytoplasmic IкB $\alpha$ concentration recovers to a level close to that before the LPS stimulation. Following the resynthesis of cytoplasmic ІкB $\alpha$, the active NFкB concentration decreases. Whether the cells were treated with or without DCPA, the nuclear NFKB concentration shows oscillation and reaches a high level of constant activity after about 3 hours. This higher level of NFKB activity is about 8 times as that before the stimulation. This oscillation behavior of nuclear NFKB was also observed by other groups in other kind of cells.[10,11,15,18] Hoffman's study demonstrates that, in fibroblasts, the negative feedback effect of IкB $\alpha$ on the NFкB activity signaling network cause the oscillation while ІкB $\beta$ and ІкB $\varepsilon$ dampen the oscillations and stabilize $\mathrm{NF}_{\kappa} \mathrm{B}$ during longer stimulations.[11]

We also measured cytoplasmic ІкB $\beta$ concentration following LPS stimulation in IC-21 cells shown in Figure 7 C. Unlike ІкВ $\alpha$, the decrease of ІкВ $\beta$ concentration following LPS stimulation is much slower. After about 90 minutes following the stimulation, the concentration of IкB $\beta$ begins to rise, at a rate that is much slower than the rising of ІкB $\alpha$ concentration. ІкВ $\beta$ concentration keeps rising to a level higher than that before LPS 

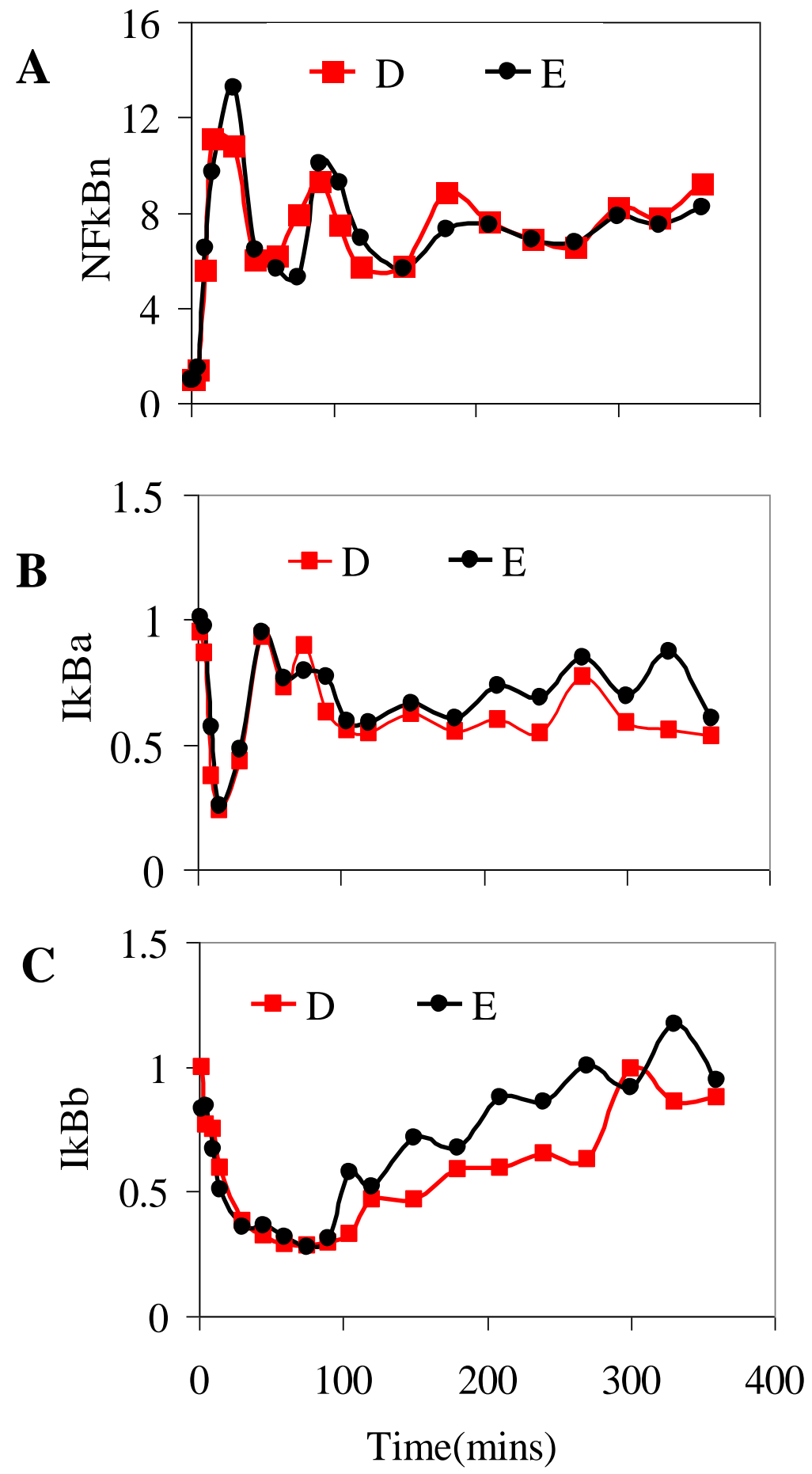

Figure 7 Summary of experimental data and normalized by the concentration before LPS stimulation (A) Nuclear NFкB (NFкBn); (B) Cytoplasm IкB $\alpha$; (C) Cytoplasm IкB $\beta$. Red squares represent experimental results with DCPA treatment while black dots represent ethanol treatment. 


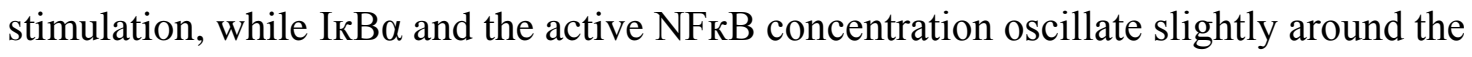
constant level. Active NFкB in the nucleus induces ІкB $\alpha$ and ІкB $\beta$ transcription. Resynthesized IкB $\alpha$ proteins bind to free NFкB in the cytoplasm to keep it in the cytoplasm. Re-synthesized IкB $\alpha$ proteins can also go to the nucleus to export free NFкB to the cytoplasm.[11,19] The negative feedback effect of IкB $\alpha$ causes the oscillation of NFкB activity. ІкB $\alpha$ and ІкB $\beta$ have distinct functions in regulating NFкB activity. [10] However, the mechanisms of IкB $\alpha$ and IкB $\beta$ regulation and how they regulate NFкB activity are still not clear.

The different dynamic profiles of ІкB $\alpha$ and ІкВ $\beta$ following an external stimulation were also observed by other groups.[10,11,23] According to Kearns's study,[23] NFKB is essential both for ІкB $\alpha$ and ІкB $\beta$ mRNA transcription. In the wild-type cells, the ІкB $\beta$ mRNA level remains constant for about 45 minutes after chronic TNF $\alpha$ stimulation, while IкB $\alpha$ mRNA level rises immediately. This is consistent with our observations on ІкВ $\beta$ protein level in the cytoplasm. We observed a 60 minute delay in resynthesis compared with ІкB $\alpha$ following the LPS stimulation.

The profile of nuclear NFKB in the cells exposed to DCPA looks similar but a little ahead of time compared to cells without DCPA treatment. In [28], it was demonstrated that DCPA has the ability to potentiate an early NFкB activity. Moreover, Klinke and coworkers demonstrate that an EMSA assay lacks the sensitivity to detect change in early NFKB activity. However, how the DCPA affects NFkB activity is still unknown.[27] Not surprisingly our EMSA results suggest that free $\mathrm{NFKB}$ concentration was not significantly decreased by DCPA treatment following LPS stimulation. As shown in Figure $7 \mathrm{~B}$, ІкВ $\alpha$ concentration decreased quickly following the stimulation and increased immediately after NFкB activated. Differences in ІкB $\alpha$ expression upon DCPA treatment do not become apparent until 3 hours following LPS stimulation. But in the first three hours of the LPS stimulation and DCPA treatment, the decrease is not that obvious. Compared with ІкB $\alpha$, ІкB $\beta$ concentration decreased relatively slowly and following a delay, increased more slowly, shown as Figure 7 C. After 6 hours' stimulation, IкB $\beta$ concentration in the cytoplasm increased to a level greater than before the stimulation. The dynamics profile for IкB $\beta$ is different from the IкB $\alpha$ dynamics profile, whereby a 60 
minute delay was observed in cytoplasmic IкB $\beta$ protein level following NFKB activity. From the western blot image, two form of ІкВ $\beta$ with different dynamics can be recognized, as shown in Figure $6 \mathrm{~B}$, but are summed together as the total cytoplasmic ІкВ $\beta$. Furthermore, DCPA treatment also decreased cytoplasmic ІкВ $\beta$ concentration following LPS stimulation. The significant decrease by DCPA treatment started from 90 minutes, a little earlier than ІкВ $\alpha$. We also noticed that the resynthesis of cytoplasmic ІкВ $\beta$ concentration starts at 90 minutes following the LPS stimulation with or without DCPA treatment and is about 60 minutes later than cytoplasmic ІкВ $\alpha$ concentration resynthesis. The slower decrease and delayed resynthesis of cytoplasmic ІкB $\beta$ suggest that the contribution of this negative feedback mechanism is not a major contributor to the observed dynamics of NFKB activation during the first 90 minutes following LPS stimulation. In the first 90 minutes, ІкВ $\alpha$ appeared to be more important in regulating NFкB activity than IкB $\beta$ at the beginning. Therefore, in IC-21 cells, IкB $\alpha$ protein is a key early regulator of $\mathrm{NF}_{\kappa} \mathrm{B}$ activity. However, the mechanism of how $\mathrm{I \kappa B} \alpha$ regulating $\mathrm{NF \kappa B}$ is still unclear. To help understand the process, we developed a mathematical model to describe the first 90 minutes following extracellular stimulation. ІкB $\alpha$ is more important as a negative feedback to regulate NFKB activity at the beginning period following LPS stimulation. Therefore, our initial effort to expand the mathematical model of NFKB activity in IC-21 cells included the contribution of ІкB $\alpha$ alone. Using this model we focused on the dynamics of $\mathrm{NF \kappa B}$ and ІкB $\alpha$ in the first 90 minutes with and without DCPA treatment and used the model to predict the rest of the stimulation time (Model 1). ІкB $\alpha$ was used to represent the functions of inhibition of NFкB activity. We also compared the difference of the two sets of parameter values that fit experimental data of $\mathrm{NF} \kappa \mathrm{B}$ and ІкB $\alpha$ to identify difference induced by DCPA treatment. Finally we extended the model to incorporate both ІкВ $\alpha$ and ІкВ $\beta$ and their distinct functions and dynamics. As suggested experimentally, ІкB $\beta$ starts to play an important role on regulating NFкB activity after 90 minutes. 


\subsection{Model topology}

\subsubsection{Mathematical Models development}

Following from experimental observation, the IкB $\beta$ resynthesis occurred after 90 minutes following LPS stimulation; therefore, we built two models.

\section{Model 1}

The first model was developed based on the simple model published by Klinke[28], but more proteins and mRNAs were added to describe the signaling network of NFKB activity. In model 1, we focused on the first 90 minutes following LPS stimulation and postulate that IкB $\alpha$ represents the major regulator of ІкB proteins at this period; for model 2 , we included both ІкВ $\beta$ and ІкB $\alpha$ as regulatory elements for NFкB. The schematic diagram of model 1 is shown in Figure 8. Activation of NFKB following LPS stimulation of the cells is depicted as a binary on/off stimulus. Before the stimulation, the activity of TLR4 is set to zero (off). During the whole LPS simulation period, TLR4 is kept as 1. Following the stimulation, LPS binding to TLR4 activates the signaling network, transferring IKK from a neutral form, IKKn, to the active form, IKKa. Active IKK phosphorylates free ІкB $\alpha$, bound ІкB $\alpha$, and ІкB $\beta$. The presence of NFкB makes the phosphorylation more efficient.[21] Free NFKB dynamically shuttles between the cytoplasm and the nucleus; within the nucleus, free NFKB binds to DNA, promoting the transcription and translation of numerous proteins including ІкB $\alpha$, ІкB $\beta$ and A20. Newly synthesized IкB $\alpha$ goes to the cytoplasm, binding to NFкB to prevent its nuclear localization or shuttles to the nucleus to inhibit its binding to DNA and exporting it out of the nucleus. Newly synthesized A20 inhibits IKK activity.

The first model consists of 14 components, as listed in Table A.1 in APPENDIX: three status of IKK including IKKn(neutral), IKKa(active), IKKi(inactive), NFкB, IкB $\alpha$, A20

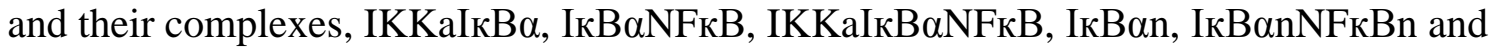
$\mathrm{NF \kappa Bn},(\mathrm{n}$ means in the nucleus), and the following mRNAs: IкBam and A20m(m denotes mRNA). IKKn(neutral) can be activated to IKKa(active), or deactivated to IKKi(inactive), which are not reversible. Biological events in this model are converted to 
25 groups of reactions listed in Table A.2 in APPENDIX; and concentration changes of these components are calculated using differential equations as shown in Table A.3 in the APPENDIX.

\section{Model 2}

Based on the first model, the second model including the regulation of IкВ $\beta$ was built to capture experimental data in the whole stimulation period. Since less is known about IкB $\beta$, most of its properties are assumed based on ІкB $\alpha$. But one major difference with IкB $\alpha$ is proposed. The delay in IкB $\beta$ mRNA synthesis was due to an unknown intermediate transcription factor (NFX), whose synthesis was dependent on NFкB activation. Therefore, we assume that NFX can shuttle between the nucleus and the cytoplasm. NFX is NFKB inducible and promotes the transcription and translation of IкB $\beta$ responsible. The schematic demonstration of the second model is shown in Figure 9. Before the stimulation, ІкB $\beta$ exists in the cytoplasm and similar to ІкB $\alpha$ is bond to NFкB. Active IKK phosphorylates ІкB $\beta$ to release NFкB. In contrast to ІкB $\alpha$ and, ІкB $\beta$ is induced through an intermediate nuclear factor NFX. New synthesized IкB $\beta$ proteins enter the cytoplasm, binding with free $\mathrm{NFKB}$ to inhibit its activity. In this model, we assume that ІкB $\beta$ NFкB can shuttle between the cytoplasm and the nucleus, while IкB $\beta$ could shuttle between the cytoplasm and the nucleus, and bind to nucleus NFкB and promote the export of this complex from the nucleus.

After classifying biochemical reactions, 46 groups of reactions are converted to describe the concentration change of 24 components, as shown in table 1 and 2. Differential equations being used to describe the rates of change of the concentrations of these components are shown in Table A.4 in APPENDIX.

For the big model, because of too many unknown parameters and most of them may be correlated, the simulation annealing program couldn't get a good fit for all the three data sets, free NFкB, ІкB $\alpha$ and ІкB $\beta$. Otherwise, more steps are needed to get the best fit efficiently. MCMC sampling may help in this way. 

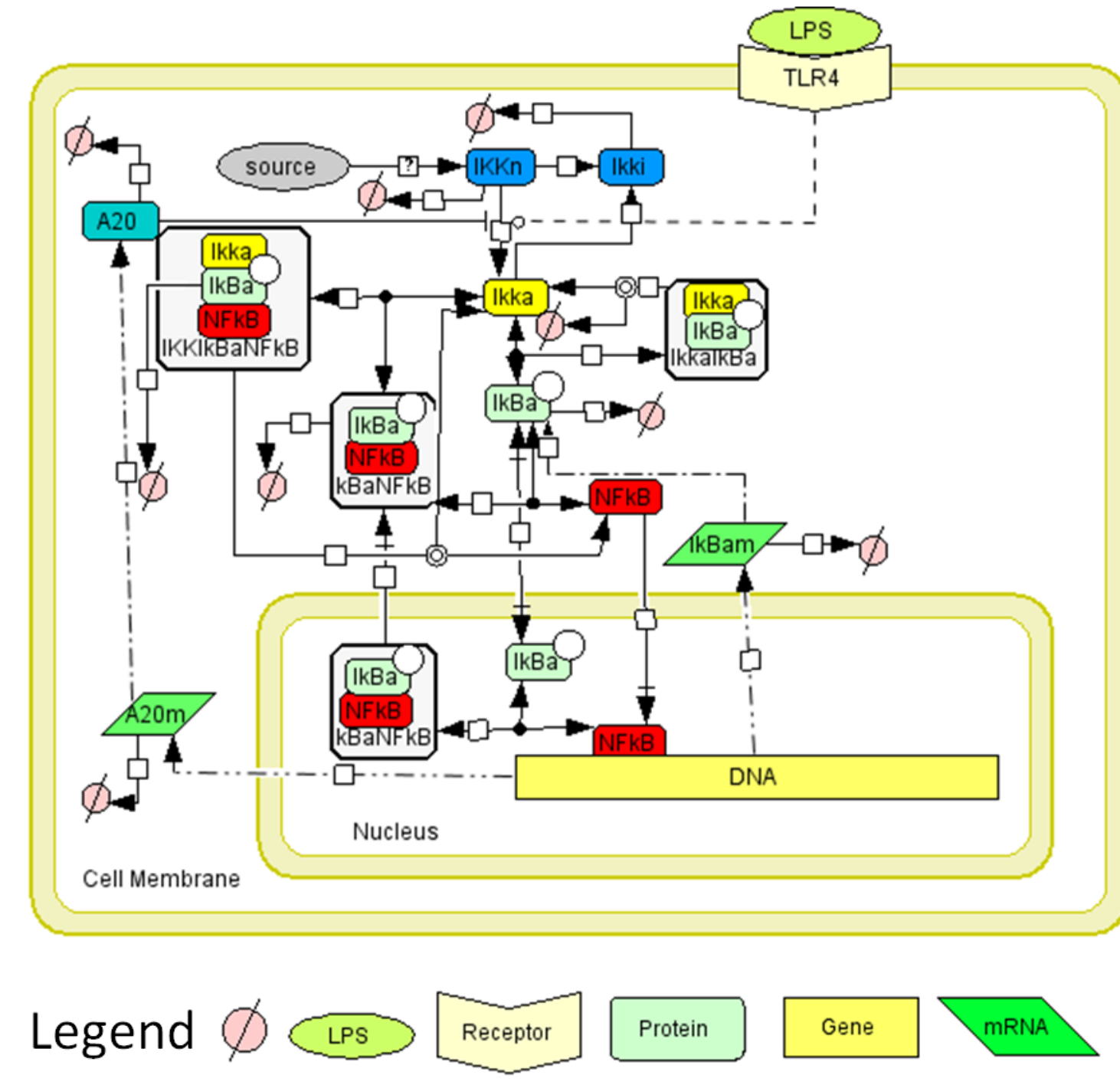

Figure 8 Schematic demonstration of the model 1 for NFKB signaling following the LPS stimulation. A schematic diagram of the biochemical events represented in the mathematical model represented using Cell Designer 4.1. The model represents synthesis of ІкВ $\alpha$ and $\mathrm{A} 20$, association and dissociation between IкВ $\alpha+$ IKКа, ІкB $\alpha+$ NFкB, and IKKa + IкB $\alpha+\mathrm{NF}_{\kappa} \mathrm{B}$, and the degradations of IKK, ІкB $\alpha$ and $\mathrm{A} 20$ proteins, and ІкВ $\alpha$ and $\mathrm{A} 20$ mRNAs, and transcriptions of ІкB $\alpha$ and $\mathrm{A} 20$ mRNAs and transportations of ІкВ $\alpha$ and NFкB between the nucleus and the cytoplasm. 


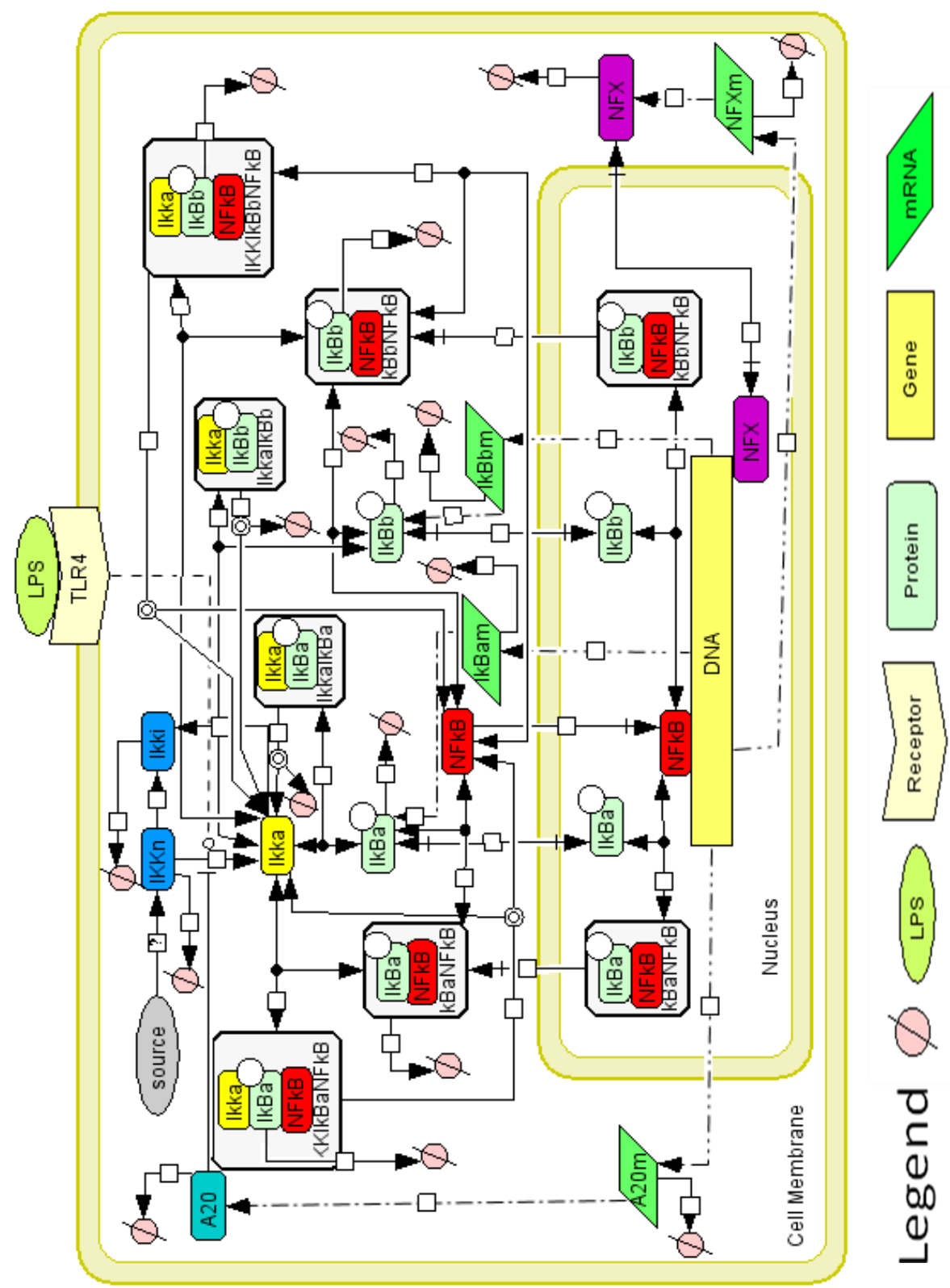

Figure 9 Schematic demonstration of the model 2 for NFкB signaling. Besides ІкB $\alpha$ as an inhibitor to $\mathrm{NF} \kappa \mathrm{B}$, ІкВ $\beta$ was added to the signaling network. The interactions between IкB $\beta$, NFкB, and IKKa were added into the model 1. Further, an unknown nuclear factor NFX was proposed to promote IкB $\beta$ mRNA transcription. The synthesis, degradation and transportation of NFX were also included in the diagram of the signaling network by Cell Designer 4.1 . 


\subsubsection{Model Calibration}

The mathematical models, shown schematically in Figure 6 and 7, were calibrated against values obtained from experimental data measured previously in our lab. The values were obtained with IC-21 cells (macrophage cell line) in response to $1 \mu \mathrm{g} / \mathrm{ml}$ LPS with $100 \mu \mathrm{M}$ ethanol (as control experiment) or with $100 \mu \mathrm{M}$ DCPA. Nucleus NFкB was measured by EMSA while total ІкВ $\alpha$ and ІкВ $\beta$ in the cytoplasm were measured by western blot. Initial data is shown in Figure 6, while the numerical summary is shown in Figure 7. The mathematical models were implemented in MATLAB as detailed in supplement 2. Maximum likelihood values for the parameter were determined using simulated annealing. The specific parameter values are shown in Table 3.2. An empirical Bayesian approach was used to estimate the uncertainty in the model parameters given the available calibration data.

\subsection{3 "A priori" identifiability analysis}

Sensitivity analysis (SA) is the study of how the variation (uncertainty) in the output of a mathematical model can be apportioned, qualitatively or quantitatively, to different sources of variation in the parameters, either rate constants or initial conditions associated with a model. Based upon how the model is constructed, different parameters influence the output of the model in the same way. These parameters that cannot be estimated separately are called unidentifiable parameters.

Correlation of the unknown parameters in model 1 was analyzed and the results are shown in Table 3.1. This symmetric table represents a correlation matrix where each element in the table represents the correlation between the two parameters in the row and in the column. If the absolute value greater than 0.95 , we will consider these two parameters are nonidentifiable. From the table, we can see that some parameters are not correlated to any other parameters. For instance, $\mathrm{k} 2$ which associates with IKK inactivation via A20, has correlation values with other parameters all smaller than 0.95. Therefore, it is not correlated to any other parameters in this model and can be identified. On the other side, some of parameters are correlated, which are unidentifiable. For 
instance, $\mathrm{s} 1$, which represents the inducible production of IкB $\alpha \mathrm{mRNA}$, and $\mathrm{t} 1$, which represents the translation rate of ІкB $\alpha$, are completely correlated (0.999). For instance, the effect of slow ІкВ $\alpha$ mRNA production on the observed cytoplasmic ІкВ $\alpha$ and nuclear $\mathrm{NF \kappa B}$ concentration could be compensated by fast translation of IкB $\alpha$ mRNA to ІкB $\alpha$ protein. Whether the production is slow and the translation is fast or the translation is slow and the production is fast will have the same effect on the observed cytoplasmic IкB $\alpha$ protein concentration. Therefore, we cannot uniquely determine $\mathrm{s} 1$ and $\mathrm{t} 1$ given the mathematical structure of the model. However, as we don't have enough information about these parameters, we allow the simulation annealing algorithms to estimate them and optimize the fitness of the model to experimental data. Then AMCMC will be used to estimate the uncertainty in the model parameters.

Table 3.1 Correlation analysis of unknown parameters in Model 1

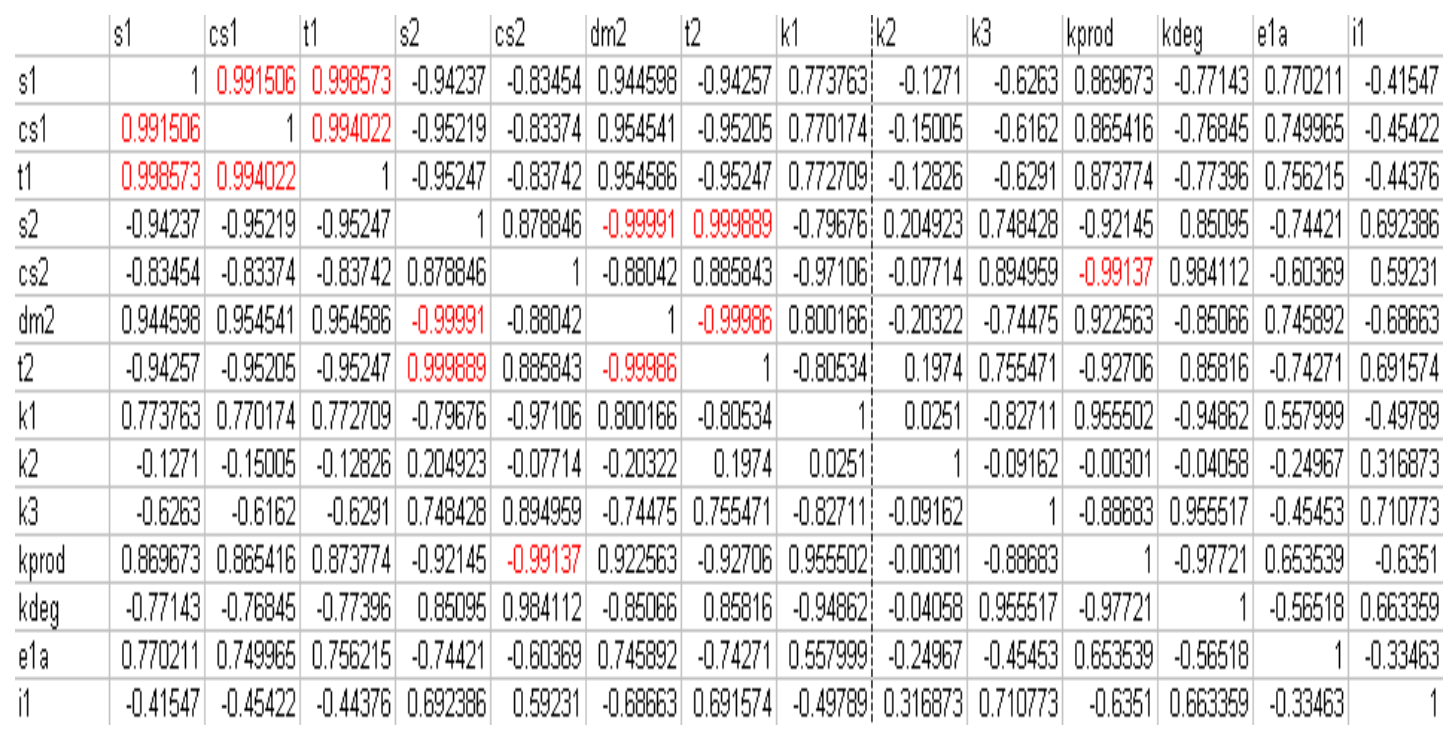


Table 3.2 Comparison of the parameter values fit to the two experimental conditions. There values represent the maximum likelihood values as determined using simulated annealing.

\begin{tabular}{|c|c|c|c|}
\hline Parameters & Definition & Without DCPA & With DCPA \\
\hline s1 & IкB $\alpha$ inducible synthesis rate & $3.80 \mathrm{e}-3$ & $2.95 e-5$ \\
\hline cs1 & I $\mathbf{B} \alpha$ constitutive synthesis rate & 3.00e-12 & $2.57 \mathrm{e}-13$ \\
\hline t1 & IкB $\alpha$ translation rate & $3.00 e-4$ & $8.23 \mathrm{e}-1$ \\
\hline $\mathbf{s 2}$ & A20 inducible synthesis rate & 314.22 & 0.24 \\
\hline cs2 & A20 constitutive synthesis rate & $3.13 e-4$ & $1.65 \mathrm{e}-11$ \\
\hline $\operatorname{dm} 2$ & A20 mRNA degradation rate & 28.23 & 0.16 \\
\hline $\mathbf{t 2}$ & A20 translation rate & 3.10 & 0.59 \\
\hline k1 & IKK activation rate & 0.93 & $2.71 \mathrm{e}-4$ \\
\hline $\mathbf{k 2}$ & IKK inactivation rate by A20 & 0.59 & 0.37 \\
\hline k3 & IKK spontaneous inactivation rate & 3.00e-7 & $1.33 \mathrm{e}-18$ \\
\hline kprod & IKKn production rate & 0.16 & $6.94 \mathrm{e}-4$ \\
\hline kdeg & IKKa, IKKn and IKKi degradation & $\mathbf{0 . 1 0}$ & $8.7 \mathrm{e}-4$ \\
\hline e1a & IкBa nuclear import rate & 4.48e-4 & $1.21 \mathrm{e}-4$ \\
\hline i1 & IкBa nuclear export rate & 3.10e-3 & $5.04 \mathrm{e}-4$ \\
\hline $\mathbf{e} 2 \mathbf{a}$ & ІкBaNFкB nuclear export rate & $1.10 \mathrm{e}-3$ & $6.80 \mathrm{e}-3$ \\
\hline
\end{tabular}




\subsubsection{Results of Simulated Annealing}

The simulation results for model 1 are compared against the experimental data without DCPA are shown in Figure 10. The first 90 minutes of total ІкВ $\alpha$ in the cytoplasm and free NFKB in the nucleus following the LPS stimulation were used to select parameter values using simulated annealing. The resulting simulation is compared against the whole 6 hours observation period in Figure 10.

As shown in Figure 10, the simulation response was based on the first 90 minutes experimental data, can still predict NFкB activity well for the rest of 6 hrs after the stimulation. However, the model predicts higher levels of cytoplasmic ІкB $\alpha$ data after 90 minutes than was experimentally observed. In other words, additional inhibitors besides ІкB $\alpha$ are needed to keep NFкB activity as measured.
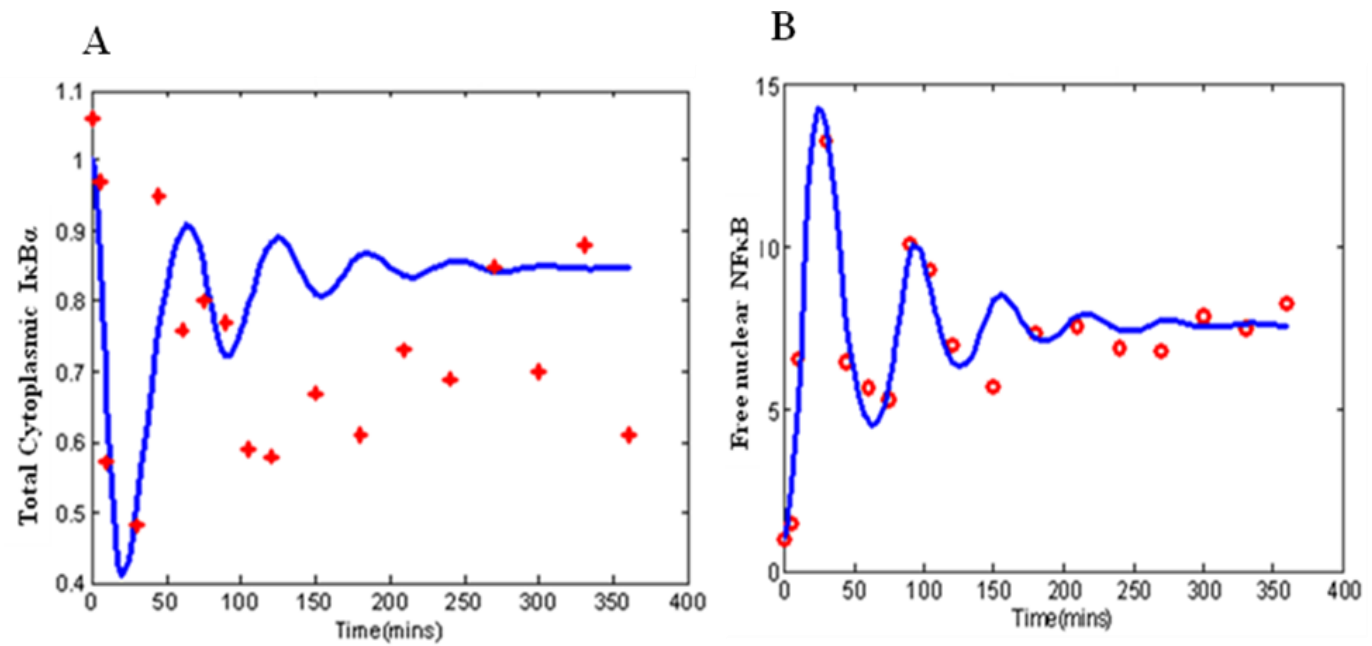

Figure 10 Simulation results for model 1 compared with experimental data without DCPA treatment using simulated annealing program. Line curves are the simulation

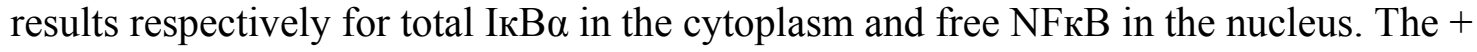
symbols are the experimental data of total cytoplasmic ІкB $\alpha$, while the o symbols are the experimental data of free nuclear NFKB. 
The simulation results for the experiment with DCPA treatment is shown in Figure 11. The simulation results for the experimental data with DCPA treatment suggest an enhanced dampening of the $\mathrm{NFKB}$ oscillations as compared to without DCPA treatment, while the overall agreement between model and data is not particularly good.
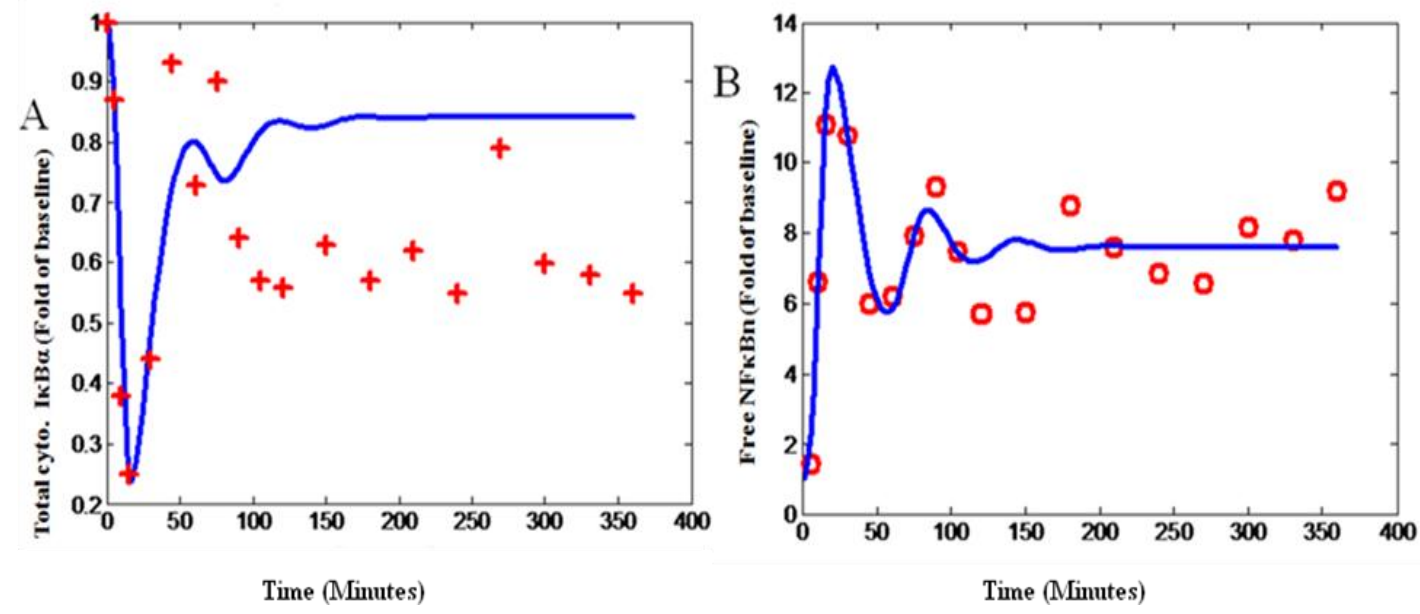

Figure 11 Simulation results for model 1 compared with experimental data with DCPA treatment by simulated annealing program. Line curves are the simulation results respectively for total IкB $\alpha$ in the cytoplasm and free NFкB in the nucleus. The + symbols are the experimental data of total cytoplasmic ІкB $\alpha$, while the o symbols are the experimental data of free nuclear NFкB.

From table 3.2, we can see most of the parameter values are much different for experiments without DCPA and with DCPA. Except k2, e1a and e2a are in the same level, all other parameter are much different. It is difficult to say which parameters are changed by DCPA. Even values for some parameters are much different, the simulated results against the two experimental conditions are still in the same level. For example, the transcription of IкB $\alpha$ mRNA, s1 and the translation of IкB $\alpha$ rnRNA should be correlated. For experimental data without DCPA treatment, $\mathrm{s} 1$ is $3.8 \mathrm{e}-3$ and $\mathrm{t} 1$ is $3.0 \mathrm{e}-4$, while for experimental data with DCPA treatment, $\mathrm{s} 1$ is $2.947 \mathrm{e}-5$ and $\mathrm{t} 1$ is $8.229 \mathrm{e}-1$. A small production rate needs a big translation rate to get the similar the protein production level. To further decide which parameters are identifiable, a priori identifiably analysis was used to determine which parameter could be structurally indentified. 


\subsection{Results of AMCMC}

A series of Markov chains generated using Metropolis-Hasting algorithm were used to estimate the conditional uncertainty in the model parameters given the experimental data with and without DCPA treatment. The proposal distribution is scaled dynamically to achieve an acceptance fraction of 0.2. The trace of the acceptance fraction is shown as a function of AMCMC step, in Figure 12 (A, C). The trace of the covariance scaling factor is shown as a function of AMCMC step, in Figure 12 (B, D). The trace of the acceptance fraction demonstrates that the scaling factor was adjusted at regular intervals to maintain the acceptance fraction around 0.2.

The trace of the conditional probability for each of the two chains against experimental data with and without DCPA treatment, shown in Figure 13, the better the fitness is, the greater the $\mathrm{P}(\mathrm{Y} \mid \Theta, \mathrm{M})$ is. From the results, chain 2 fits the results better than Chain 1.

The Gelman-Rubin potential scale reduction factor (PSRF) was applied to the model predictions to access the convergence of the cumulative Markov Chains.[37] The Gelman-Rubin PSRF statistics were calculated for the species observed experimentally as a function of time and AMCMC step and shown graphically as a contour plot in Figure 14. 

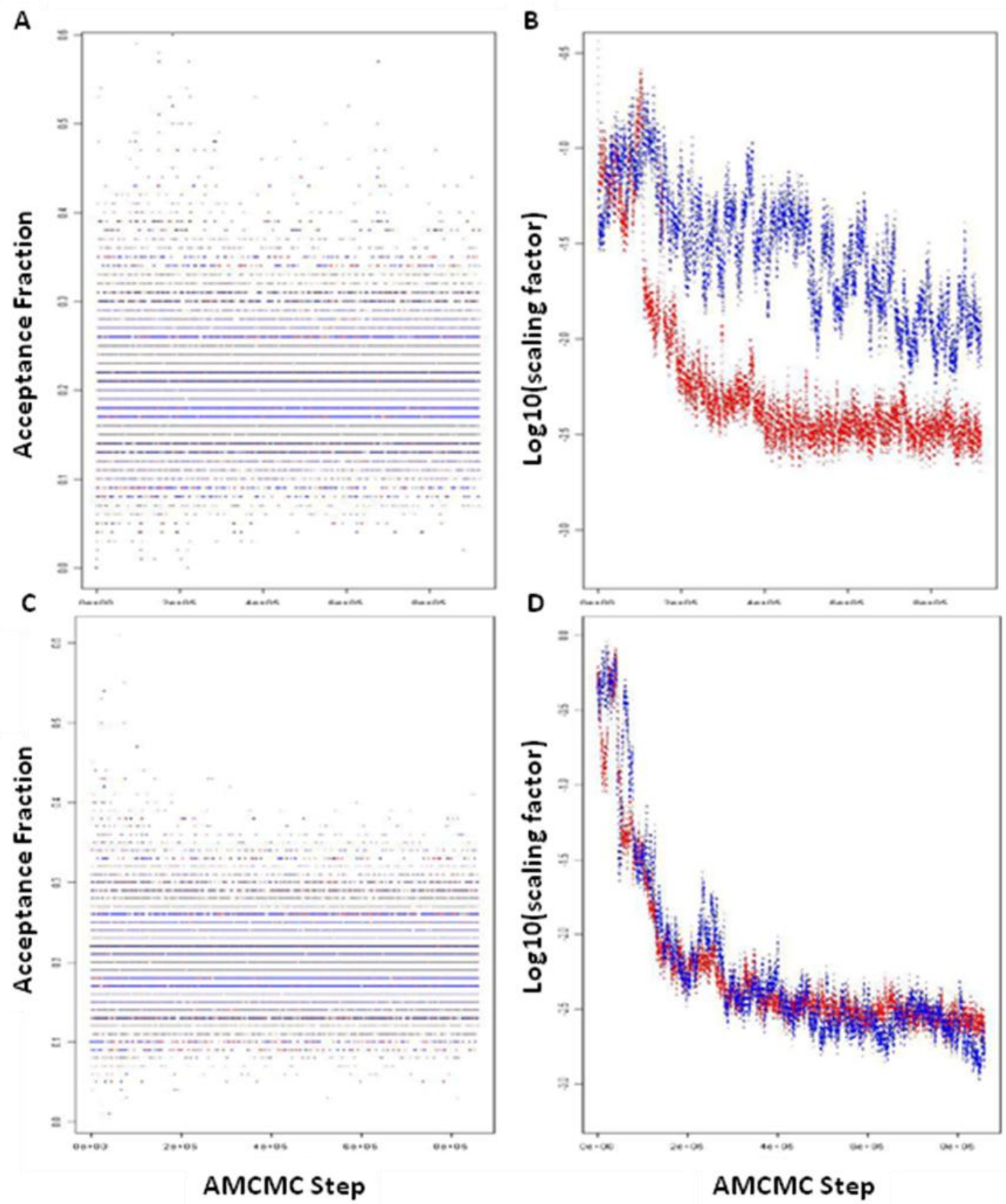

Figure 12 Evolution of the performance of the AMCMC algorithm. AMCMC model fits for DCPA treated (panels C and D) and untreated cells (panels A and B) are shown separately. The proposal covariance scaling factor $(B, D)$ and the acceptance fraction $(\mathrm{A}, \mathrm{C})$ are shown as a function of AMCMC step against experimental data. The results for each of the two parallel chains are shown in different colors: chain 1 (Red) and chain 2 (Blue). 


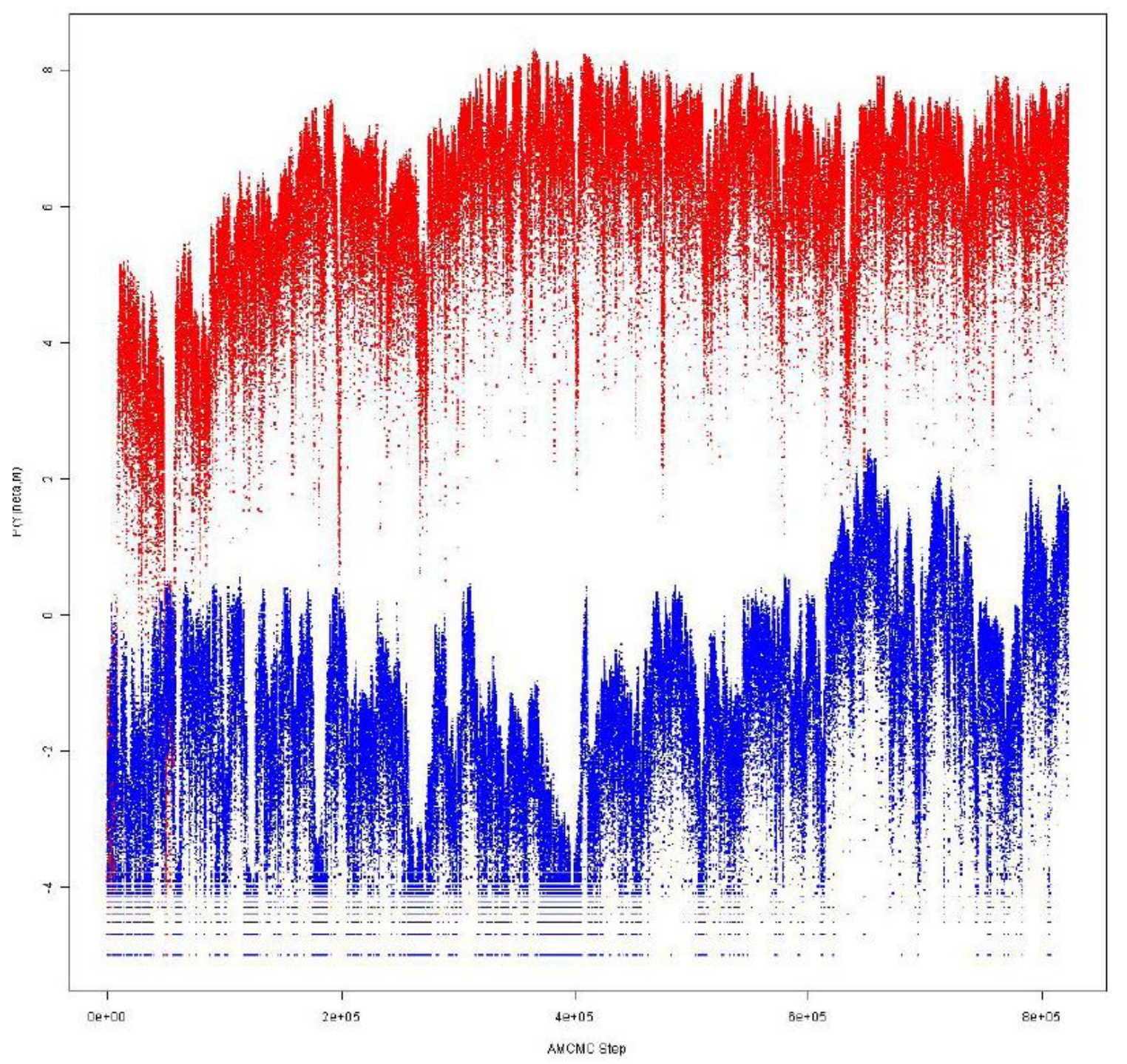

Figure 13 Evolution in the likelihood, $\mathrm{P}(\mathrm{Y} \mid \Theta, \mathrm{M})$, as a function of AMCMC step. The normalized likelihood value is shown as a function of AMCMC step for both two parallel chains against experimental data without DCPA treatment. The results for each of the two chains are shown in different colors: chain 1(Blue), chain 2(Red).

The colored contours correspond to values of the PSRF. The model predictions exhibited a potential scale reduction factor of below 1.2 immediately after the "learning" period. The variability among chains, as represented by an increase in PSFR, increased as a function of simulation time, existed for both $\mathrm{NF \kappa B}$ and ІкB $\alpha$. This behavior was due to under-sampling at longer times relative to earlier times. For comparison, the 95th 
percentile, 5th percentile, and median responses for each of the two chains are overlaid upon the experimental data without DCPA treatment in Figure 15. Traces for each of the parameters are shown in Figure 16. Density distribution for the model parameters is shown in Figure 17. Covariance structure of $\mathrm{P}(\Theta \mid \mathrm{Y})$ is shown in Figure 18.

DCPA

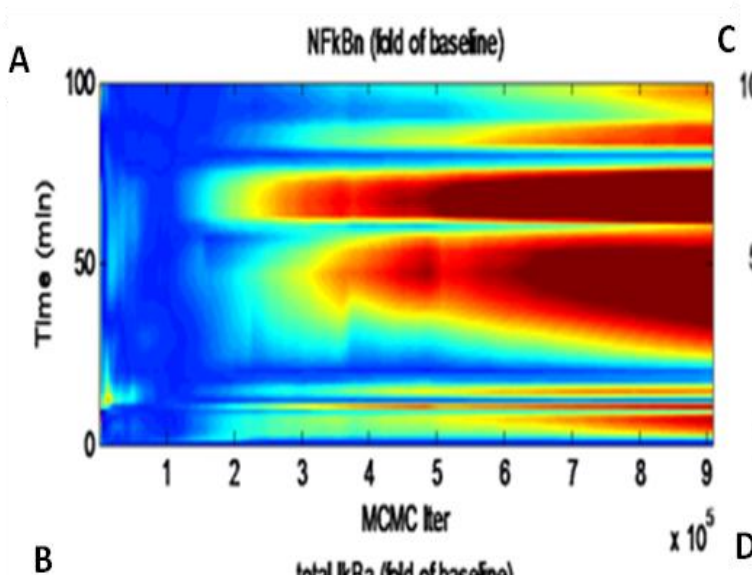

B

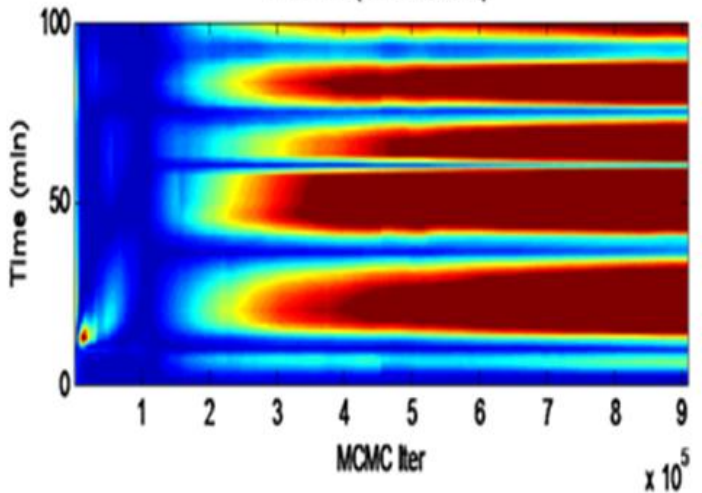

No DCPA

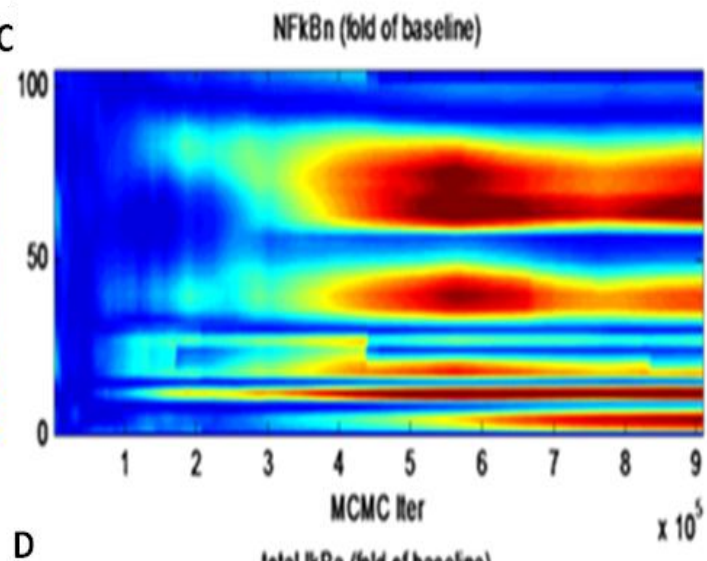

lotal IKBa (bld of baseline)

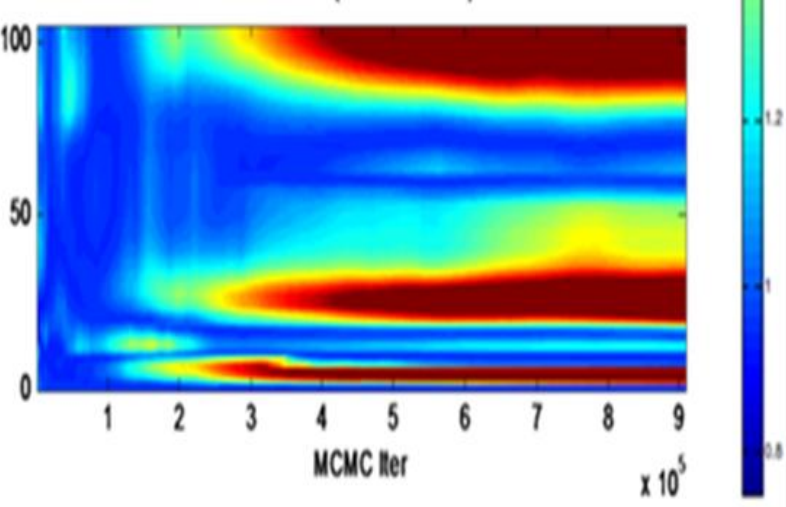

Figure 14 Gelman-Rubin assessment of the Convergence of AMCMC . A contour plot of the Gelman-Rubin statistic applied to the model predictions is shown as a function of time (i.e., the y-axis) and as a function of the cumulative chain up to a specific AMCMC step (i.e., the x-axis). Two parallel chains were used to calculate the Gelman-Rubin statistics for the simulated (panels A and C) Free NFкB expression in the nucleus and (panels B and D) total IKB $\alpha$ in the cytoplasm. Values less than 1.2 suggest convergence of the chains. 
A

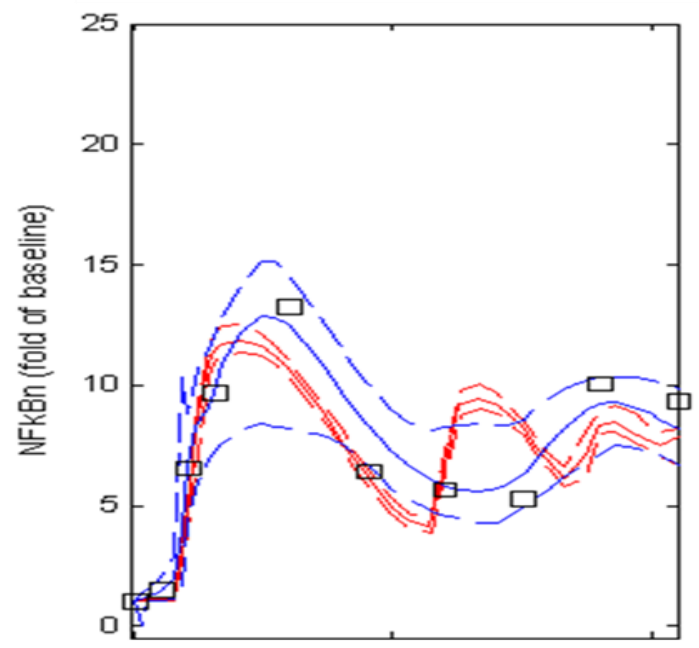

C

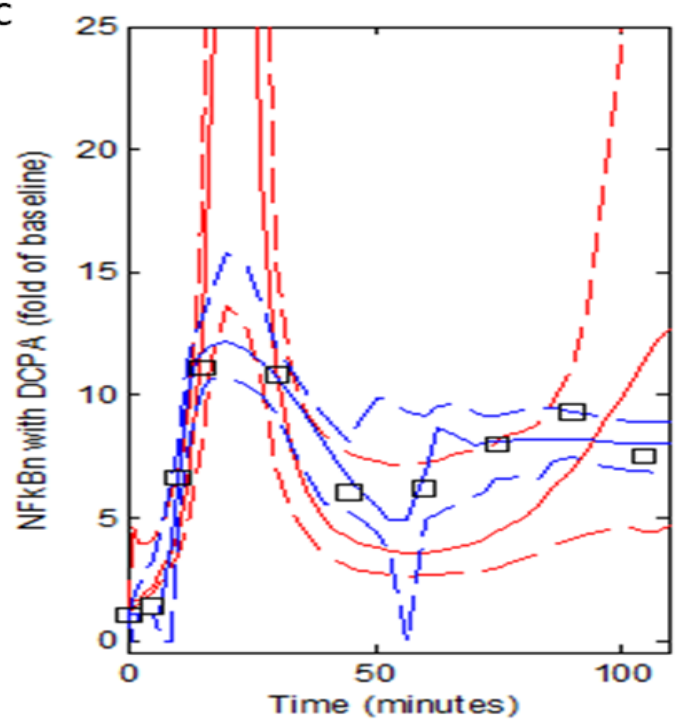

B

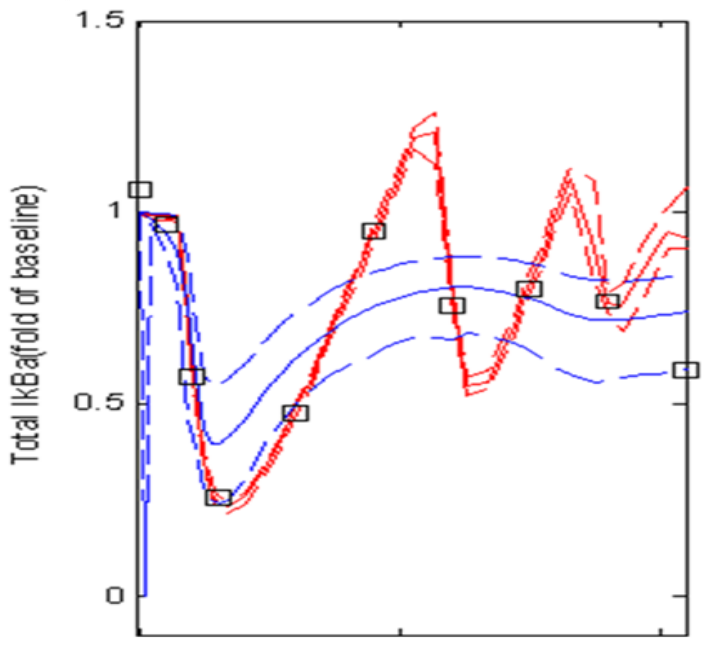

D

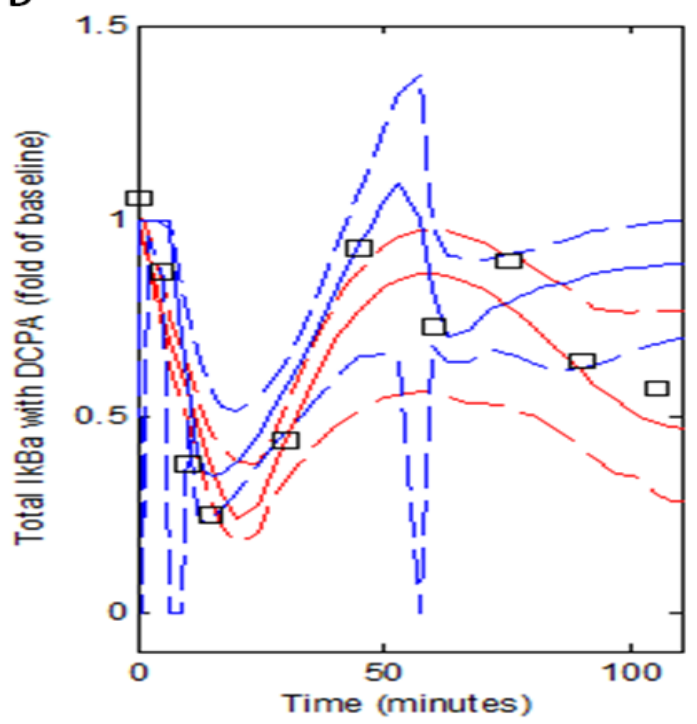

Figure 15 The mathematical model 1 for early signaling events reproduces the early dynamics for activation of NFKB. Simulated results (lines) are compared against the experimental observations without DCPA treatment (symbols). The uncertainty in the model predictions obtained from each chain is represented by three lines of the same color: the most likely prediction is represented by the solid lines and the dashed lines represent the 95th and 5th percentile of the predicted response. The results for each of the three parallel chains are shown in different colors: chain 1 (Red), chain 2 (Blue). (A, C) Simulated response (lines) versus measured free NFKB (squares) in the nucleus; (B, D) Simulated response (lines) versus measured total ІкB $\alpha$ (squares) in the cytoplasm. 
In Figure 14, the Gelmn Rubin statistic suggests convergence between the two chains at the initial start point. At longer times the two predictions from the two chains diverge. In Figure 16, the trace of the parameters suggests that the accepted parameter values are very different for the two chains.

The posterior distribution in the predictions (see in Figure 15) shows that even both chains (red and blue) reproduce most the experimental data in the first $90 \mathrm{~min}$, but their oscillation frequencies are much different. The blue chain fits the NFKB data better while the red chain fits the ІкВ $\alpha$ data better. It seems that the frequencies of these two sets of data are different. One chain tries to catch the frequency of one set data while the other tries to catch the frequency of the other one. Even after 1 million steps, these two chains still can't find a set of parameter values to fit both frequencies. According to Hyyot's work[54] and Nelson's study[55], the external stimulations can cause the frequency of NFкB to vary a lot. Because $\mathrm{NF}_{\kappa} \mathrm{B}$ and ІкB $\alpha$ were measured on different dates, a slight of difference of the LPS stimulation maybe cause the variance of signaling frequency.

From the normalized error of the model prediction, shown as Figure 17, we can see that, the ranges of parameters in the blue chains are much bigger than those of the red one. The blue chain has a difficult time to find a best fitness for both of the data. This is also because of the correlations among parameters in the signaling network. From the Covariance structure of $\mathrm{P}(\Theta \mid \mathrm{Y})$, shown as Figure 18, we can also see that most of the parameters are correlated, which is consistent with the results from the a priori identifiably analysis. 

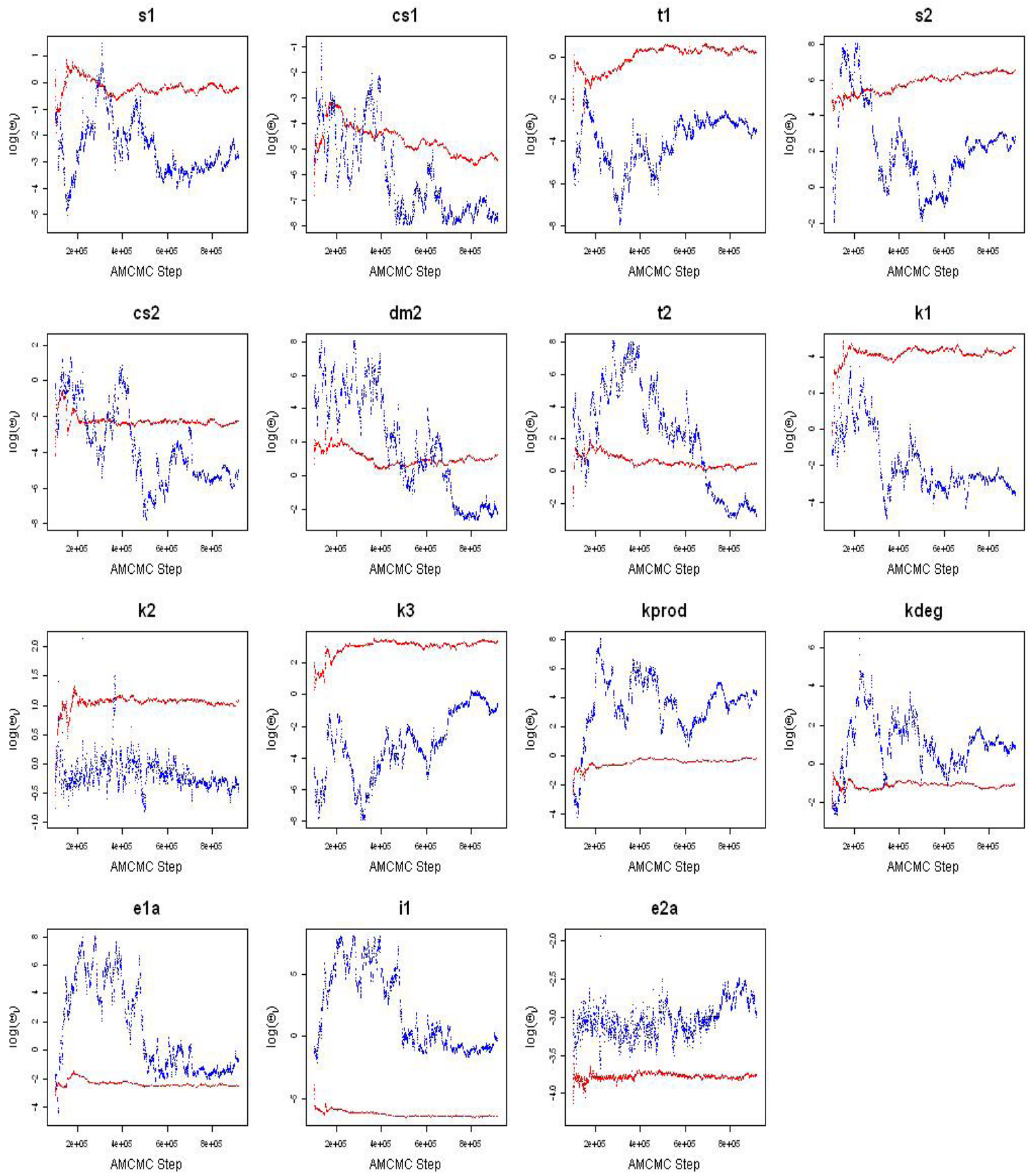

Figure 16 AMCMC summary plots for each of the model parameters for model 1 without DCPA treatment. The trace of each of the model parameters is shown as a function of MCMC step. The traces for two parallel chains are shown in different colors: chain 1 (Red) and chain 2 (Blue). 

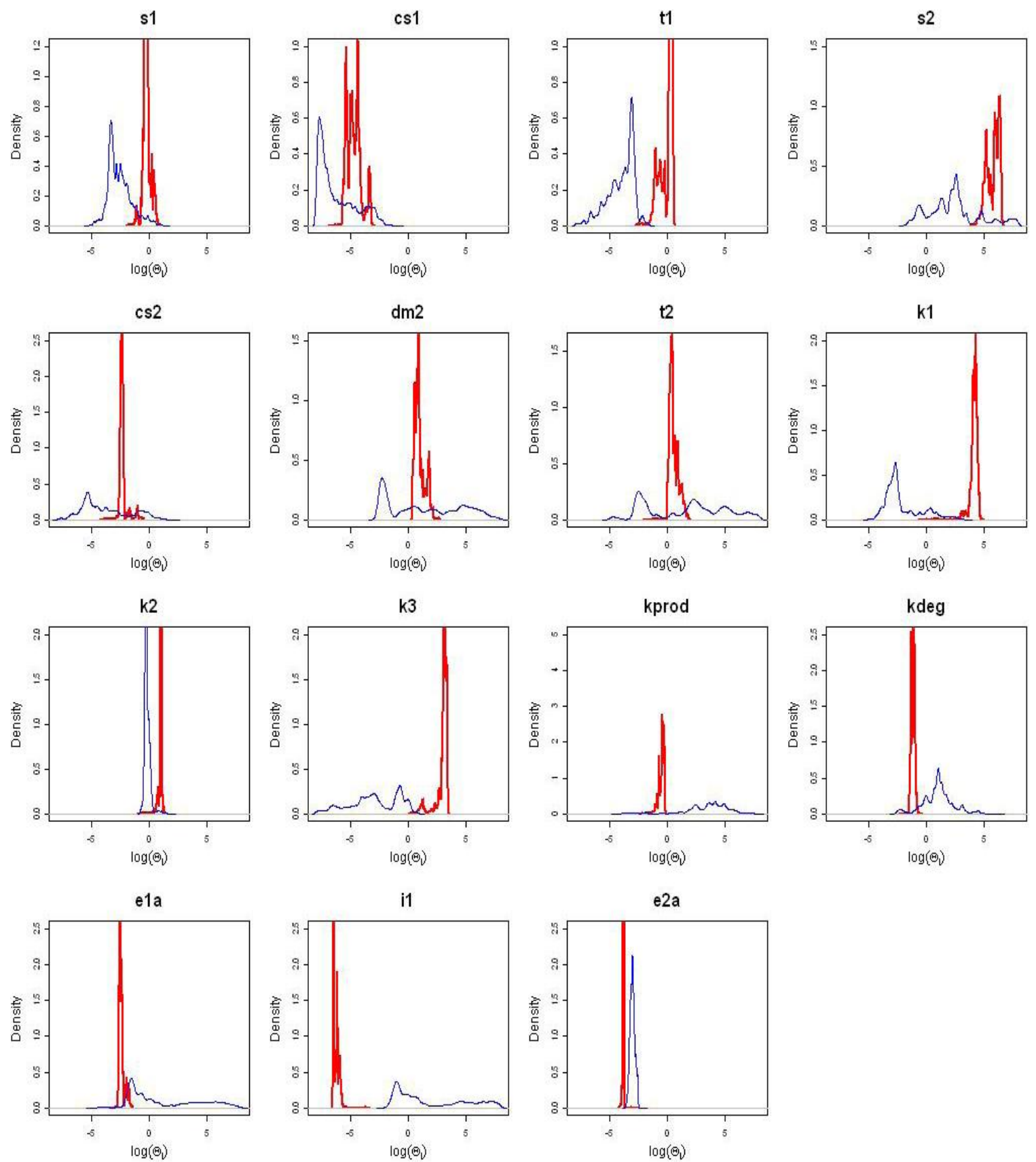

Figure 17 Normalized Distributions in Parameters for model 1 without DCPA treatment. The distribution in the sum of the normalized error between the calibration data and the model predictions is shown for each study used in the analysis. Distribution for the two parallel chains against experimental data without DCPA treatment is shown in different colors: chain 1(Blue) and chain 2(Red). 


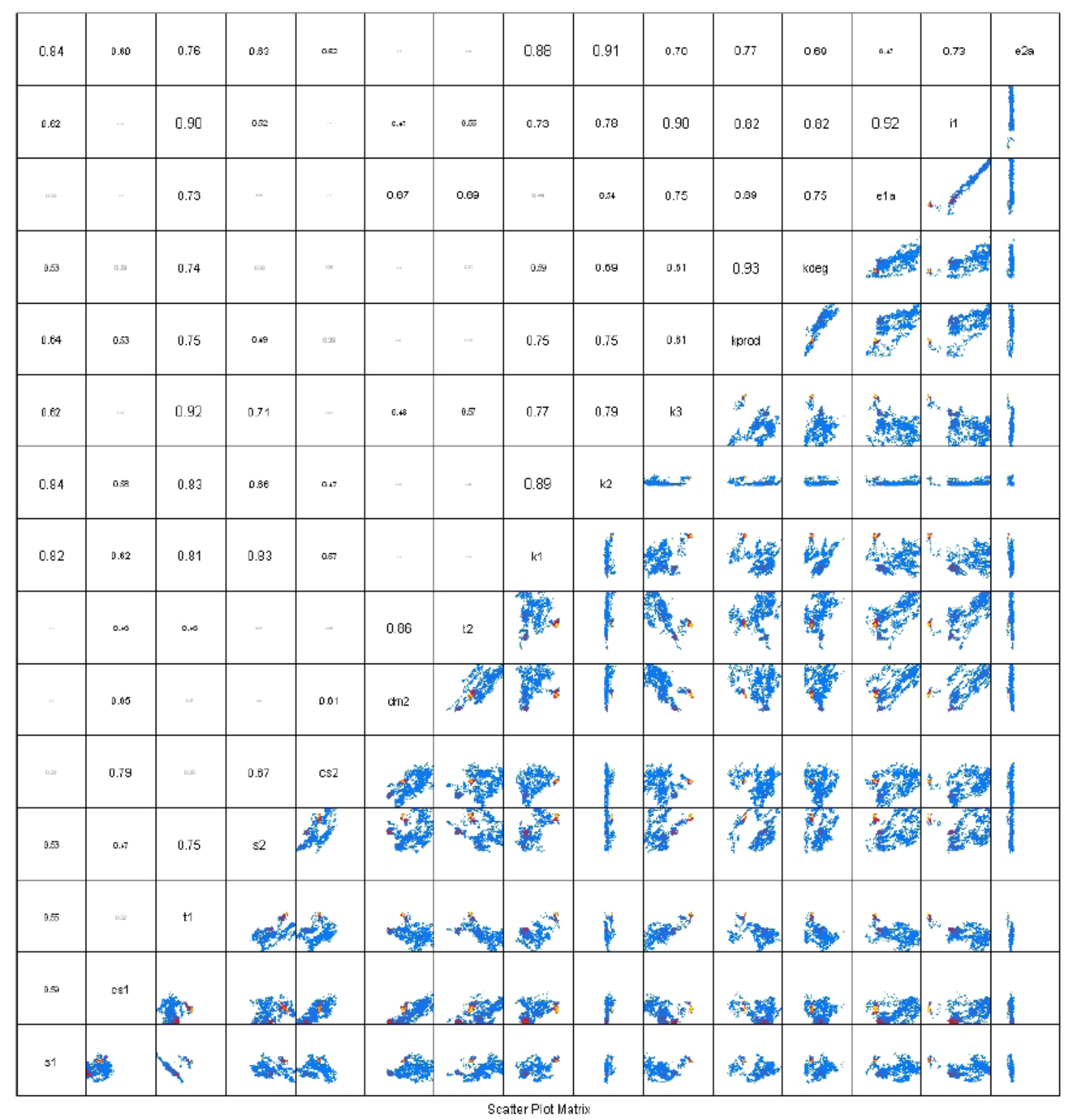

Figure 18 Covariance structure of $\mathrm{P}(\Theta \mid \mathrm{Y})$ for model 1 without DCPA treatment. The pairwise correlation coefficients of the parameters derived from all two thinned (Kthin = 200) Markov chains are shown above the diagonal. A high value for the correlation coefficient suggests that the parameters are unidentifiable given the calibration data. Below the diagonal, pairwise projections of the marginalized probability density for $\mathrm{P}$ $(\Theta \mid \mathrm{Y})$ are shown. The parameter names are shown on the diagonal. Each scatter plot axis spans a range of 1012(i.e., (log-mean-6.0 to log-mean+6.0)). The values in each scatter plot are centered at the log-mean values (i.e., the expectation maximum) determined from two parallel Markov Chains each containing 900,000 MCMC steps. 

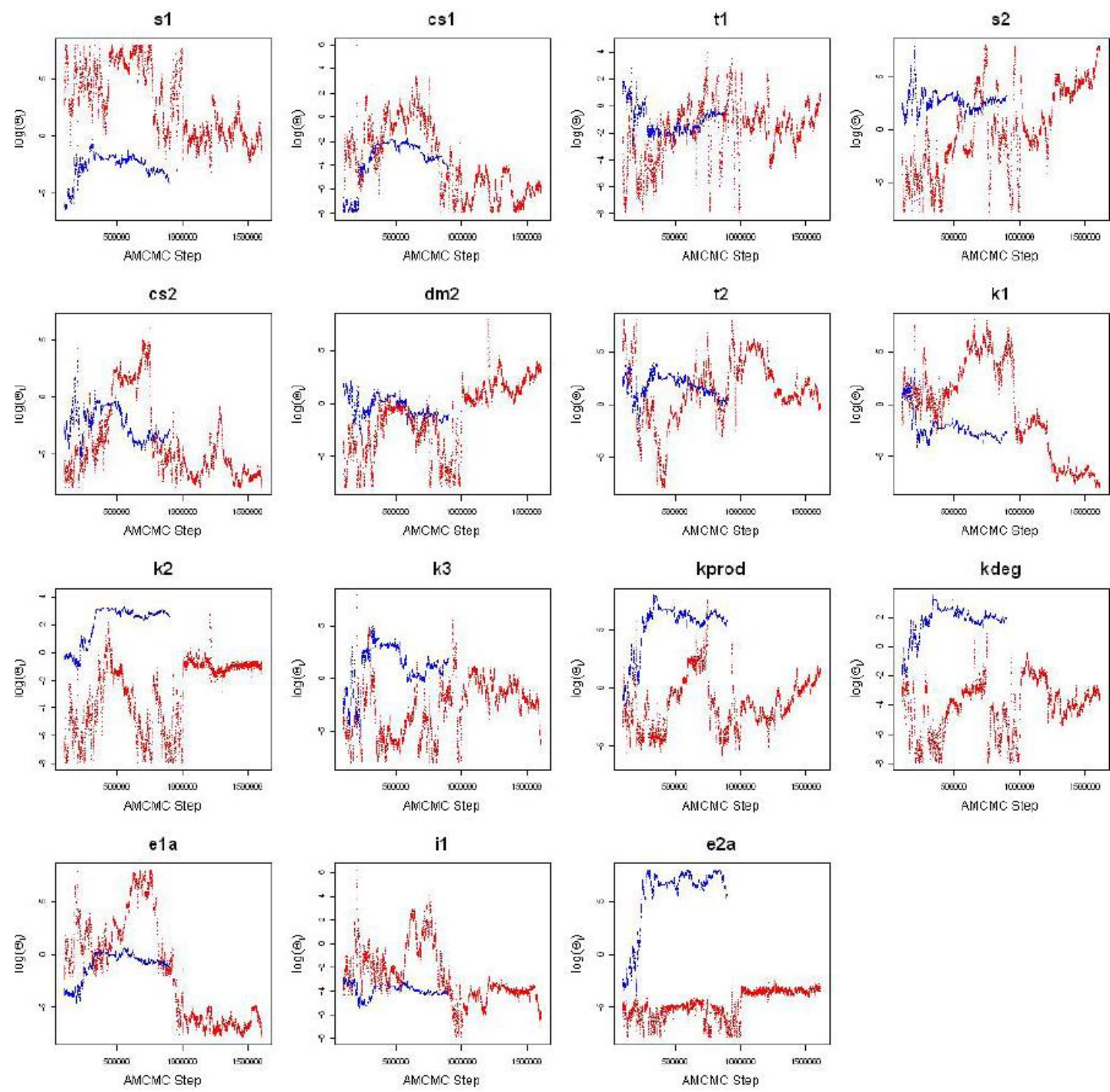

Figure 19 AMCMC summary plots for each of the model parameters for experimental data with DCPA treatment. The trace of each of the model parameters is shown as a function of MCMC step. The traces for two parallel chains are shown in different colors: chain 1 (Red) and chain 2 (Blue)

For the experimental data with DCPA treatment, we also did MCMC sampling to compare with the result for experimental data with DCPA treatment. From the convergence plot, shown as Figure 14, we can see that some of points are converged while some of them are not. Combined with the prediction of the simulation results, shown as Figure 15, although both chains could fit most of the data points, the frequency vary so much that they are not converged at other time points. From that we can also expect the parameter values also vary a lot, shown as in Figure 19 and Figure 20. 

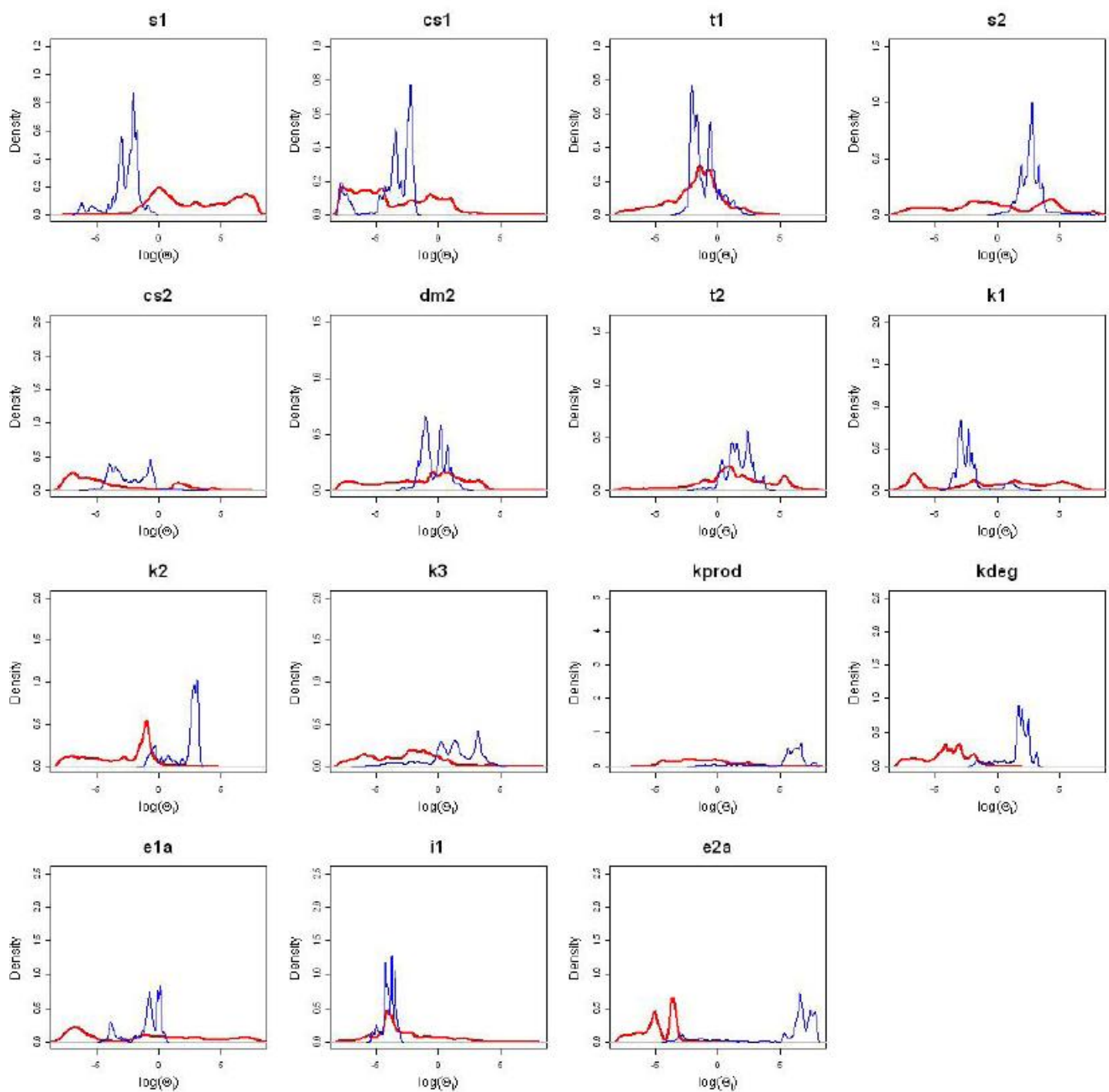

Figure 20 Normalized Distributions in Parameters for experimental data with DCPA treatment. The distribution in the sum of the normalized error between the calibration data and the model predictions is shown for each study used in the analysis. Distribution for the two parallel chains are shown in different colors: chain 1(Blue) and chain 2(Red)

Using the first 90 minutes' experimental data to estimate the values of the parameter and the rest of 6 hours experimental period has some limits like the oscillation frequency of $\mathrm{NF \kappa B}$ activity and the prediction vary much. To further test the model, we applied the AMCMC algorithm to the data of the whole 6 hours experimental period. From the results for with and without DCPA treatment, we can see that the model predictions are 
more consistent compared with that only using the first 90 minutes of data, shown as Figure 21 and Figure 22. However, even the model are more converged, but from the trace of all the parameters, shown as Figure 27, the parameters sampling by two chains are in two different valleys.
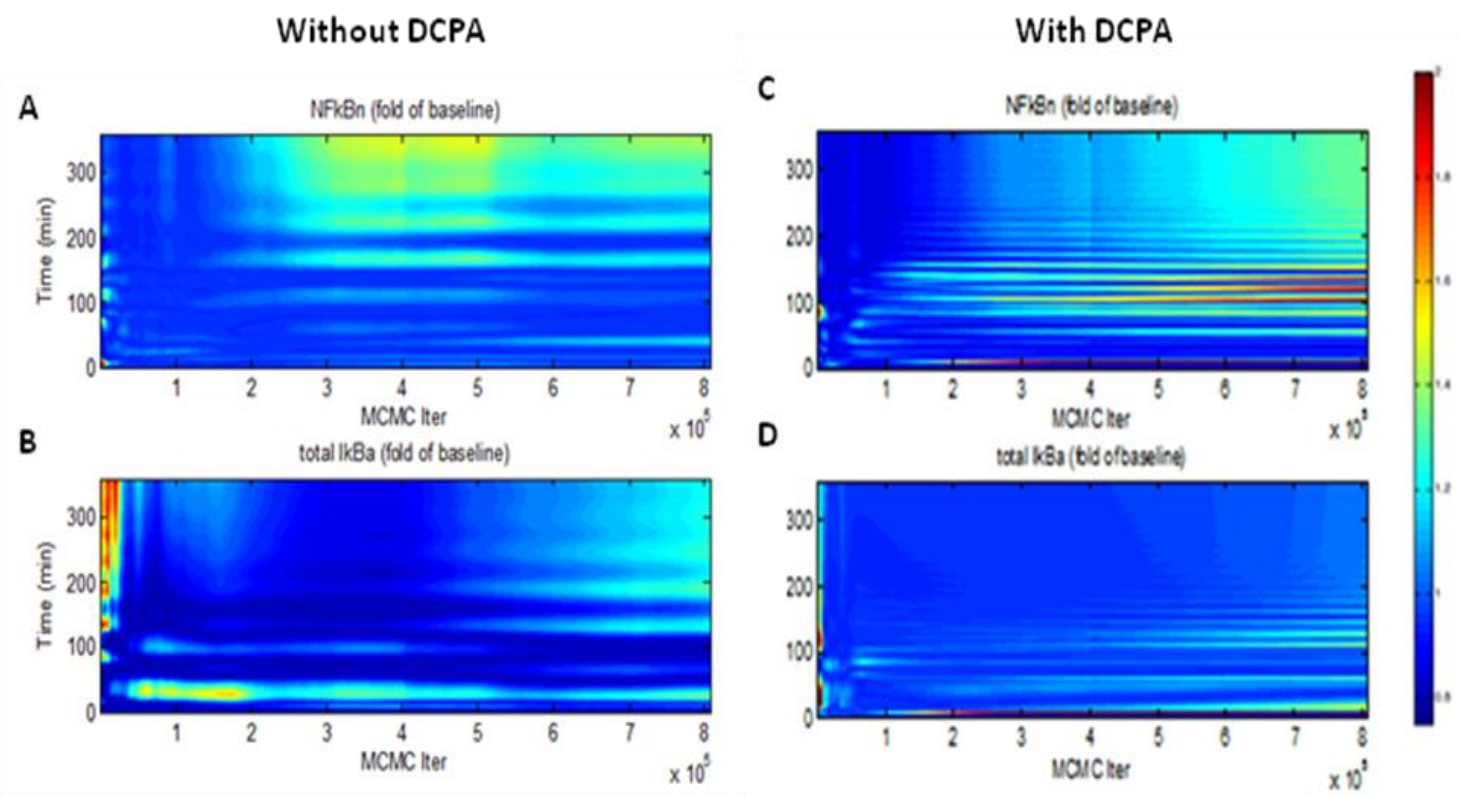

Figure 21 - Convergence of AMCMC . A contour plot of the Gelman-Rubin statistic of the model predictions as a function of time (i.e., the y-axis) calculated as a function of the cumulative chain up to a specific AMCMC step (i.e., the x-axis). Two parallel chains were used to calculate the Gelman-Rubin statistics for the simulated Free NFкB(panels A, C) expression in the nucleus and total ІкB $\alpha$ (panels B,D) in the cytoplasm without and with DCPA treatment. Values less than 1.2 suggest convergence of the chains. The models were fit to the entire six hour time period following;PS stimulation without and with DCPA treatment. 

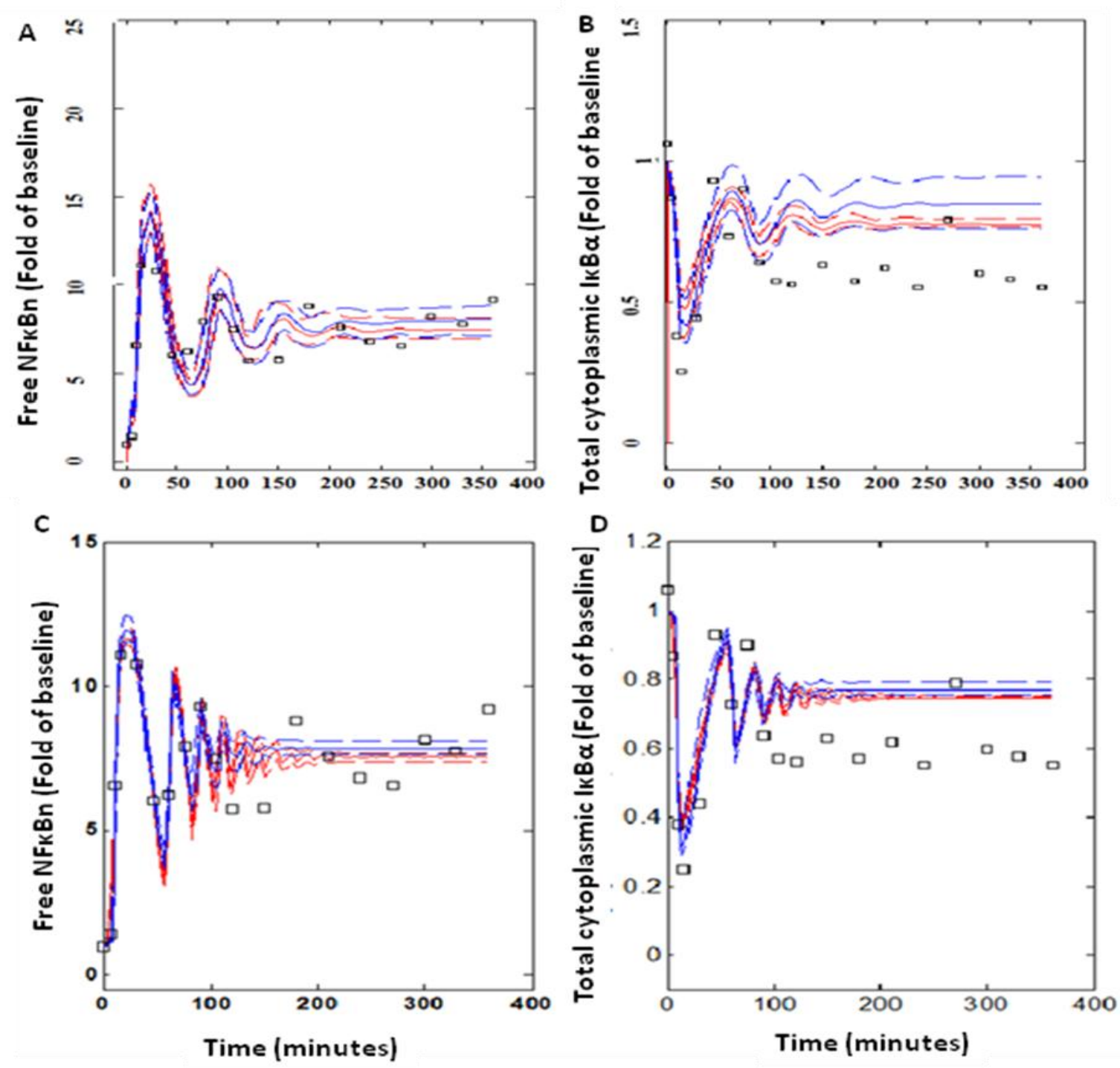

Figure 22 The mathematical model 1 for early signaling events reproduces the early dynamics for activation of free $\mathrm{NF \kappa B}$ expression $(\mathrm{A}, \mathrm{C})$ in the nucleus and ІкB $\alpha(\mathrm{B}, \mathrm{D})$ in the cytoplasm. Simulated results (lines) are compared against the experimental observations (symbols) used to calibrate the mathematical model for the entire 6 hours experimental data without DCPA treatment (panels A and B) and with DCPA treatment (panels $\mathrm{C}$ and $\mathrm{D}$ ). The uncertainty in the model predictions obtained from each chain is represented by three lines of the same color: the most likely prediction is represented by the solid lines and the dashed lines represent the 95th and 5th percentile of the predicted response. The results for each of the three parallel chains are shown in different colors: chain 1 (Red), chain 2 (Blue). 

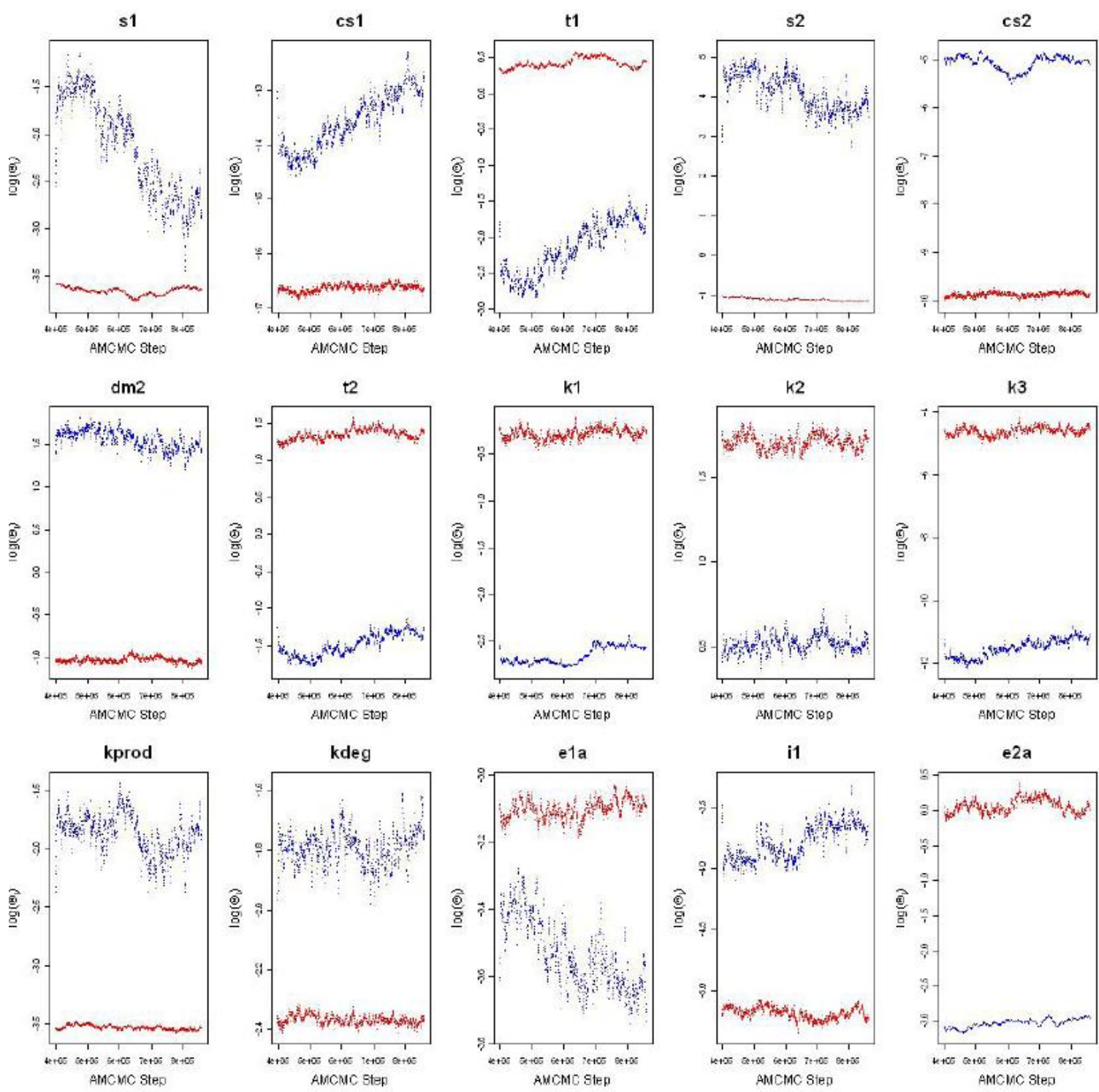

Figure 23 AMCMC summary plots for each of the model parameters for experimental data without DCPA treatment. The trace of each of the model parameters is shown as a function of MCMC step. The traces for two parallel chains are shown in different colors: chain 1 (Red) and chain 2 (Blue). 


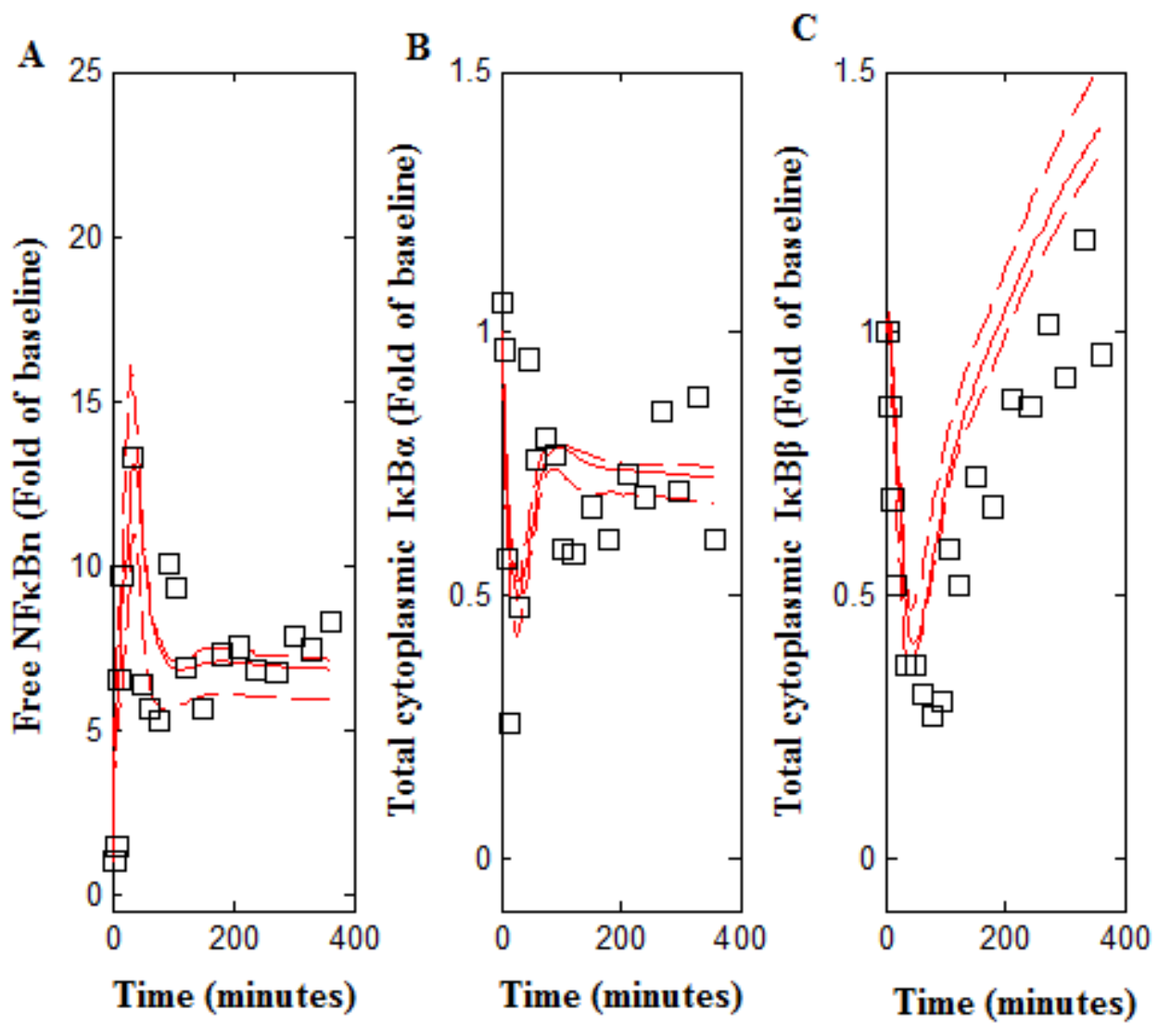

Figure 24 The mathematical model 2 for early signaling events reproduces the early

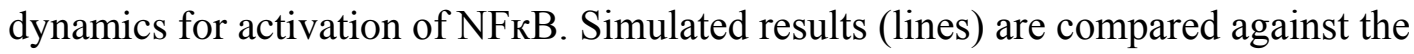
experimental observations (symbols) used to calibrate the mathematical model. The uncertainty in the model predictions obtained from each chain is represented by three lines of the same color: the most likely prediction is represented by the solid lines and the dashed lines represent the 95th and 5th percentile of the predicted response. The results for each of the three parallel chains are shown in different colors: chain 1 (Red), (A) Simulated response (lines) versus measured free NFкB (squares) in the nucleus without DCPA treatment; (B) Simulated response (lines) versus measured total ІкB $\alpha$ (squares) in the cytoplasm without DCPA treatment; (C) Simulated response (lines) versus measured total ІкB $\beta$ (squares) in the cytoplasm without DCPA treatment.

According Peng group's work, Foxj1 is essential to ІкB $\beta$ transcription.[24] 
Combine the measured cytoplasmic ІкB $\beta$ data, which re-increased after 90 minutes following the LPS stimulation, ІкВ $\beta$ should play an important role to regulate NFкB activity in IC-21 cells after 90 minutes following the LPS stimulation. Therefore, to better understand the regulation of NFкB activity in macrophages, ІкВ $\beta$ should be included into the signaling network.

For the big model, to involve ІкВ $\beta$ in the signaling network, more parameters are introduced, which causes more calculation in the modeling progress. From our current MCMC prediction, we can see that the big model couldn't catch the second peak of NFкB. However, it gives a good simulation of the trend of all $\mathrm{NF}_{\kappa} \mathrm{B}$, ІкB $\alpha$ and ІкB $\beta$ following LPS stimulation in macrophages. More experimental data are needed to estimate some parameters to reduce the number of being-fitted parameters. 


\section{CHAPTER 4}

\section{Conclusion}

\subsection{Regulation of NFKB activity following LPS stimulation}

Macrophages play an important role in the immune system. NFKB is an essential nuclear transcription factor in many kinds of cells including macrophages. NFкB induces or promotes the productions of lots of proteins. Conversely, the activity of NFKB is also regulated by other proteins. From our experimental data, ІкВ $\alpha$ proteins play a major role in regulating $\mathrm{NFKB}$ activity. Our mathematical Model 1 works well by using the first 90 minutes data to predict the rest of the 6 hours' experiment measured free NFкB in the nucleus and total ІкВ $\alpha$ in the cytoplasm. Further, the stimulation results show that additional proteins besides ІкB $\alpha$ are needed to keep the NFкB activity in the level as measured after 90 minutes following the LPS stimulation. This result is consistent with our experimental results which showed that ІкB $\beta$ proteins are produced 90 minutes after LPS stimulationand eventually rise to a higher level than that before the LPS stimulation. Therefore, we conclude that ІкВ $\alpha$ proteins are playing a major role in regulating the NFкB activity in the beginning of the LPS stimulation and then ІкВ $\beta$ proteins become more important as the time increases.

\subsection{Mathematical Modeling of NFкB signaling network}

Based on our conclusion from experiment measured $\mathrm{NF} \kappa \mathrm{B}$, ІкB $\alpha$ and ІкB $\beta$, we developed two mathematical models, model 1 and model 2. In model 1, ІкB $\alpha$ represent the role of inhibitors of NFKB and is also induced by NFKB. A20 is used to regulate IKK activity and also induced by NFKB. Two negative feedbacks involve 14 components and 25 groups of reactions. Twenty seven parameters are associated with these reactions between the 14 components. From simulation annealing results, model 1 works well for 
the NFкB signaling. Furthermore, more ІкВ $\alpha$ proteins are predicted than measured, which is consistent with the increased ІкВ $\beta$ proteins measured by the experiment. Model 2 uses an unknown nuclear factor NFX to introduce ІкB $\beta$ mRNA and also cause the delay of IкB $\beta$ mRNA transcription, comparing with IкB $\alpha$ mRNA. Model 2 includes 46 groups of reactions, translations and transportations. The simulation annealing program was not able to select appropriate simulate this high dimensional model. We used MCMC sampling to fit the model and could simulate for all $\mathrm{NF} \kappa \mathrm{B}$, ІкB $\alpha$ and ІкB $\beta$, as measured by the experiment. However, the fit was not good enough to catch most of the observed dynamics. More information about the parameters in the signaling network and the unknown nuclear factor NFX is needed to further improve Model 2.

From the a priori identifiability analysis, some of these parameters in Model 1 are correlated to each other. Comparing the parameter values fitted by the simulation annealing program, they are much different for the experimental data without DCPA and with DCPA treatment. It is difficult to say whether these differences are because of the DCPA effect or just a result of the correlation between parameters. Similarly, we can expect parameters are correlated in the Model 2, too.

\subsection{AMCMC to estimate the conditional uncertainty in the model parameters}

Two parallel Markov chains generated using Metropolis-Hasting algorithm were used to estimate the conditional uncertainty in the model parameters against experimental data with and without DCPA treatment. Using data of the first 90 minutes following the LPS stimulation, the model doesn't converge, although it could catch most of the data points. The frequency of the predicted oscillations varies a lot between different chains. This may be because of the frequency of the two data sets NFкB and ІкB $\alpha$ were measured under slightly different conditions. Slight difference in the external stimulation by LPS may cause the difference of frequency of these two data sets.

However, when we include all the data from the whole 6 hours experiments, the convergence of the model is improved. The predictions of the two chains for experimental data with and without DCPA are much more consistent. However, the 
improved fit may be due to inclusion of additional parameters into the model. Model discrimination criteria should be used to compare these two models. Overall more information about parameters will help to estimate the unknown parameters and predict the system. 


\section{REFERENCE}

[1] Pikarsky E, Porat R M, Stein I, Abramovitch R, Amit S, Kasem S, Gutkovich-Pyest E, Urieli-Shoval S, Galun E and Ben-Neriah Y, NF-kB functions as a tumour promoter in inflammation-associated cancer. NATURE, VOL. 431, 2004, Pg: 461-466.

[2] Bierhaus A, Schiekofer S, Schwaninger M, et al, Diabetes-Associated Sustained Activation of the Transcription Factor Nuclear Factor-кB. DIABETES, VOL. 50, 2001, Pg: 2792-2808

[3] Karin M and Greten F R, NF kappa B: Linking inflammation and immunity to cancer development and progression. NATURE REVIEWS IMMUNOLOGY, Vol. 5, 2005, Iss.: 10, Pg: 749-759.

[4] Karin M, Nuclear factor- $\kappa \mathrm{B}$ in cancer development and progression. NATURE, Vol. 441, 2006, Pg: 431-436.

[5] Hayden M and Ghosh S, Shared Principles in NF-אB Signaling. Cell, Vol. 132, Iss.: 2, 2008, Pg: 344-362,

[6] Wu J T and Kral J G, The NF-кB/IкB Signaling System: A Molecular Target in Breast Cancer Therapy. Journal of Surgical Research, Vol. 123, 2005, Pg: 158-169

[7] Vallabhapurapu S and Karin M, Regulation and Function of NF-кB Transcription Factors in the Immune System. Annu. Rev. Immunol., Vol. 27, 2009, Pg: 693-733

[8] Coornaert B, Carpentier I and Beyaert R, A20: Central Gatekeeper in Inflammation and Immunity. Journal of Biological Chemistry, Vol.284, No.13, 2009, Pg: 8217-8221.

[9] Karin M and Ben-Neriah Y. Phosphorylation meets ubiquitination: the centrol of NFкB Activity. Annual Review OF Immunology, Vol. 18, 2000, Pg: 621-663. 
[10] Tran K, Merika M and Thanos D. Distinct Functional Properties of ІкB $\alpha$ and I кB $\beta$. MOLECULAR AND CELLULAR BIOLOGY, Vol. 17, No. 9, 1997, Pg: 5386-5399

[11] Hoffmann A, Levchenko A, Scott ML, Baltimore D, The IkappaB-NF-kappaB signaling module: temporal control and selective gene activation. Science, Vol. 298, 2002, Pg: 1241-1245

[12] Cheong R, Hoffmann A and Levchenko A. Understanding NF- $\kappa B$ signaling via mathematical modeling. Molecular Systems Biology, Vol. 4, 2008, Pg: 192

[13] Lipniacki T, Paszek P, Brasier A R, Luxon B, and Kimmel M, Mathematical model of NF-kB regulatory module. J. Theor. Biol. Vol.228, 2004, Pg: 195-215.

[14] Gao M and Karin M, Regulating the Regulators: Control of Protein Ubiquitination and Ubiquitin-like Modifications by Extracelluar Stimuli. Molecular Cell, Vol.19, 2005, Pg: 581-593

[15] Lee E G, Boone D L, Chai S, Libby S L, Chien M, Lodolce J P, and Ma A, Failure to regulate TNF-induced NF-кB and cell death responses in A20-deficient mice. Science, Vol. 289, 2000, Pg: 2350-2354.

[16] D L Boone, E E Turer, E G Lee, et. al., The ubiquitin-modifying enzyme A20 is required for termination of Toll-like receptor responses. NATURE IMMUNOLOGY, Vol. 5, 2004, Pg: 1052-1060

[17] Wertz I E, O’Rourke K M, Zhou H, Eby M, Aravind L, Seshagiri S, Wu P, Wiesmann C,Baker R, Boone D L, Ma A, Koonin E V and Dixit V M, De-ubiquitination and ubiquitin ligase domains of A20 downregulate NF-kB signalling. NATURE, Vol.430, 2004, Pg: 694-699

[18] Renner F and Schmitz M L, Autoregulatory feedback loops terminating the NF- кB response, Trends in Biochemical Sciences, Vol.34, No.3, 2009, Pg: 128-135 
[19] Sun S, Ganchi P, Ballard D W and Greene WC, NF-кB Controls Expression of Inhibitor IкB $\alpha$ : Evidence for an Inducible Autoregulatory Pathway. Science, Vol. 259, 1993, Pg: 1912-1915

[20] Pando M P, Verma I M, Signal-dependent and -independent degradation of free and NF-kB-bound IkBa: J. Biol. Chem. Vol. 275, 2000, Pg: 21278-21286.

[21] Mathes E, O’Dea E L, Hoffmann A, and Ghosh G, NF-кВ dictates the degradation pathway of IкB $\alpha$. The EMBO Journal, Vol. 27, No. 9, 2008, Pg:13571367

[22] Zandi E, Chen Y and Karin M, Direct phosphorylation of IkB by IKKa and IKKb: discrimination between free and NF-kBbound substrate. Science, Vol. 281, 1998, Pg: 1360-1363.

[23] Kearns J D, Basak S, Werner S, Huang C, and Hoffmann A, IkB $\varepsilon$ provides negative feedback to control the dynamics of NF-KB signaling and gene expression. J. Cell Biol. Vol. 173, 2006, Pg: 659-664.

[24] Lin L, Spoor M S, Gerth A J, Brody S L and Peng S L, Modulation of Th1 Activation and Inflammation by the NF-кB Repressor Foxj1. SCIENCE, Vol. 303, 2004, Pg: $1017-1020$

[25]Cameron P, McGachy A, Anderson M, Paul A, Coombs G, Mottram J, Alexander J and Plevin R, Inhibition of Lipopolysaccharide-Induced Macrophage IL-12 Production by Leishmania mexicana Amastigotes: The Role of Cysteine Peptidases and the NF-кB Signaling Pathway. The Journal of Immunology, Vol. 173, 2004, Pg: 3297-3304

[26] Gilmore T D, and Herscovitch M, Inhibitors of NF-kappaB signaling: 785 and counting. Oncogene, Vol. 25, 2006, Pg: 6887-6899.

[27] Xie Y C, Schafer R and Barnett J B, Inhibitory effect of 3,4-dichloro-propionaniline on cytokine production by macrophages is associated with LPS-mediated signal transduction. J. Leukoc. Biol., Vol. 61, 1997, Pg: 745-752. 
[28] Klinke D, Ustyugova I, Brundage K and Barnett J. Modulating Temporal Control of NF-kappaB Activation: Implications for Therapeutic and Assay Selection. Biophysical Journal, 2008, Vol. 94, No.11, Pg: 6-11

[29] Frost L L, Neeley Y X, Schafer R, Gibson L F and Barnett J B, Propanil inhibits tumor necrosis factor-a production by reducing nuclear levels of the transcription factor nuclear factor-kb in the macrophage cell line IC-21. Toxicol. Appl. Pharmacol. Vol. 172, 2001, Pg: 186-193.

[30] Covert M W, Leung T H, Gaston J E and Baltimore D, Achieving stability of lipopolysaccharide-induced NF-kappaB activation. Science, Vol. 309, 2005, Pg: 18541857

[31] Kearns J and Hoffmann A. Integrating Computational and Biochemical Studies to Explore Mechanisms in NF- кB Signaling. JOURNAL OF BIOLOGICAL CHEMISTRY Vol. 284, No.9, 2009, Pg: 5439-5443

[32] Werner S L, Kearns J D, Zadorozhnaya V, Lynch C, O’Dea E, Boldin M P, Ma A, Baltimore D and Hoffmann A. Encoding NF-кB temporal control in response to TNF: distinct roles for the negative regulators ІкВ $\alpha$ and A20. Genes \& Development, Vol. 22, 2008, Pg: 2093-2101

[33] Hoffmann A, Leung Tand Baltimore D. Genetic analysis of NF-kB/Rel transcription factors defines functional specificities. The EMBO Journal, Vol. 22, No. 20, 2003, Pg: $5530-5539$

[34] Kim J M, Voll R E, Ko C and Kim D S, et. al. A New Regulatory Mechanism of

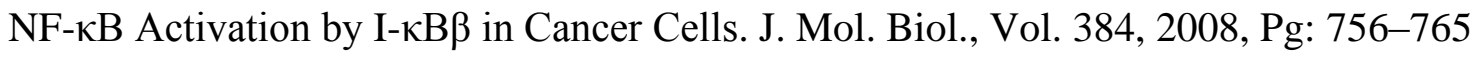

[35] Pawson T and Nash P. Assembly of Cell Regulatory Systems through Protein Interaction Domains. Science, Vol. 300, 2003, Pg: 445-452 
[36] Carlotti F, Dower S K, Qwarnstrom E E, Dynamic shuttling of nuclear factor kappa $\mathrm{B}$ between the nucleus and cytoplasm as a consequence of inhibitor dissociation. J. Biol. Chem. Vol. 275, 2000, Pg: 41028-41034

[37] Klinke D J, An Empirical Bayesian Approach for Model-based Inference of Cellular Signaling Networks, 2009.

[38] Ghosh S and Karin M, Missing Pieces in the NF-кB Puzzle. Cell, Vol. 109, 2002, Pg: 81-96.

[39] Cheng J, Ryseck R AND Attar R. Functional Redundancy of the Nuclear Factor kB Inhibitors IkBa and IkBb. J. Exp. Med, Vol. 188, No. 6, 1998, Pg: 1055-1062

[40] Chen $\mathrm{Y}, \mathrm{Wu} \mathrm{J}$ and Ghosh $\mathrm{G}, \mathrm{\kappa B}-\mathrm{Ras}$ binds to the unique insert within the ankyrin repeat domain of IкB $\beta$ and regulates cytoplasmic retention of IкB $\beta \cdot \mathrm{NF \kappa B}$ complexes. J. Biol. Chem. Vol. 278, 2003, Pg: 23101-23106

[41] Feldmann M, Brennan F M, and Maini R N, Role of Cytokines in Rheumatoid Arthritis. Annu. Rev. Immunol., Vol. 14, 1996, Pg: 397-440

[42] Roy L D, Pathangey L B, Tinder T L, and Mkherjee P, Breast Cancer Associated Metastasis is Significantly Increased in a Model of Autoimmune Arthritis. Nature Precedings, hdI10101/npre.2008.2632.1

[43] Blattner C, Kannouche P, Litfin M, Bender K, Rahmsdorf H J, Angulo J F and Herrlich P, UV-induced stabilization of c-fos and other short-lived mRNAs. Mol. Cell. Biol. Vol. 20, 2000, Pg: 3616-3625

[44] Heilker R, Freuler F, Vanek M, Pulfer R, Kobel T, Peter J, Zerwes H G, Hofstetter H and Eder J, The kinetics of association and phosphorylation of IkB isoforms by IkB kinase 2 correlate with their cellular regulation in human endothelial cells. Biochemistry, Vol. 38, 1999, Pg: 6231-6238 
[45] Cheong R, Bergmann A, Werner S L, Regal J, Hoffmann A and Levchenko A, Transient IkappaB kinase activity mediates temporal NFkappaB dynamics in response to a wide range of tumor necrosis factor-alpha doses. J Biol Chem, Vol. 281, 2006, Pg: 2945-2950

[46] Werner S L, Barken D and Hoffmann A, Stimulus specificity of gene expression programs determined by temporal control of IKK activity. Science, Vol. 309, 2005, Pg: 1857-1861 .

[47] Hertlein E, Wang J, Ladner K, Bakkar N and Guttridge D. RelA/p65 Regulation of ІкВ $\beta$. Molecular and Cellular Biology. Vol.25, No.12, 2005, Pg: 4956-4968

[48] Suyang H, Phillips R, Douglas I and Ghosh S.

Role of Unphosphorylated, Newly Synthesized IkBb in

Persistent Activation of NF-kB. Molecular and Cellular Biology. Vol.16, No.10, 1996, Pg: 5444-5449

[49] Phillips R and Ghosh S. Regulation of IkBb in WEHI 231 Mature B Cells. Molecular and Cellular Biology. Vol.17, No.8, 1997, Pg: 4390-4396

[50] Hirano F, Chung M, Tanaka H, Maruyama N, Makino I, Moore D D and Scheidereit C. Alternative Splicing Variants of IkBb Establish Differential NF-kB Signal Responsiveness in Human Cells. Molecular and Cellular Biology. Vol.18, No.5, 1998, Pg: 2596-2607

[51] Rogers S, Khanin R, Girolami M: Bayesian model-based inference of transcription factor activity. BMC Bioinformatics 2007, 8(Suppl 2):S2.

[52] Jacquez, J. A., and T. Perry. 1990. Parameter estimation: local identifiability of parameters. Am. J. Physiol. 258:E727-E736.

[53] Wilkinson D. Bayesian Methods in Bioinformatics and computational systems biology. Briefings in Bioinformatics. Vol.8, No.2:109-116 [54] Haayot F, Jayaprakash C. NF-Kb oscillations and cell-to-cell variablility. Journal of Theoretical Biology. Doi:10.1016/j.jtbi.2005.10.018 
[55] Nelson D E, Ihekwaba A E C, and White M R H, et al. SCIENCE, Vol. 306, 2004:704-708.

[56] Busetti F. Simulated annealing overview. http:www.google.com 


\section{APPENDIX}

Table A.1 List of Models Variables

\begin{tabular}{|c|c|c|}
\hline Variable Name & Definition & Units \\
\hline TLR4 & Toll-like receptor 4 & 1 \\
\hline R0 & LPS Stimulation signal & - \\
\hline IKKn & Free neutral cytoplasmic IKK proteins & $\mu \mathrm{M}$ \\
\hline IKKn & Free active cytoplasmic IKK proteins & $\mu \mathrm{M}$ \\
\hline IKKn & Free inactive cytoplasmic IKK proteins & $\mu \mathrm{M}$ \\
\hline IkBa & Free cytoplasmic IkBa proteins & $\mu \mathrm{M}$ \\
\hline NFkB & Free cytoplasmic NFkB & $\mu \mathrm{M}$ \\
\hline IKKaIkBa & Cytoplasmic IKKa-IkBa complexes & $\mu \mathrm{M}$ \\
\hline IKKaIkBaNFkB & Cytoplasmic IKKa-IkBaNFkB complexes & $\mu \mathrm{M}$ \\
\hline A 20 & Cytoplasmic A20 proteins & $\mu \mathrm{M}$ \\
\hline $\mathrm{A} 20 \mathrm{~m}$ & A20 mRNA & $\mu \mathrm{M}$ \\
\hline IkBam & IkBa mRNA & $\mu \mathrm{M}$ \\
\hline IkBan & Free Nuclear IkBa proteins & $\mu \mathrm{M}$ \\
\hline NFkBn & Free Nuclear NFkB & $\mu \mathrm{M}$ \\
\hline IkBaNFkB & Cytoplasmic IkBaNFkB complexes & $\mu \mathrm{M}$ \\
\hline IkBanNFkBn & Nuclear IkBa-NFkB complexes & $\mu \mathrm{M}$ \\
\hline $\mathrm{IkBb}(\#)$ & Free cytoplasmic IkBb proteins & $\mu \mathrm{M}$ \\
\hline IkBbNFkB (\#) & Cytoplasmic IkBbNFkB complexes & $\mu \mathrm{M}$ \\
\hline $\operatorname{IKKaIkBb}(\#)$ & Cytoplasmic IKKa-IkBb complexes & $\mu \mathrm{M}$ \\
\hline IKKaIkBbNFkB (\#) & Cytoplasmic IKKa-IkBaNFkB complexes & $\mu \mathrm{M}$ \\
\hline $\operatorname{IkBbm}(\#)$ & $\mathrm{IkBb}$ mRNA & $\mu \mathrm{M}$ \\
\hline $\operatorname{IkBbn}(\#)$ & Free Nuclear IkBb proteins & $\mu \mathrm{M}$ \\
\hline IkBbnNFkBn (\#) & Nuclear IkBb-NFkB complexes & $\mu \mathrm{M}$ \\
\hline NFX (\#) & Unknown transcription factor $\mathrm{X}$ & $\mu \mathrm{M}$ \\
\hline NFXn (\#) & Nuclear unknown transcription factor $\mathrm{X}$ & $\mu \mathrm{M}$ \\
\hline NFXm (\#) & Unknown transcription factor $\mathrm{X}$ mRNA & $\mu \mathrm{M}$ \\
\hline
\end{tabular}

(\#) represents the components which are involved only in Model 2. 
Table A.2 Reaction rate equations of Model 1 and Model 2 for NFкB signaling pathway

Reaction Rate Relationship

Reaction class 1: IkBa-NFkB Association

$\mathrm{R} 1 \mathrm{a}=\mathrm{a} 1 * \mathrm{NFkB} * \mathrm{IkBa}$

$\mathrm{R} 1 \mathrm{~b}=\mathrm{a} 1 * \mathrm{NFkBn} * \mathrm{IkBan}$

$\mathrm{R} 1 \mathrm{c}=\mathrm{a} 1 * \mathrm{NFkB} * \mathrm{IKKaIkBa}$

Reaction class 2: IKKa-IkBa Association

$\mathrm{R} 2 \mathrm{a}=\mathrm{a} 2 * \mathrm{IKKa} * \mathrm{IkBa}$

$\mathrm{R} 2 \mathrm{~b}=\mathrm{a} 2 * \mathrm{f} 1 * \mathrm{IKKa} * \mathrm{IkBaNFkB}$

Reaction class 3: IkBa-NFkB dissociation

$\mathrm{R} 3 \mathrm{a}=\mathrm{d} 1 * \mathrm{IkBaNFkB}$

$\mathrm{R} 3 \mathrm{~b}=\mathrm{d} 1 * \mathrm{IkBanNFkBn}$

$\mathrm{R} 3 \mathrm{c}=\mathrm{d} 1 *$ IKKaIkBaNFkB

Reaction class 4: IKKa-IkBa dissociation

$\mathrm{R} 4 \mathrm{a}=\mathrm{d} 2 * \mathrm{IKKaIkBa}$

$\mathrm{R} 4 \mathrm{~b}=\mathrm{d} 2 * \mathrm{f} 1 *$ IKKaIkBaNFkB

Reaction class 5: IKKa-IkBa Catalytic dissociation

$\mathrm{R} 5 \mathrm{a}=\mathrm{kcat} * \mathrm{IKKaIkBa}$

$\mathrm{R} 5 \mathrm{~b}=\mathrm{kcat} * \mathrm{f} 2 * \mathrm{IKKaIkBaNFkB}$

Reaction class 6: Degradation of IKK

$\mathrm{R} 6 \mathrm{a}=\mathrm{kdeg} * \mathrm{IKKn}$

$\mathrm{R} 6 \mathrm{~b}=\mathrm{kdeg} * \mathrm{IKKa}$

$\mathrm{R} 6 \mathrm{c}=\operatorname{kdeg} * \mathrm{IKKi}$

Reaction class 7: Degradation of free IkBa proteins 
$\mathrm{R} 7=\mathrm{de} 1 * \mathrm{IkBa}$

Reaction class 8: Degradation of IkBa complex to NFkB

$\mathrm{R} 8=\mathrm{de} 3 * \mathrm{IkBaNFkB}$

Reaction class 9: Degradation of A20 proteins

$\mathrm{R} 9=\mathrm{de} 2 * \mathrm{~A} 20$

Reaction class 10: Degradation of IkBa mRNA

$\mathrm{R} 10=\mathrm{dm} 1 * \mathrm{IkBam}$

Reaction class 11: Degradation of A20 mRNA

$\mathrm{R} 11=\mathrm{dm} 2 * \mathrm{~A} 20 \mathrm{~m}$

Reaction class 12: Synthesis of IKKn

$\mathrm{R} 12=\operatorname{kprod}$

Reaction class 13: Inducible synthesis of IkBa mRNA

$\mathrm{R} 13=\mathrm{s} 1 * \mathrm{NFkBn}$

Reaction class 14: Inducible synthesis of A20 mRNA

$\mathrm{R} 14=\mathrm{s} 2 * \mathrm{NFkBn}$

Reaction class 15: Constitutive synthesis of IkBa mRNA

$\mathrm{R} 15=\mathrm{cs} 1$

Reaction class 16: Constitutive synthesis of A20 mRNA

$\mathrm{R} 16=\mathrm{cs} 2$

Reaction class 17: Translation from IkBa mRNA to IkBa proteins

$\mathrm{R} 17=\mathrm{t} 1 * \mathrm{IkBam}$ 
Reaction class 18: Translation from A20 mRNA to A20 proteins

$\mathrm{R} 18=\mathrm{t} 2 * \mathrm{~A} 20 \mathrm{~m}$

Reaction class 19: Activation of IKKn to IKKa

$\mathrm{R} 19=\mathrm{k} 1 * \mathrm{R} 0 * \mathrm{IKKn} * \mathrm{TLR} 4$

Reaction class 20: Inactivation of IKKa because of A20

$\mathrm{R} 20=\mathrm{k} 2 * \mathrm{R} 0 * \mathrm{~A} 20 * \mathrm{IKKa}$

Reaction class 21: Spontaneous Inactivation of IKKn to IKKi

$\mathrm{R} 21=\mathrm{k} 3 * \mathrm{IKKa}$

Reaction class 22: IkBa Import to the nucleus

$\mathrm{R} 22=\mathrm{i} 1 \mathrm{a} * \mathrm{IkBa}$

Reaction class 23: IkBa export from the nucleus to cytoplasm

$\mathrm{R} 23=\mathrm{e} 1 \mathrm{a} * \mathrm{IkBan}$

Reaction class 24: IkBanNFkBn export from the nucleus to cytoplasm

$\mathrm{R} 24=\mathrm{e} 2 \mathrm{a} * \mathrm{IkBanNFkBn}$

Reaction class 25: NFkB import to the nucleus from cytoplasm

$\mathrm{R} 25=\mathrm{i} 1 * \mathrm{NFkB}$

Reaction class 26: IkBb-NFkB Association (\#)

$\mathrm{R} 26 \mathrm{a}=\mathrm{a} 3 * \mathrm{NFkB} * \mathrm{IkBb}$

$\mathrm{R} 26 \mathrm{~b}=\mathrm{a} 3 * \mathrm{NFkB} * \mathrm{IKKaIkBb}$

$\mathrm{R} 26 \mathrm{c}=\mathrm{a} 3 * \mathrm{NFkBn} * \mathrm{IkBbn}$

Reaction class 27: IKKa-IkBb Association (\#) 


$$
\begin{aligned}
& \mathrm{R} 27 \mathrm{a}=\mathrm{a} 4 * \mathrm{IKKa} * \mathrm{IkBb} \\
& \mathrm{R} 27 \mathrm{~b}=\mathrm{a} 4 * \mathrm{f} 3 * \mathrm{IKKa} * \mathrm{IkBbNFkB}
\end{aligned}
$$

Reaction class 28: IkBb-NFkB dissociation (\#)

$$
\mathrm{R} 28 \mathrm{a}=\mathrm{d} 3 * \mathrm{IkBbNFkB}
$$$$
\mathrm{R} 28 \mathrm{~b}=\mathrm{d} 3 * \text { IKKaIkBbNFkB }
$$

$\mathrm{R} 28 \mathrm{c}=\mathrm{d} 3 * \mathrm{IkBbnNFkBn}$

Reaction class 29: IKKa-IkBb dissociation (\#)

$\mathrm{R} 29 \mathrm{a}=\mathrm{d} 4 * \mathrm{IKKaIkBb}$

$\mathrm{R} 29 \mathrm{~b}=\mathrm{d} 4 *$ IKKaIkBbNFkB

Reaction class 30: IKKa-IkBbCatalytic dissociation (\#)

$\mathrm{R} 30 \mathrm{a}=\mathrm{kcatb} * \mathrm{IKKaIkBa}$

$\mathrm{R} 30 \mathrm{~b}=\mathrm{kcatb} * \mathrm{f} 2 *$ IKKaIkBaNFkB

Reaction class 31: Degradation of free IkBb proteins (\#)

$\mathrm{R} 31=\mathrm{de} 4 * \mathrm{IkBb}$

Reaction class 32: Degradation of IkBb complex to NFkB (\#)

$\mathrm{R} 32=\operatorname{de} 5 * \mathrm{IkBbNFkB}$

Reaction class 33: Degradation of NFX mRNA (\#)

$\mathrm{R} 33=\mathrm{dm} 3 * \mathrm{NFXm}$

Reaction class 34: Degradation of IkBb mRNA (\#)

$\mathrm{R} 34=\mathrm{dm} 4 * \mathrm{IkBbm}$

Reaction class 35: Inducible synthesis of NFX mRNA (\#)

$$
\mathrm{R} 35=\mathrm{s} 3 * \mathrm{NFkBn}
$$


Reaction class 36: Inducible synthesis of IkBb mRNA (\#)

$\mathrm{R} 36=\mathrm{s} 4 * \mathrm{NFXn}$

Reaction class 37: Constitutive synthesis of NFX mRNA (\#)

$\mathrm{R} 37=\operatorname{cs} 3$

Reaction class 38: Constitutive synthesis of IkBb mRNA (\#)

$\mathrm{R} 38=\mathrm{cs} 4$

Reaction class 39: Translation from NFX mRNA to NFX proteins (\#)

$\mathrm{R} 39=\mathrm{t} 3 * \mathrm{NFXm}$

Reaction class 40: Translation from IkBb mRNA to IkBb proteins (\#)

$\mathrm{R} 40=\mathrm{t} 4 * \mathrm{IkBbm}$

Reaction class 41: NFX Import to the nucleus (\#)

$\mathrm{R} 41=\mathrm{i} 3 * \mathrm{NFX}$

Reaction class 42: NFX export from the nucleus to cytoplasm (\#)

$\mathrm{R} 42=\mathrm{e} 3 * \mathrm{NFXn}$

Reaction class 43: IkBb Import to the nucleus (\#)

$\mathrm{R} 43=\mathrm{i} 1 \mathrm{~b} * \mathrm{IkBb}$

Reaction class 44: IkBb export from the nucleus to cytoplasm (\#)

$\mathrm{R} 44=\mathrm{e} 1 \mathrm{~b} * \mathrm{IkBbn}$

Reaction class 45: IkBbnNFkBn export from the nucleus to cytoplasm (\#)

$\mathrm{R} 45=\mathrm{e} 2 \mathrm{~b} * \mathrm{IkBbnNFkBn}$

Reaction class 46: Degradation of NFX Proteins (\#) 
$\mathrm{R} 46=\operatorname{de} 6 * \mathrm{NFX}$

(\#) represents the components which are involved only in Model 2.

Table A.3 Differential equations that define the mathematical model 1 for NFkB signaling pathway

\begin{tabular}{ll}
\hline$d I K K n / d t$ & $=R 12-R 19-R 6 a$ \\
\hline $\mathrm{dIKKa} / \mathrm{dt}$ & $=\mathrm{R} 19-\mathrm{R} 20-\mathrm{R} 21-\mathrm{R} 6 \mathrm{~b}-\mathrm{R} 2 \mathrm{a}-\mathrm{R} 2 \mathrm{~b}+\mathrm{R} 4 \mathrm{a}+\mathrm{R} 4 \mathrm{~b}+\mathrm{R} 5 \mathrm{a}+\mathrm{R} 5 \mathrm{~b}$ \\
$\mathrm{dIKKi} / \mathrm{dt}$ & $=\mathrm{R} 20+\mathrm{R} 21-\mathrm{R} 6 \mathrm{c}$ \\
$\mathrm{dIKKaIkBa} / \mathrm{dt}$ & $=\mathrm{R} 2 \mathrm{a}-\mathrm{R} 4 \mathrm{a}-\mathrm{R} 5 \mathrm{a}-\mathrm{R} 1 \mathrm{c}+\mathrm{R} 3 \mathrm{c}$ \\
$\mathrm{dIKKaIkBaNFkB} / \mathrm{dt}$ & $=\mathrm{R} 1 \mathrm{c}+\mathrm{R} 2 \mathrm{~b}-\mathrm{R} 3 \mathrm{c}-\mathrm{R} 4 \mathrm{~b}-\mathrm{R} 5 \mathrm{~b}$ \\
$\mathrm{dNFkB} / \mathrm{dt}$ & $=\mathrm{R} 3 \mathrm{a}+\mathrm{R} 3 \mathrm{c}-\mathrm{R} 1 \mathrm{a}-\mathrm{R} 1 \mathrm{c}+\mathrm{R} 5 \mathrm{~b}+\mathrm{R} 8-\mathrm{R} 25$ \\
$\mathrm{dNFkBn} / \mathrm{dt}$ & $=\mathrm{R} 3 \mathrm{~b}+\mathrm{kv} * \mathrm{R} 25-\mathrm{R} 1 \mathrm{~b}$ \\
$\mathrm{dA20/dt}$ & $=\mathrm{R} 18-\mathrm{R} 9-\mathrm{R} 20$ \\
$\mathrm{dA20m} / \mathrm{dt}$ & $=\mathrm{R} 16+\mathrm{R} 14-\mathrm{R} 11$ \\
$\mathrm{dIkBa} / \mathrm{dt}$ & $=\mathrm{R} 3 \mathrm{a}-\mathrm{R} 1 \mathrm{a}+\mathrm{R} 4 \mathrm{a}-\mathrm{R} 2 \mathrm{a}-\mathrm{R} 22+\mathrm{R} 23 / \mathrm{kv}+\mathrm{R} 17-\mathrm{R} 7$ \\
$\mathrm{dIkBan} / \mathrm{dt}$ & $=\mathrm{R} 3 \mathrm{~b}-\mathrm{R} 1 \mathrm{~b}+\mathrm{kv} * \mathrm{R} 22-\mathrm{R} 23$ \\
$\mathrm{dIkBam} / \mathrm{dt}$ & $=\mathrm{R} 13+\mathrm{R} 15-\mathrm{R} 10$ \\
$\mathrm{dIkBaNFkB} / \mathrm{dt}$ & $=\mathrm{R} 1 \mathrm{a}-\mathrm{R} 3 \mathrm{a}-\mathrm{R} 2 \mathrm{~b}+\mathrm{R} 4 \mathrm{~b}+\mathrm{R} 24 / \mathrm{kv}-\mathrm{R} 8$ \\
$\mathrm{dIkBanNFkBn} / \mathrm{dt}$ & $=\mathrm{R} 1 \mathrm{~b}-\mathrm{R} 3 \mathrm{~b}-\mathrm{R} 24$ \\
\hline
\end{tabular}


Table A.4 Differential equations that define the mathematical model 2 for NFkB signaling pathway

\begin{tabular}{|c|c|}
\hline$d I K K n / d t$ & $=R 12-R 19-R 6 a$ \\
\hline $\mathrm{dIKKa} / \mathrm{dt}$ & $=\mathrm{R} 19-\mathrm{R} 20-\mathrm{R} 21-\mathrm{R} 6 \mathrm{~b}-\mathrm{R} 2 \mathrm{a}-\mathrm{R} 2 \mathrm{~b}+\mathrm{R} 4 \mathrm{a}+\mathrm{R} 4 \mathrm{~b}+\mathrm{R} 5 \mathrm{a}+$ \\
\hline \multicolumn{2}{|c|}{ R5b-R27a - R27b + R29a + R29b + R30a +R30b } \\
\hline $\mathrm{dIKKi} / \mathrm{dt}$ & $=\mathrm{R} 20+\mathrm{R} 21-\mathrm{R} 6 \mathrm{c}$ \\
\hline $\mathrm{dIKKaIkBa/dt}$ & $=R 2 a-R 4 a-R 5 a-R 1 c+R 3 c$ \\
\hline dIKKaIkBaNFkB/dt & $=R 1 c+R 2 b-R 3 c-R 4 b-R 5 b$ \\
\hline $\mathrm{dNFkB} / \mathrm{dt}$ & $=R 3 a+R 3 c-R 1 a-R 1 c+R 5 b+R 8-R 25+R 28 a+R 28 b-$ \\
\hline \multicolumn{2}{|c|}{$\mathrm{R} 26 \mathrm{a}-\mathrm{R} 26 \mathrm{~b}+\mathrm{R} 30 \mathrm{~b}+\mathrm{R} 32$} \\
\hline $\mathrm{dNFkBn} / \mathrm{dt}$ & $=\mathrm{R} 3 \mathrm{~b}+\mathrm{kv} * \mathrm{R} 25-\mathrm{R} 1 \mathrm{~b}-\mathrm{R} 26 \mathrm{c}+\mathrm{R} 28 \mathrm{c}$ \\
\hline $\mathrm{dA} 20 / \mathrm{dt}$ & $=\mathrm{R} 18-\mathrm{R} 9-\mathrm{R} 20$ \\
\hline $\mathrm{dA} 20 \mathrm{~m} / \mathrm{dt}$ & $=\mathrm{R} 16+\mathrm{R} 14-\mathrm{R} 11$ \\
\hline $\mathrm{dIkBa} / \mathrm{dt}$ & $=\mathrm{R} 3 \mathrm{a}-\mathrm{R} 1 \mathrm{a}+\mathrm{R} 4 \mathrm{a}-\mathrm{R} 2 \mathrm{a}-\mathrm{R} 22+\mathrm{R} 23 / \mathrm{kv}+\mathrm{R} 17-\mathrm{R} 7$ \\
\hline $\mathrm{dIkBan} / \mathrm{dt}$ & $=\mathrm{R} 3 \mathrm{~b}-\mathrm{R} 1 \mathrm{~b}+\mathrm{kV} * \mathrm{R} 22-\mathrm{R} 23$ \\
\hline $\mathrm{dIkBam} / \mathrm{dt}$ & $=\mathrm{R} 13+\mathrm{R} 15-\mathrm{R} 10$ \\
\hline $\mathrm{dIkBaNFkB} / \mathrm{dt}$ & $=\mathrm{R} 1 \mathrm{a}-\mathrm{R} 3 \mathrm{a}-\mathrm{R} 2 \mathrm{~b}+\mathrm{R} 4 \mathrm{~b}+\mathrm{R} 24 / \mathrm{kv}-\mathrm{R} 8$ \\
\hline $\mathrm{dIkBanNFkBn/dt}$ & $=\mathrm{R} 1 \mathrm{~b}-\mathrm{R} 3 \mathrm{~b}-\mathrm{R} 24$ \\
\hline $\mathrm{dIkBb} / \mathrm{dt}$ & $=\mathrm{R} 40-\mathrm{R} 26 \mathrm{a}-\mathrm{R} 27 \mathrm{a}+\mathrm{R} 28 \mathrm{a}+\mathrm{R} 29 \mathrm{a}-\mathrm{R} 31-\mathrm{R} 43+\mathrm{R} 44 / \mathrm{kv}$ \\
\hline $\mathrm{dIkBbNFkB/dt}$ & $=\mathrm{R} 26 \mathrm{a}-\mathrm{R} 27 \mathrm{~b}-\mathrm{R} 28 \mathrm{a}+\mathrm{R} 29 \mathrm{~b}-\mathrm{R} 32+\mathrm{R} 45 / \mathrm{kv}$ \\
\hline $\mathrm{dIKKaIkBb/dt}$ & $=R 27 a-R 29 a-R 26 b-R 30 a+R 28 b$ \\
\hline $\mathrm{dIKKaIkBbNFkB/dt}$ & $=R 26 b+R 27 b-R 28 b-R 29 b-R 30 b$ \\
\hline $\mathrm{dIkBbm} / \mathrm{dt}$ & $=\mathrm{R} 36+\mathrm{R} 38-\mathrm{R} 34$ \\
\hline $\mathrm{dNFX} / \mathrm{dt}$ & $=\mathrm{R} 39-\mathrm{R} 41+\mathrm{R} 42 / \mathrm{kv}-\mathrm{R} 46$ \\
\hline $\mathrm{dNFXn/dt}$ & $=\mathrm{kv} * \mathrm{R} 41-\mathrm{R} 42$ \\
\hline $\mathrm{dNFXm} / \mathrm{dt}$ & $=\mathrm{R} 37+\mathrm{R} 35-\mathrm{R} 33$ \\
\hline $\mathrm{dIkBbn} / \mathrm{dt}$ & $=\mathrm{R} 43 / \mathrm{kv}-\mathrm{R} 44-\mathrm{R} 26 \mathrm{c}+\mathrm{R} 28 \mathrm{c}$ \\
\hline $\mathrm{dIkBbnNFkBn/dt}$ & $=R 26 c-R 28 c-R 45$ \\
\hline
\end{tabular}


Table A.5 List of parameters and corresponding values model 1 and model 2. The values for the reaction rate parameters correspond to the maximum likelihood values Numerical subscripts indicate the reaction class to which the parameters correspond. Values determined during model calibration are indicated by an asterisk (*).

\begin{tabular}{|c|c|c|c|c|}
\hline Symbol & Definition & Value & Units & Refs \\
\hline a1 & IkBa-NFkB association rate & 0.5 & $\mathrm{~s}^{-1}$ & 11,13 \\
\hline a2 & IKKa-IkBa association rate & & $\mu \mathrm{M}^{-1} \mathrm{~s}^{-1}$ & $*$ \\
\hline f1 & The factor of NFkB on IKKa-IkBa association & 0.2 & - & 11,22 \\
\hline kcat & KKa-IkBa catalytic dissociation rate & & $\mathrm{s}^{-1}$ & * \\
\hline $\mathrm{f} 2$ & The factor of NF-kB on IKKa-IkBa catalysis & 5 & - & 11,22 \\
\hline $\mathrm{d} 1$ & IkBa-NFkB reversible dissociation rate & $1.25 \mathrm{e}-3$ & $\mathrm{~s}^{-1}$ & 11 \\
\hline $\mathrm{d} 2$ & IKKa-IkBa reversible dissociation rate & $0.5 \mathrm{e}-3$ & $\mathrm{~s}^{-1}$ & 11 \\
\hline s1 & IkBa-inducible mRNA synthesis & & $\mathrm{s}^{-1}$ & * \\
\hline s2 & A20-inducible mRNA synthesis & & $\mathrm{s}^{-1}$ & $*$ \\
\hline $\operatorname{cs} 1$ & IkBa-constitutive mRNA synthesis & & $\mu \mathrm{M} \mathrm{s}^{-1}$ & * \\
\hline cs 2 & A20-constitutive mRNA synthesis & & $\mu \mathrm{M} \mathrm{s}^{-1}$ & * \\
\hline de1 & Spontaneous, free IkBa protein degradation & 0.0001 & $\mathrm{~s}^{-1}$ & 20 \\
\hline de 2 & A20 protein degradation & 0.0003 & $\mathrm{~s}^{-1}$ & 13 \\
\hline de3 & IkBa degradation (complexed to NF-kB) & $2 e-5$ & $\mathrm{~s}^{-1}$ & 20 \\
\hline $\mathrm{dm} 1$ & IkBa mRNA degradation & 0.0004 & $\mathrm{~s}^{-1}$ & 43 \\
\hline $\mathrm{dm} 2$ & A20 mRNA degradation & & $\mathrm{s}^{-1}$ & * \\
\hline $\mathrm{t} 1$ & IkBa translation rate & 0.5 & $\mathrm{~s}^{-1}$ & 13 \\
\hline $\mathrm{t} 2$ & A20 translation rate & & $\mathrm{s}^{-1}$ & * \\
\hline $\mathrm{k} 1$ & IKK activation rate & 0.0025 & $\mathrm{~s}^{-1}$ & 13 \\
\hline $\mathrm{k} 2$ & IKK inactivation rate by $\mathrm{A} 20$ & 0.1 & $\mathrm{~s}^{-1}$ & 13 \\
\hline $\mathrm{k} 3$ & IKKspontaneous inactivation rate & 0.0015 & $\mathrm{~s}^{-1}$ & 13 \\
\hline kprod & IKKn production rate & $2.5 e-5$ & $\mathrm{~s}^{-1}$ & 13 \\
\hline kdeg & IKKa, IKKn and IKKi degradation & $1.25 \mathrm{e}-4$ & $\mathrm{~s}^{-1}$ & 13 \\
\hline $\mathrm{kv}$ & Cytoplasmic to nuclear volume & 7 & - & 45 \\
\hline i1 & NF-kB nuclear import rate & 0.09 & $\mathrm{~s}^{-1}$ & 11 \\
\hline i1a & IkBa nuclear import rate & 0.0003 & $\mathrm{~s}^{-1}$ & 11 \\
\hline
\end{tabular}




\begin{tabular}{|c|c|c|c|c|}
\hline e1a & IkBa nuclear export rate & 0.0002 & $\mathrm{~s}^{-1}$ & 11 \\
\hline $\mathrm{e} 2 \mathrm{a}$ & IkBa-NFkB nuclear export rate & 0.014 & $\mathrm{~s}^{-1}$ & $*$ \\
\hline \multirow[t]{2}{*}{ dcpa } & DCPA treatment concentration & 0 or 100 & $\mu \mathrm{M}$ & - \\
\hline & The following parameters are only in Model 2 & & & \\
\hline a3 & $\mathrm{IkBb}-\mathrm{NFkB}$ association rate & 0.5 & $\mathrm{~s}^{-1}$ & 11,13 \\
\hline a4 & IKKa-IkBb association rate & & $\mu \mathrm{M}^{-1} \mathrm{~s}^{-1}$ & $*$ \\
\hline f3 & The factor of NFkB on IKKa-IkBb association & 5 & - & 11,22 \\
\hline kcatb & KKa-IkBa catalytic dissociation rate & & $\mathrm{s}^{-1}$ & $*$ \\
\hline $\mathrm{f} 4$ & The factor of NF-kB on IKKa-IkBb catalysis & 5 & - & 11,22 \\
\hline d3 & IkBb-NFkB reversible dissociation rate & $1.25 \mathrm{e}-3$ & $\mathrm{~s}^{-1}$ & 11 \\
\hline $\mathrm{d} 4$ & IKKa-IkBb reversible dissociation rate & $0.5 e-3$ & $\mathrm{~s}^{-1}$ & 11 \\
\hline s3 & NFX-inducible mRNA synthesis & & $\mathrm{s}^{-1}$ & $*$ \\
\hline s4 & IkBb -inducible mRNA synthesis & & $\mathrm{s}^{-1}$ & $*$ \\
\hline $\operatorname{cs} 3$ & NFX-constitutive mRNA synthesis & & $\mu \mathrm{M} \mathrm{s}^{-1}$ & $*$ \\
\hline $\operatorname{cs} 4$ & IkBb-constitutive mRNA synthesis & & $\mu \mathrm{M} \mathrm{s}^{-1}$ & $*$ \\
\hline de4 & Spontaneous, free $\mathrm{IkBb}$ protein degradation & 0.0001 & $\mathrm{~s}^{-1}$ & 20 \\
\hline $\operatorname{de} 5$ & IkBb degradation (complexed to NF-kB) & $2 \mathrm{e}-5$ & $\mathrm{~s}^{-1}$ & 20 \\
\hline $\mathrm{dm} 4$ & IkBb mRNA degradation & 0.0004 & $\mathrm{~s}^{-1}$ & 43 \\
\hline $\mathrm{dm} 3$ & NFX mRNA degradation & & $\mathrm{s}^{-1}$ & $*$ \\
\hline $\mathrm{t} 4$ & $\mathrm{IkBb}$ translation rate & 0.5 & $\mathrm{~s}^{-1}$ & 13 \\
\hline $\mathrm{t} 3$ & NFX translation rate & & $\mathrm{s}^{-1}$ & $*$ \\
\hline i3 & NFX nuclear import rate & 0.09 & $\mathrm{~s}^{-1}$ & $*$ \\
\hline e3 & NFX export rate from nucleus & 0.0003 & $\mathrm{~s}^{-1}$ & $*$ \\
\hline
\end{tabular}


Supplement 1: Description of biochemical reactions and converting them to ordinary differential equations

IKKn: IKK in neutral state

The first term describes IKKn synthesis; the second one describes the depletion of IKKn due to the TLR4 signal-induced transformation into active form IKKa, while the last one describes the spontaneous degradation.

$\mathrm{dIKKn} / \mathrm{dt}=\operatorname{kprod}-\mathrm{k} 1 * \mathrm{R} 0 * \mathrm{IKKn} * \mathrm{TLR} 4-\mathrm{kdeg} * \mathrm{IKKn}$

IKKa: IKK in active state

The first line represents the activation of IKK by TLR4 signal, the deactivation of IKK induced by A20 and spontaneous deactivation of active IKK; The second line and the third line reprensent spontaneous degradation of IKKa, depletion of free IKKa due to formation of complexes of IKKaIkBa and IKKaIkBaNFkB, and concentration change of IKKa due to dissociation of IKKaIkBa and IKKaIkBaNFkB complexes. The presence of NFkB enhances the effecient of IKKa and IkBa interaction by a factor f1[9]. The final line represents the concentration change due to catalysis. IKKa is still active after catalystic phosphralation.

$$
\begin{aligned}
\mathrm{dIKKa} / \mathrm{dt}= & \mathrm{k} 1 * \mathrm{IKKn} * \mathrm{TLR} 4-\mathrm{k} 2 * \mathrm{R} 0 * \mathrm{~A} 20 * \mathrm{IKKa}-\mathrm{k} 3 * \mathrm{IKKa} \\
& -\mathrm{kdeg} * \mathrm{IKKa}-\mathrm{a} 2 * \mathrm{IKKa} * \mathrm{IkBa}-\mathrm{a} 2 * \mathrm{f} 1 * \mathrm{IKKa} * \mathrm{IkBaNFkB} \\
& +\mathrm{d} 2 * \mathrm{IKKaIkBa}+\mathrm{d} 2 * \mathrm{f} 1 * \mathrm{IKKaIkBaNFkB} \\
& +\mathrm{kcat} * \mathrm{IKKaIkBa}+\mathrm{kcat} * \mathrm{f} 2 * \mathrm{IKKaIkBaNFkB}
\end{aligned}
$$

IKKi: inactive state of IKK

First term describes inactive IKK forming due to A20, the second describes the concentration increase of IKKi due to IKKa spontaneous deactivation, while the third one represents the degradation of IKKi. IKKi is assued has the same spontaneous degradation rate as IKKn and IKKa.

$\mathrm{dIKKi} / \mathrm{dt}$

$$
=\mathrm{k} 2 * \mathrm{~A} 20 * \mathrm{IKKa}+\mathrm{k} 3 * \mathrm{IKKa}-\mathrm{kdeg} * \mathrm{IKKi}
$$

IKKaIkBa: complex of IKKa and IkBa 
The first line describes the concentration change of IKKaIkBa due to IkBa associates, dissociates with IKKa and catalytic by IKKa; The second line represents association and dissociation between IKKaIkBa and NFkB.

dIKKaIkBa/dt $\quad=\mathrm{a} 2 *$ IKKa $*$ IkBa $-\mathrm{d} 2 *$ IKKaIkBa - kcat $*$ IKKaIkBa

$$
- \text { a1 * NFkB * IKKaIkBa + d1 * IKKaIkBaNFkB }
$$

IKKaIkBaNFkB: complex of IKKa, IkBa and NFkB

The first line represents the association and dissociation between IKKaIkBa and NFkB;

the second line represents the association and dissociation between IKKa and IkBaNFkB; The final line describel the depletion of IKKaIkBaNFkB due to the catalysis process. $\mathrm{dIKKaIkBaNFkB} / \mathrm{dt}=\mathrm{a} 1 * \mathrm{NFkB} *$ IKKaIkBa $-\mathrm{d} 1 *$ IKKaIkBaNFkB

$$
\begin{aligned}
& +\mathrm{a} 2 * \mathrm{f} 1 * \mathrm{IKKa} * \mathrm{IkBaNFkB}-\mathrm{d} 2 * \mathrm{f} 1 * \text { IKKaIkBaNFkB } \\
& \text { - kcat } * \mathrm{f} 2 * \text { IKKaIkBaNFkB }
\end{aligned}
$$

NFkB: Free cytoplasmic NFkB

The first line describes free NFkB concentration increase due to dissociation of IkBaNFkB and IKKaIkBaNFkB; the second line describes the decrease of free NFkB due to association with IkBa, IKKaIkBa and shuttling into the nucleus. The final line represents the concentration increase due to IKKa catalytic degrading IkBa and spontonous degradation of bound IkBa. The factor $\mathrm{f} 2$ represents the effect of the presence of NFkB on IKKa phosphralating IkBa[9].

$\mathrm{dNFkB} / \mathrm{dt}$

$$
\begin{aligned}
& =\mathrm{d} 1 * \mathrm{IkBaNFkB}+\mathrm{d} 1 * \mathrm{IKKaIkBaNFkB} \\
& -\mathrm{a} 1 * \mathrm{NFkB} * \mathrm{IkBa}-\mathrm{a} 1 * \mathrm{NFkB} * \text { IKKaIkBa - i } 1 * \text { NFkB } \\
& +\mathrm{kcat} * \mathrm{f} 2 * \text { IKKaIkBaNFkB }+ \text { de } 3 * \text { IkBaNFkB }
\end{aligned}
$$

NFkBn: Free NFkB in the nucleus

First term and second represent free NFkBn changes due to dissociation and association between IkBa and NFkB in the nucleus; and the last term reprensents that NFkB imports to the nucleus from the cytoplasm. Because of the volume of cytoplasm is larger than the nucleus, $\mathrm{kv}=$ the volume of the cytoplasm / the volume of the nucleus, the concentration change due to importion is kv times of that in the cytoplasm.

$\mathrm{dNFkBn} / \mathrm{dt}=\mathrm{d} 1 * \mathrm{IkBanNFkBn}-\mathrm{a} 1 * \mathrm{NFkBn} * \mathrm{IkBan}+\mathrm{kv} * \mathrm{i} 1 * \mathrm{NFkB}$ (7) A20: A20 protein in the cytoplasm 
First term discripes A20 protein production rate due to the translation from A20 mRNA; the second term represent degradation of A20 protein; and the final term represents that free A20 decreases because of inhibiting IKK activity. We assume that TLR4 consductive signaling is required to activate A20.

$\mathrm{dA} 20 / \mathrm{dt}=\mathrm{t} 2 * \mathrm{~A} 20 \mathrm{~m}-\mathrm{de} 2 * \mathrm{~A} 20-\mathrm{k} 2 * \mathrm{TLR} 4 * \mathrm{~A} 20 * \mathrm{IKKa}$

A20m: A20 messenger RNA

We seperate the synthesis of A20 mRNA to two parts. One is constuctive and the other is first-order dependent on free NFkB concentration in the nucleus. The last term represents first order degradation of A20 mRNA.

$\mathrm{dA} 20 \mathrm{~m} / \mathrm{dt} \quad=\mathrm{cs} 2+\mathrm{s} 2 * \mathrm{NFkBn}-\mathrm{dm} 2 * \mathrm{~A} 20 \mathrm{~m}$

IkBa: Free IkBa in the cytoplasm

The first and second lines represent the concentration change of free IkBa due to the dissociation and association obetween IkBa and $\mathrm{NFkB}$, and between IKKa and IkBa; the last line represents free IkBa protein importing to, exporting from the neucleus, translation form IkBa mRNA and spontanous degradation.

$\mathrm{dIkBa} / \mathrm{dt}$

$$
\begin{aligned}
= & \mathrm{d} 1 * \mathrm{IkBaNFkB}-\mathrm{a} 1 * \mathrm{NFkB} * \mathrm{IkBa} \\
& +\mathrm{d} 2 * \mathrm{IKK} \mathrm{IIKBa}-\mathrm{a} 2 * \mathrm{IKKa} * \mathrm{IkBa} \\
& -\mathrm{i} 1 \mathrm{a} * \mathrm{IkBa}+\mathrm{e} 1 \mathrm{a} * \mathrm{IkBan} / \mathrm{kv}+\mathrm{t} 1 * \mathrm{IkBam}-\mathrm{de} 1 * \mathrm{IkBa}
\end{aligned}
$$

IkBan: Free IkBa in the nucleus

First line represents IkBa concentration change due to the dissociation and association between IkBa and NFkB; the sencond line represents IkBa concentration change caused by free IkBa shuttling between the cytoplasm and the nucleus.

$\mathrm{dIkBan} / \mathrm{dt}$

$$
\begin{aligned}
= & \mathrm{d} 1 * \mathrm{IkBanNFkBn}-\mathrm{a} 1 * \mathrm{NFkBn} * \mathrm{IkBan} \\
& +\mathrm{kv} * \mathrm{i} 1 \mathrm{a} * \mathrm{IkBa}-\mathrm{e} 1 \mathrm{a} * \mathrm{IkBan}
\end{aligned}
$$

IkBam: IkBa messenger RNA

We seperate the synthesis of IkBa mRNA to two parts. One is constuctive and the other is first-order dependent on free NFkB concentration in the nucleus. The last term represents first order degradation of IkBa mRNA.

$\mathrm{dIkBam} / \mathrm{dt}=\mathrm{cs} 1+\mathrm{s} 1 * \mathrm{NFkBn}-\mathrm{dm} 1 * \mathrm{IkBam}$ 
IkBaNFkB: cytoplasmic IkBaNFkB complex

First line represents the concentration change of IkBaNFkB due to the association and dissociation between IkBa and NFkB; second line describes the the concentration change of IkBaNFkB due to the association and dissociation between IKKa and IkBa NFkB. $\mathrm{NFkB}$ increases the association rate of IKKa and IkBa according experimental data[9]. Based on the motif-motif interaction principle, the affinity of IKKa and IkBa doesn't change, so the dissociation between them also is increased by $\mathrm{f} 1$ times. The final line represents the exporting of IkBaNFkB from the nucleus and the degradation of IkBaNFkB.

$\mathrm{dIkBaNFkB} / \mathrm{dt}=\mathrm{a} 1 * \mathrm{NFkB} * \mathrm{IkBa}-\mathrm{d} 1 * \mathrm{IkBaNFkB}$

$$
\begin{aligned}
& \text { - a2 * f1 * IKKa * IkBaNFkB + d2 * f1 * IKKaIkBaNFkB } \\
& \text { + e2a } * \text { IkBanNFkBn / kv - de3 } * \text { IkBaNFkB }
\end{aligned}
$$

IkBanNFkBn: IkBaNFkB complex in the nucleus

First line represents the concentration change due to the association and dissociation between NFkBn and IkBan; the second line represents the exporting of IkBan NFkBn from the nucleus.

$\mathrm{dIkBanNFkBn} / \mathrm{dt}=\mathrm{a} 1 * \mathrm{NFkBn} * \mathrm{IkBan}-\mathrm{d} 1 * \mathrm{IkBanNFkBn}$

$$
\text { - e2a*IkBanNFkBn }
$$

The second model will add IkBb into the signaling network. IkBb can reacte with IKKa and NFkB in the cytoplasm and can also bind with NFkB in the nucleus. The different of $\mathrm{IkBb}$ and $\mathrm{IkBa}$ is that $\mathrm{IkBb}$ is induced by an unknow nuclear factor $\mathrm{X}$ which is induced by NFkB. 10 more equations are added, described as below. However, the differential equations of IKK, NFkB and NFkBn will be changed due to their interaction with IkBb. IKKa: IKK in active state

The first line represents the activation of IKK by TLR4 signal, the deactivation of IKK induced by A20 and spontaneous deactivation of active IKK; The second line and the third line reprensent spontaneous degradation of IKKa, depletion of free IKKa due to formation of complexes of IKKaIkBa and IKKaIkBaNFkB, and concentration change of IKKa due to dissociation of IKKaIkBa and IKKaIkBaNFkB complexes. The presence of NFkB enhances the effecient of IKKa and IkBa interaction by a factor f1[9]. The fourth line represents the concentration change due to catalysis. IKKa is still active after 
catalystic phosphralation. IKKa can also phosprolate IkBb. The last three lines represents the association between IKKa and IkBb, IKKa and IkBbNFkB, and catalysis of IKKaIkBb and IKKaIkBbNFkB. Factors $\mathrm{f} 3$ and $\mathrm{f} 4$ represent the effects of NFkB on IKKa associating and catalysizing $\mathrm{IkBb}$.

$$
\begin{aligned}
\mathrm{dIKKa} / \mathrm{dt}= & \mathrm{k} 1 * \mathrm{IKKn} * \mathrm{TLR} 4-\mathrm{k} 2 * \mathrm{R} 0 * \mathrm{~A} 20 * \mathrm{IKKa}-\mathrm{k} 3 * \mathrm{IKKa} \\
& -\mathrm{kdeg} * \mathrm{IKKa}-\mathrm{a} 2 * \mathrm{IKKa} * \mathrm{IkBa}-\mathrm{a} 2 * \mathrm{f} 1 * \mathrm{IKKa} * \mathrm{IkBaNFkB} \\
& +\mathrm{d} 2 * \mathrm{IKKaIkBa}+\mathrm{d} 2 * \mathrm{f} 1 * \mathrm{IKKaIkBaNFkB} \\
& +\mathrm{kcat} * \mathrm{IKKaIkBa}+\mathrm{kcat} * \mathrm{f} 2 * \mathrm{IKKaIkBaNFkB} \\
& -\mathrm{a} 4 * \mathrm{IKKa} * \mathrm{IkBb}-\mathrm{a} 4 * \mathrm{f} 3 * \mathrm{IKKa} * \mathrm{IkBbNFkB} \\
& +\mathrm{d} 4 * \mathrm{IKKaIkBb}+\mathrm{d} 4 * \mathrm{f} 3 * \mathrm{IKKaIkBbNFkB} \\
& +\mathrm{kcat} * \mathrm{IKKaIkBb}+\mathrm{kcatb} * \mathrm{f} 4 * \mathrm{IKKaIkBbNFkB}
\end{aligned}
$$

NFkB: Free cytoplasmic NFkB

The first line describes free NFkB concentration increase due to dissociation of IkBaNFkB and IKKaIkBaNFkB; the second line describes the decrease of free NFkB due to association with IkBa, IKKaIkBa and shuttling into the nucleus. The Third line represents the concentration increase due to IKKa catalytic degrading IkBa and spontonous degradation of bound $\mathrm{IkBa}$. The factor $\mathrm{f} 2$ represents the effect of the presence of NFkB on IKKa phosphralating IkBa[9]. The last three lines represent the concentration of NFkB due to its dissociation and association with $\mathrm{IkBb}, \mathrm{IKKaIkBb}$, and degradation of $\mathrm{IkBb}$ due to IKKa phospralation and spontanous degradation.

$\mathrm{dNFkB} / \mathrm{dt}$

$$
\begin{aligned}
& =\mathrm{d} 1 * \mathrm{IkBaNFkB}+\mathrm{d} 1 * \mathrm{IKKaIkBaNFkB} \\
& -\mathrm{a} 1 * \mathrm{NFkB} * \mathrm{IkBa}-\mathrm{a} 1 * \mathrm{NFkB} * \mathrm{IKKaIkBa}-\mathrm{i} 1 * \mathrm{NFkB}(6 *) \\
& +\mathrm{kcat} * \mathrm{f} 2 * \mathrm{IKKaIkBaNFkB}+\mathrm{de} 3 * \mathrm{IkBaNFkB} \\
& +\mathrm{d} 3 * \mathrm{IkBbNFkB}+\mathrm{d} 3 * \mathrm{IKKaIkBbNFkB} \\
& -\mathrm{a} 3 * \mathrm{NFkB} * \mathrm{IkBb}-\mathrm{a} 3 * \mathrm{NFkB} * \mathrm{IKKaIkBb} \\
& +\mathrm{kcatb} * \mathrm{f} 4 * \mathrm{IKKaIkBbNFkB}+\mathrm{de} 5 * \mathrm{IkBbNFkB}
\end{aligned}
$$


NFkBn: Free NFkB in the nucleus

First term and second represent free NFkBn changes due to dissociation and association between IkBa and NFkB in the nucleus; and the third term reprensents that NFkB imports to the nucleus from the cytoplasm. Because of the volume of cytoplasm is larger than the nucleus, $\mathrm{kv}=$ the volume of the cytoplasm / the volume of the nucleus, the concentration change due to importion is kv times of that in the cytoplasm. The last line represents the dissociation and association between $\mathrm{NFkB}$ and $\mathrm{IkBb}$ in the nucleus.

$\mathrm{dNFkBn} / \mathrm{dt}=\mathrm{d} 1 * \mathrm{IkBanNFkBn}-\mathrm{a} 1 * \mathrm{NFkBn} * \mathrm{IkBan}+\mathrm{kv} * \mathrm{i} 1 * \mathrm{NFkB}$

$$
+\mathrm{d} 3 * \mathrm{IkBbnNFkBn}-\mathrm{a} 3 * \mathrm{NFkBn} * \mathrm{IkBbn}
$$

$\mathrm{IkBb}$ : Free $\mathrm{IkBb}$ in the cytoplasm

The first and second lines represent the concentration change of free $\mathrm{IkBb}$ due to the dissociation and association obetween IkBb and $\mathrm{NFkB}$, and between IKKa and IkBb; the last line represents free $\mathrm{IkBb}$ protein importing to, exporting from the neucleus, translation form IkBb mRNA and spontanous degradation.

$\mathrm{dIkBb} / \mathrm{dt}$

$$
\begin{aligned}
= & \mathrm{d} 3 * \mathrm{IkBbNFkB}-\mathrm{a} 3 * \mathrm{NFkB} * \mathrm{IkBb} \\
& +\mathrm{d} 4 * \mathrm{IKKaIkBb}-\mathrm{a} 4 * \mathrm{IKKa} * \mathrm{IkBb} \\
& -\mathrm{i} 1 \mathrm{~b} * \mathrm{IkBb}+\mathrm{e} 1 \mathrm{~b} * \mathrm{IkBbn} / \mathrm{kv}+\mathrm{t} 4 * \mathrm{IkBbm}-\mathrm{de} 4 * \mathrm{IkBb}
\end{aligned}
$$

IkBbNFkB: cytoplasmic IkBbNFkB complex

First line represents the concentration change of $\mathrm{IkBbNFkB}$ due to the association and dissociation between $\mathrm{IkBb}$ and $\mathrm{NFkB}$; second line describes the the concentration change of IkBbNFkB due to the association and dissociation between IKKa and IkBb NFkB. NFkB increases the association rate of IKKa and IkBb according experimental data[9]. Based on the motif-motif interaction principle, the affinity of IKKa and IkBb doesn't change, so the dissociation between them also is increased by $\mathrm{f} 3$ times. The final line represents the exporting of IkBbNFkB from the nucleus and the degradation of $\mathrm{IkBbNFkB}$.

$\mathrm{dIkBaNFkB} / \mathrm{dt}=\mathrm{a} 3 * \mathrm{NFkB} * \mathrm{IkBa}-\mathrm{d} 3 * \mathrm{IkBbNFkB}$

$$
\text { - a4 * f3 * IKKa } * \text { IkBbNFkB + d4 * f3 * IKKaIkBbNFkB }
$$




$$
+\mathrm{e} 2 \mathrm{~b} * \mathrm{IkBbnNFkBn} / \mathrm{kv}-\mathrm{de} 5 * \mathrm{IkBbNFkB}
$$

IKKaIkBb: complex of IKKa and IkBb

The first line describes the concentration change of IKKaIkBb due to IkBb associates, dissociates with IKKa and catalytic by IKKa; The second line represents association and dissociation between IKKaIkBb and NFkB.

$\mathrm{dIKKaIkBa} / \mathrm{dt}=\mathrm{a} 4 * \mathrm{IKKa} * \mathrm{IkBb}-\mathrm{d} 4 * \mathrm{IKKaIkBb}-\mathrm{kcatb} * \mathrm{IKKaIkBb}$

$$
- \text { a3 } * \mathrm{NFkB} * \text { IKKaIkBb }+ \text { d3 } * \text { IKKaIkBbNFkB }
$$

IKKaIkBbNFkB: complex of IKKa, IkBb and NFkB

The first line represents the association and dissociation between IKKaIkBb and NFkB; the second line represents the association and dissociation between IKKa and IkBbNFkB; The final line describel the depletion of IKKaIkBbNFkB due to the catalysis process. $\mathrm{dIKKaIkBbNFkB/dt}=\mathrm{a} 3 * \mathrm{NFkB} *$ IKKaIkBb $-\mathrm{d} 3 *$ IKKaIkBbNFkB

$$
\begin{aligned}
& +\mathrm{a} 4 * \mathrm{f} 3 * \mathrm{IKKa} * \mathrm{IkBbNFkB}-\mathrm{d} 4 * \mathrm{f} 3 * \mathrm{IKKaIkBbNFkB} \\
& \text { - kcatb } * \mathrm{f} 4 * \mathrm{IKKaIkBbNFkB}
\end{aligned}
$$

IkBbm: IkBb messenger RNA

We seperate the synthesis of IkBb mRNA to two parts. One is constuctive and the other is first-order dependent on free NFkB concentration in the nucleus. The last term represents first order degradation of $\mathrm{IkBb}$ mRNA.

$\mathrm{dIkBbm} / \mathrm{dt}=\mathrm{cs} 4+\mathrm{s} 4 * \mathrm{NFkBn}-\mathrm{dm} 4 * \mathrm{IkBbm}$

NFX: unknown transcription factor

There is a time delay for IkBb transcription following NFkB activity.[23] This time delay may be caused by an intermidate transcription factor, like foxj1[24] . But we don't know much about this intermidate transcription factor. In the following equation, the first term represents the production of NFX translation from RNA, and the second and the third terms describe the concentration change of NFX due to shuttling between the cytoplasm and the nucleus; the final term represents the degradation of NFX.

$\mathrm{dNFX} / \mathrm{dt}=\mathrm{t} 3 * \mathrm{NFXm}-\mathrm{i} 3 * \mathrm{NFX}+\mathrm{e} 3 * \mathrm{NFXn} / \mathrm{kv}-\mathrm{de} 6 * \mathrm{NFX}$

NFXn: NFX in the nucleus

First term represents NFX imports to the nucleus while the second term represents its exporting from the nucleus. 
$\mathrm{dNFXn/dt \quad} \quad=\mathrm{kv} * \mathrm{i} 3 * \mathrm{NFX}-\mathrm{e} 3 * \mathrm{NFXn}$

NFXm: NFX messenger RNA

We assumethat NFX is produced by two parts, one is constudctive synthesis rate cs3, and another part is induced by NFkB. The first term represents the constudctive synthesis of NFX mRNA and the second represents the inducible synthesis, while the final one represnts the degradation of NFX mRNA.

$\mathrm{dNFXm} / \mathrm{dt} \quad=\mathrm{cs} 3+\mathrm{s} 3 * \mathrm{NFkBn}-\mathrm{dm} 3 * \mathrm{NFXm}$

IkBbn: Free IkBb in the nucleus

First line represents $\mathrm{IkBb}$ concentration change due to the dissociation and association between $\mathrm{IkBb}$ and $\mathrm{NFkB}$; the sencond line represents $\mathrm{IkBb}$ concentration change caused by free $\mathrm{IkBb}$ shuttling between the cytoplasm and the nucleus.

$\mathrm{dIkBbn} / \mathrm{dt}$

$$
\begin{aligned}
= & \mathrm{d} 3 * \mathrm{IkBbnNFkBn}-\mathrm{a} 3 * \mathrm{NFkBn} * \mathrm{IkBban} \\
& +\mathrm{kv} * \mathrm{i} 1 \mathrm{~b} * \mathrm{IkBb}-\mathrm{e} 1 \mathrm{~b} * \mathrm{IkBbn}
\end{aligned}
$$

IkBbnNFkBn: IkBbNFkB complex in the nucleus

First line represents the concentration change due to the association and dissociation between NFkBn and IkBan; the second line represents the exporting of IkBbnNFkBn from the nucleus.

$\mathrm{dIkBbnNFkBn/dt} \quad=\mathrm{a} 3 * \mathrm{NFkBn} * \mathrm{IkBbn}-\mathrm{d} 3 *$ IkBbnNFkBn

$$
\text { - e2b* IkBbnNFkBn }
$$


Supplement 2: Mathatical models coded in Matlab

\% calc_Yhat_nfkb_01.m

function Y_hat = calc_Yhat_nfkb_01(k, X_pred);

\%Dimension declarations:

n_diffeqn $=14$;

n_algeb $=0$;

n_tot = n_diffeqn + n_algeb;

id = ones(n_diffeqn, 1 );

id $\left(n \_\right.$diffeqn+1:n_tot $)=\operatorname{zeros}\left(n \_a l g e b, 1\right)$;

\%Initial conditions:

[y0, data $]=$ loadParams01(k, n_tot);

t0 =0;

$\%$ set up options

$\%$

options = CVodeSetOptions('RelTol',1.e-6,'AbsTol',1.e-6,...

'NonlinearSolver','Newton','MaxNumSteps',6000);

CVodeMalloc(@nfkb_core01,t0,y0,options,data);

tp0 = X_pred $(1,1)-60 * 10 ;$

[status,t,y] = CVode(tp0,'Normal');

if ( status $==0$ )

$$
\text { yp0 = y; }
$$

else

$$
\text { yp0 = eps. }{ }^{*} \text { ones }\left(n \_t o t, 1\right) ;
$$

end;

iout $=1$;

$\mathrm{Y}=\operatorname{zeros}\left(1, \mathrm{n} \_\right.$tot $)$;

$\mathrm{Y}(1,:)=\mathrm{yp} 0{ }^{\prime} ;$

nout $=$ size $\left(X \_\right.$pred, 1$)$; 


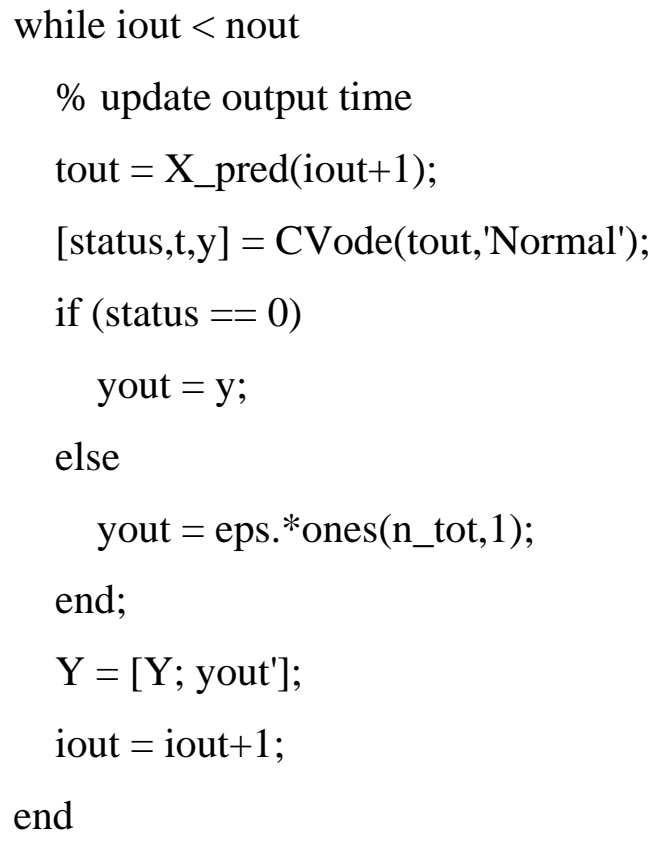




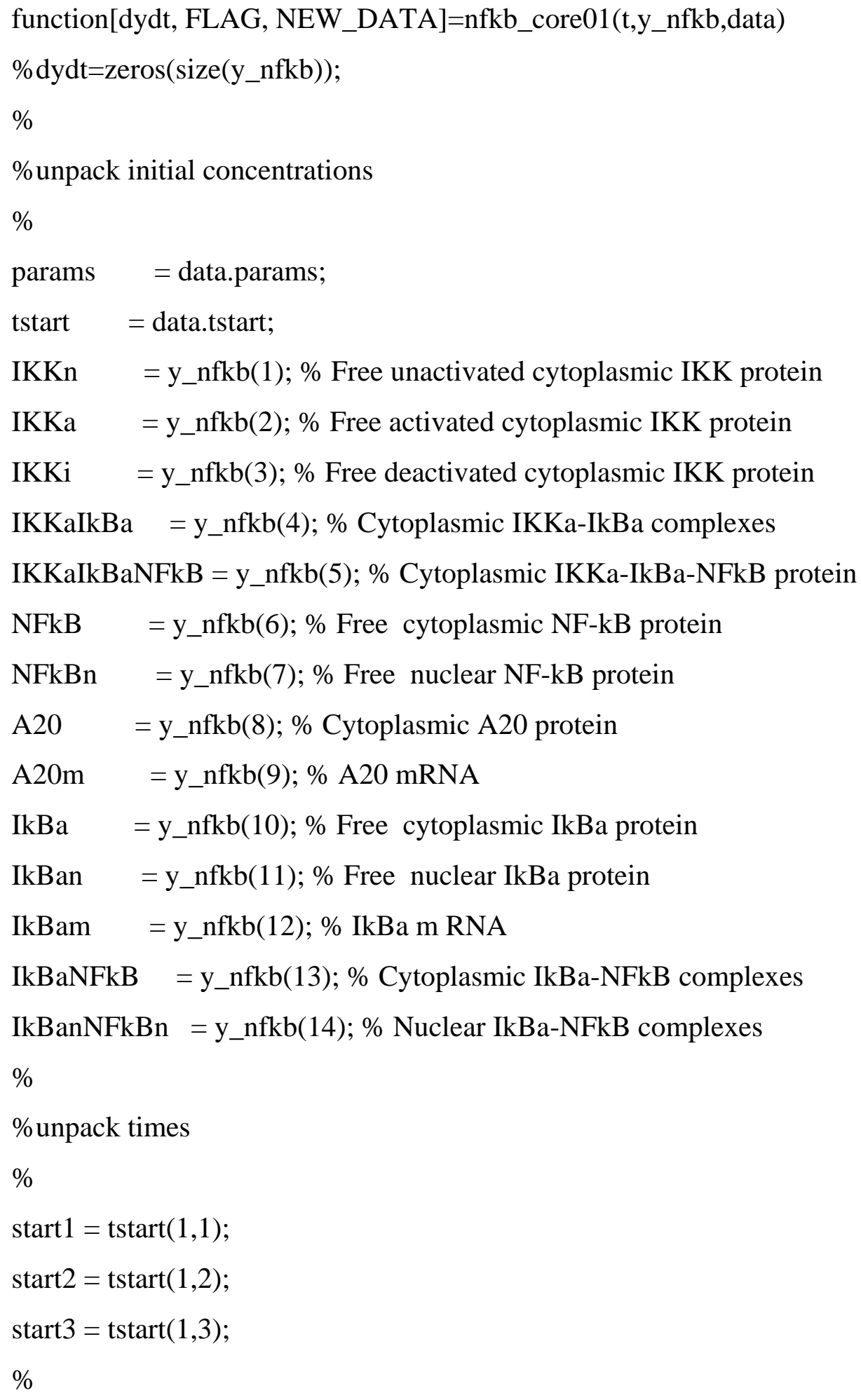




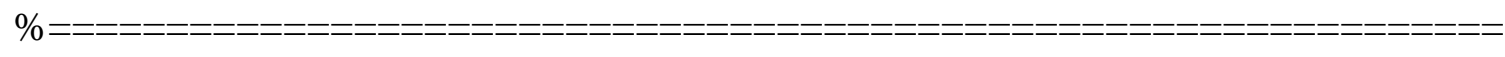

\%unpack parameters

$\%$

a1 $=10^{\wedge}$ params $(1,1) ; \% 0.5 \%$ microM-1 sec- IKBa2NFkB association Hoffmann et al.

$\mathrm{a} 2=10^{\wedge}$ params $(2,1) ; \% \mathrm{mM}-1$ sec-1 IKKa IkBa association fitting

$\mathrm{f} 1=10^{\wedge}$ params $(3,1) ; \% 0.2$ the factor of NFkB on IKKa-IkBa association Hoffmann et al.

kcat $=10^{\wedge}$ params $(4,1) ; \%$ sec-1 IKKajIkBa catalysis fitting

$\mathrm{f} 2=10^{\wedge}$ params $(5,1) ; \% 5 \%$ the factor of NFkB on IKKa-IkBa catalysis Hoffmann et al

$\mathrm{d} 1=10^{\wedge}$ params $(6,1) ; \% \mathrm{IkBa}-\mathrm{NFkB}$ reversible dissociation rate $1.25 \mathrm{e}-3 \quad \mathrm{~s}-1$

(2)

$\mathrm{d} 2=10^{\wedge}$ params $(7,1) ; \% \mathrm{IKK}-\mathrm{IkBa}$ reversible dissociation rate $\quad 0.5 \mathrm{e}-3 \mathrm{~s}-1$

$\mathrm{s} 1=10^{\wedge}$ params $(8,1) ; \%$ 5.0e7 \% sec-1 IkBa-inducible mRNA synthesis fitting

$\operatorname{cs} 1=10^{\wedge}$ params $(9,1) ; \% 0.0 \% \mathrm{mM}$ sec-1 IkBa-constitutive mRNA synthesis

Assumption

$\mathrm{dm} 1=10^{\wedge}$ params $(10,1) ; \% 0.0004 \%$ sec-1 IkBa mRNA degradation Fitted, Blattner et al.

$\mathrm{t} 1=10^{\wedge}$ params $(11,1) ; \% 0.5 \%$ sec-1 IkBa translation rate Fitted lipniak 2004

$\operatorname{de} 1=10^{\wedge}$ params $(12,1) ; \% 0.0001 \%$ sec-1 Spontaneous, free IkBa protein degradation

Pando and Verma (2000)

de3 $=10^{\wedge}$ params $(13,1) ; \% 0.00002 \%$ sec-1 IkBa degradation (complexed to NF-kB)

Pando and Verma (2000)

$\mathrm{s} 2=10^{\wedge}$ params $(14,1) ; \%$ sec-1 A20-inducible mRNA synthesis fitting

$\operatorname{cs} 2=10^{\wedge}$ params $(15,1) ; \% 0.0 \% \mathrm{mM}$ sec-1 A20-constitutive mRNA synthesis

Assumption

$\operatorname{dm} 2=10^{\wedge}$ params $(16,1) ; \%$ sec-1 A20 mRNA degradation fitting

$\mathrm{t} 2=10^{\wedge}$ params $(17,1) ; \% 0.5 \%$ sec-1 A20 translation rate fitting

de2 $=10^{\wedge}$ params $(18,1) ; \% 0.0003 \%$ sec-1 A20 protein degradation Fitted

$\mathrm{k} 1=10^{\wedge}$ params $(19,1) ; \% 0.0025 \%$ sec-1 IKK activation rate caused by TNF Fitted

$\mathrm{k} 2=10^{\wedge}$ params $(20,1) ; \% 0.1 \%$ sec-1 IKK inactivation rate caused by A20 Fitted

$\mathrm{k} 3=10^{\wedge}$ params $(21,1) ; \% 0.0015 \%$ sec-1 IKK spontaneous inactivation rate Fitted

$\operatorname{kprod}=10^{\wedge}$ params $(22,1) ; \% 0.000025 \% \mathrm{mM}$ sec-1 IKKn production rate Fitted

kdeg $=10^{\wedge}$ params $(23,1) ; \% 0.000125 \%$ sec-1 IKKa, IKKn and IKKi degradation Fitted 
\% NF 0:06 V mM V Total amount of free and complexed NF-kB

Assumption, Carlotti

$\mathrm{kv}=10^{\wedge}$ params $(24,1) ; \% 5 \%$ Cytoplasmic to nuclear volume Assumption

$\mathrm{i} 1=10^{\wedge}$ params $(25,1) ; \% 0.0025 \%$ sec-1 NF-kB nuclear import Fitted

ila $=10^{\wedge}$ params $(26,1) ; \% 0.001 \%$ sec-1 IkBa nuclear import Fitted

$\mathrm{e} 1 \mathrm{a}=10^{\wedge}$ params $(27,1) ; \% 0.0005 \%$ sec-1 IkBa nuclear export Assumption

e2a $=10^{\wedge}$ params $(28,1) ; \% 0.01 \%$ sec-1 (IkBajNF-kBP nuclear export Fitted

$\mathrm{kd} 1=10^{\wedge}$ params $(29,1) ; \% 0.1 \% \mathrm{mM}$ Dissociation constant for NF-kB to $\mathrm{kB} 1$ sites

$\mathrm{kd} 2=10^{\wedge}$ params $(30,1) ; \% 0.1 \% \mathrm{mM}$ Dissociation constant for NF-kB to $\mathrm{kB} 2$ sites

inhibited by DCPA

alpha1 $=10^{\wedge}$ params $(31,1) ; \%$ effect of DCPA on activation of IKK

alpha $2=10^{\wedge}$ params $(32,1) ; \%$ effect of DCPA on inducible production of IkBat

dcpa $=10^{\wedge}$ params $(33,1) ; \%$ DCPA concentration

$\%$

$\%$ Rate equations

$\%$

$\mathrm{R} 0=1.0 *(\operatorname{erf}(2 *(\mathrm{t}-\mathrm{start} 2))-\operatorname{erf}(2 *(\mathrm{t}-\mathrm{start} 3))) ;$

$\mathrm{R} 0 \mathrm{a}=\mathrm{dcpa} *(\operatorname{erf}(2 *(\mathrm{t}-\mathrm{start} 2))-\operatorname{erf}(2 *(\mathrm{t}-\mathrm{start} 3)))$

$\mathrm{DCPA}=\mathrm{R} 0 \mathrm{a}$;

TLR4 = 1;

\%Reaction class 1: IkBa-NFkB Association

$\mathrm{R} 1 \mathrm{a}=\mathrm{a} 1 * \mathrm{NFkB} * \mathrm{IkBa}$;

$\mathrm{R} 1 \mathrm{~b}=\mathrm{a} 1 * \mathrm{NFkBn} * \mathrm{IkBan}$;

$\mathrm{R} 1 \mathrm{c}=\mathrm{a} 1 * \mathrm{NFkB} * \mathrm{IKKaIkBa}$

\%Reaction class 2: IKKa-IkBa Association

$\mathrm{R} 2 \mathrm{a}=\mathrm{a} 2 * \mathrm{IKKa} * \mathrm{IkBa}$

$\mathrm{R} 2 \mathrm{~b}=\mathrm{a} 2 * \mathrm{f} 1 * \mathrm{IKKa} * \mathrm{IkBaNFkB}$

\%Reaction class 3: IkBa-NFkB dissociation

$\mathrm{R} 3 \mathrm{a}=\mathrm{d} 1 * \mathrm{IkBaNFkB}$; 


$$
\begin{aligned}
& \mathrm{R} 3 \mathrm{~b}=\mathrm{d} 1 * \mathrm{IkBanNFkBn} \\
& \mathrm{R} 3 \mathrm{c}=\mathrm{d} 1 * \text { IKKaIkBaNFkB; }
\end{aligned}
$$

\% Reaction class 4: IKKa-IkBa dissociation

$\mathrm{R} 4 \mathrm{a}=\mathrm{d} 2 *$ IKKaIkBa;

$\mathrm{R} 4 \mathrm{~b}=\mathrm{d} 2 * \mathrm{f} 1 * \mathrm{IKKaIkBaNFkB}$

\%Reaction class 5: IKKa-IkBa Catalytic dissociation

$\mathrm{R} 5 \mathrm{a}=\mathrm{kcat} * \mathrm{IKKaIkBa} ; \% *(1+\mathrm{alpha} 1 * \mathrm{DCPA} /(\mathrm{DCPA}+\mathrm{kd} 1))$;

$\mathrm{R} 5 \mathrm{~b}=\mathrm{kcat} * \mathrm{f} 2 * \mathrm{IKKaIkBaNFkB} ; \% *(1+$ alpha $1 * \mathrm{DCPA} /(\mathrm{DCPA}+\mathrm{kd} 1))$;

\%Reaction class 6: Degradation of IKK

$\mathrm{R} 6 \mathrm{a}=\mathrm{kdeg} * \mathrm{IKKn}$;

$\mathrm{R} 6 \mathrm{~b}=\mathrm{kdeg} * \mathrm{IKKa}$;

$\mathrm{R} 6 \mathrm{c}=\mathrm{kdeg} * \mathrm{IKKi} ;$

\%Reaction class 7: Degradation of free IkBa proteins

$\mathrm{R} 7=\mathrm{de} 1 * \mathrm{IkBa}$;

\%Reaction class 8: Degradation of IkBa complex to NFkB

$\mathrm{R} 8=\mathrm{de} 3 * \mathrm{IkBaNFkB}$

$\%$ Reaction class 9: Degradation of A20 proteins

$\mathrm{R} 9=\operatorname{de} 2 * \mathrm{~A} 20$

\%Reaction class 10: Degradation of IkBa mRNA

$\mathrm{R} 10=\mathrm{dm} 1 * \mathrm{IkBam} ;$

\%Reaction class 11: Degradation of A20 mRNA

$\mathrm{R} 11=\mathrm{dm} 2 * \mathrm{~A} 20 \mathrm{~m} ;$ 
\%Reaction class 12: Synthesis of IKKn

$\mathrm{R} 12$ = kprod;

$\%$ Reaction class 13: Inducible synthesis of IkBa mRNA

$\mathrm{R} 13=\mathrm{s} 1 * \mathrm{NFkBn} *(1-$ alpha2 $* \mathrm{DCPA} /(\mathrm{DCPA}+\mathrm{kd} 2))$;

$\%$ Reaction class 14: Inducible synthesis of A20 mRNA

$\mathrm{R} 14=\mathrm{s} 2 * \operatorname{NFkBn} *(1-$ alpha2 $*$ DCPA $/($ DCPA + kd2 $)) ;$

\%Reaction class 15: Constitutive synthesis of IkBa mRNA

$\mathrm{R} 15=\mathrm{cs} 1$;

\%Reaction class 16: Constitutive synthesis of A20 mRNA

$\mathrm{R} 16=\mathrm{cs} 2$;

\%Reaction class 17: Translation from IkBa mRNA to IkBa proteins

$\mathrm{R} 17=\mathrm{t} 1 * \mathrm{IkBam} ;$

\%Reaction class 18: Translation from A20 mRNA to A20 proteins

$\mathrm{R} 18=\mathrm{t} 2 * \mathrm{~A} 20 \mathrm{~m} ;$

\%Reaction class 19: Activation of IKKn to IKKa

$\mathrm{R} 19=\mathrm{k} 1 * \mathrm{R} 0 * \mathrm{IKKn} * \mathrm{TLR} 4 *(1+$ alpha1*DCPA/(DCPA+kd1) $;$

\%Reaction class 20: Inactivation of IKKa because of A20

$\mathrm{R} 20=\mathrm{k} 2 * \mathrm{R} 0 * \mathrm{~A} 20 * \mathrm{IKKa}$;

$\%$ Reaction class 21: Spontaneous Inactivation of IKKa to IKKi

$\mathrm{R} 21=\mathrm{k} 3 * \mathrm{IKKa}$;

\% Reaction class 22: IkBa Import to the nucleus 
$\mathrm{R} 22=\mathrm{i} 1 \mathrm{a} * \mathrm{IkBa}$

\%Reaction class 23: IkBa export from the nucleus to cytoplasm $\mathrm{R} 23=\mathrm{e} 1 \mathrm{a} * \mathrm{IkBan} ;$

$\%$ Reaction class 24: IkBanNFkBn export from the nucleus to cytoplasm $\mathrm{R} 24=\mathrm{e} 2 \mathrm{a} * \mathrm{IkBanNFkBn} ;$

\%Reaction class 25: NFkB import to the nucleus from cytoplasm $\mathrm{R} 25=\mathrm{i} 1 * \mathrm{NFkB} *(1+$ alpha $2 * \mathrm{DCPA} /(\mathrm{DCPA}+\mathrm{kd} 1))$;

$\%$ Differential equations that define the mathematical model for NFkB signaling pathway.

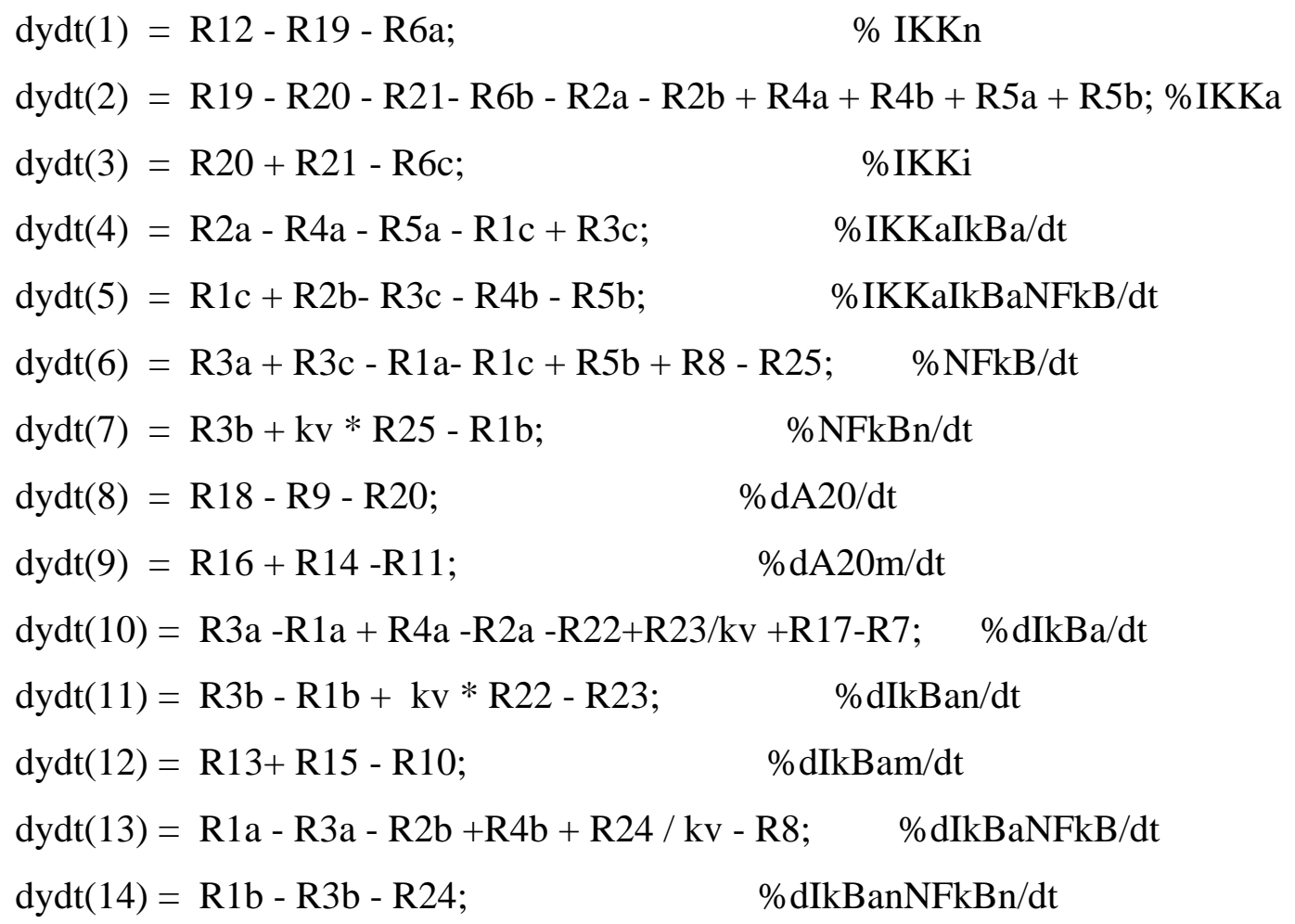

$F L A G=0$;

NEW_DATA $=[]$; 
return;

function $[\mathrm{y} 0$, data $]=$ loadParams01(k, n_tot $)$

$\%$ Initial conditions:

$\mathrm{y} 0=$ zeros$\left(\mathrm{n} \_\right.$tot, 1$)$;

$\mathrm{y} 0(1,1)=0.02 ; \quad \%$ mico M IKKn

$\%$ y0 $(10,1)=0.06 ; \quad \%$ Rice and Ernst $(1993)$

$\mathrm{y} 0(13,1)=0.06 ; \quad \%$ mico M IkBa-NFkB cheong 2006

\%------------------------------

$\%$ PARAMETERS

$\%$

params = zeros $(33,1)$;

$\operatorname{params}(1,1)=\log 10(0.5) ; \quad \% 0.5$ a1 microM-1 sec-1 IkBa-NFkB association

Hoffmann et al. (2002)

$\operatorname{params}(2,1)=\log 10(0.0225) ; \quad \%$ a2 microM-1 sec-1 IKKa-IkBa association

Assumption

params $(3,1)=\log 10(7) ; \quad \% 5 \mathrm{f} 1$ the factor of NFkB on IKKa-IkBa association

Hoffmann et al.

$\operatorname{params}(4,1)=\log 10(0.00407) ; \quad \%$ kcat $\%$ sec-1 IKKajIkBa catalysis fitting

params $(5,1)=\log 10(5) ; \quad \%$ f $2 \%$ the factor of NFkB on IKKa-IkBa catalysis

Hoffmann et al

params $(6,1)=\log 10(0.0005) ; \quad \% \mathrm{~d} 1 \% \mathrm{IkBa}-\mathrm{NFkB}$ reversible dissociation rate

$1.25 \mathrm{e}-3 \quad \mathrm{~s}-1$

$\operatorname{params}(7,1)=\log 10(1.25 \mathrm{e}-3) ; \quad \% \mathrm{~d} 2=10^{\wedge} \operatorname{params}(7,1) ; \%$ IKK-IkBa reversible

dissociation rate $\quad 0.5 \mathrm{e}-3 \mathrm{~s}-1$

params $(8,1)=\mathrm{k}(1,1) ; \quad \% \mathrm{~s} 1=10^{\wedge} \operatorname{params}(8,1) ; \% 5.0 \mathrm{e} 7 \%$ sec-1 IkBa-inducible mRNA synthesis fitting $\operatorname{params}(9,1)=\log 10(1.0256 \mathrm{e}-11) ; \% \operatorname{cs} 1=10^{\wedge} \operatorname{params}(9,1) ; \% 0.0 \% \mathrm{mM}$ sec-1 IkBaconstitutive mRNA synthesis Assumption 
$\operatorname{params}(10,1)=\log 10(0.0004) ; \% \mathrm{dm} 1=10^{\wedge} \operatorname{params}(10,1) ; \% 0.0004 \%$ sec-1 IkBa mRNA degradation Fitted, Blattner et al.

$\operatorname{params}(11,1)=\mathrm{k}(2,1) ; \quad \% \mathrm{t} 1=10^{\wedge} \operatorname{params}(11,1) ; \% 0.5 \%$ sec-1 IkBa translation rate Fitted lipniak 2004

$\operatorname{params}(12,1)=\log 10(0.000113) ; \%$ de1 $=10^{\wedge} \operatorname{params}(12,1) ; \% 0.0001 \%$ sec-1

Spontaneous, free IkBa protein degradation Pando and Verma (2000)

$\operatorname{params}(13,1)=\log 10(0.0000225) ; \%$ de $3=10^{\wedge} \operatorname{params}(13,1) ; \% 0.00002 \%$ sec-1 IkBa degradation (complexed to NF-kB) Pando and Verma (2000)

params $(14,1)=\mathrm{k}(3,1) ; \quad \% \mathrm{~s} 2=10^{\wedge}$ params $(14,1) ; \%$ sec-1 A20-inducible mRNA synthesis fitting

$\operatorname{params}(15,1)=\mathrm{k}(4,1) ; \% \operatorname{cs} 2=10^{\wedge} \operatorname{params}(15,1) ; \% 0.0 \% \mathrm{mM}$ sec-1 A20-constitutive mRNA synthesis Assumption

$\operatorname{params}(16,1)=\mathrm{k}(5,1) ; \quad \% \mathrm{dm} 2=10^{\wedge} \operatorname{params}(16,1) ; \%$ sec-1 A20 mRNA

degradation fitting

$\operatorname{params}(17,1)=\mathrm{k}(6,1) ; \quad \% \mathrm{t} 2=10^{\wedge} \operatorname{params}(17,1) ; \% 0.5 \%$ sec-1 A20 translation rate fitting

$\operatorname{params}(18,1)=\log 10(0.0003) ; \%$ de $2=10^{\wedge} \operatorname{params}(18,1) ; \% 0.0003 \%$ sec-1 A20 protein degradation Fitted

params $(19,1)=\mathrm{k}(7,1) ; \quad \% \mathrm{k} 1 \mathrm{sec}-1 \quad 0.0025 \mathrm{IKK}$ activation rate caused by TNF

Fitted

params $(20,1)=\mathrm{k}(8,1) ; \quad \% \mathrm{k} 2$ sec-1 $\quad$ IKK inactivation rate caused by A20 Fitted $\operatorname{params}(21,1)=\log 10(3.2374 \mathrm{e}-10) ; \quad \% \mathrm{k} 3 \mathrm{sec}-1 \quad$ IKK spontaneous inactivation rate

Fitted

$\operatorname{params}(22,1)=\mathrm{k}(9,1) ; \quad \%$ kprod IKKn synthesis rate

params $(23,1)=\mathrm{k}(10,1) ; \quad \%$ kdeg sec-1 IKKa, IKKn and IKKi degradation Fitted

params $(24,1)=\log 10(7) ; \quad \% \mathrm{kv} 7 \quad$ Cytoplasmic to nuclear volume Assumption

7 Cheong 2006, 5 Lipniacki 2004, 2006

params $(25,1)=\mathrm{k}(12,1) ; \% \log 10(0.0013) ; \%$ i1 sec-1 NF-kB nuclear import Fitted \%0.0025 Lipniacki 2004, 2006; 0.09 Werner 2005 $\operatorname{params}(26,1)=\mathrm{k}(11,1)+\log 10(2) ; \%$ ila sec-1 IkBa nuclear import Fitted \%0.001 Lipniacki 2004, 0.002 Lipniacki 2006, 0.0003 Werner 2005 
params $(27,1)=\mathrm{k}(11,1) ; \%$ ela sec-1 IkBa nuclear export Assumption \%0.0005 Lipniacki 2004, 0.005 Lipniacki 2006, 0.0002 Werner 2005 params $(28,1)=\mathrm{k}(13,1)$; \% e2a sec-1 IkBa-NF-kB nuclear export Fitted \%0.01 Lipniacki 2004, 0.05 Lipniacki 2006, 0.014 Werner 2005

$\operatorname{params}(29,1)=\log 10(5) ; \quad \% \mathrm{kd} 1 \mathrm{mM} \quad$ Half-maximum DCPA concentration $\operatorname{params}(30,1)=\log 10(5) ; \quad \% \mathrm{kd} 2 \mathrm{mM} \quad$ Half-maximum DCPA concentration params $(31,1)=\log 10(0.48) ; \quad \%$ alpha1 $\quad$ Effect of DCPA on activating IKK params $(32,1)=\log 10(0.013) ; \quad \%$ alpha2 effect of DCPA on NFkB inducible producing IkBa mRNA $\operatorname{params}(33,1)=\log 10(1.0 \mathrm{e}-20)$; \%CPA concentration is $100 \mathrm{uM}$

if $\operatorname{size}($ params, 1$)==1$ params $=$ params'; $\quad \%$ convert $\mathrm{K}$ to a column vector instead of a row vector end;

$\%$ start and stop times of LPS bolus in nfkb_core01 file tstart $=[02000 * 606 * 60 * 60+2000 * 60] ;$ $\%$ pack parameters into data struct data params = params; data.tstart $=$ tstart;

return;

function $[\mathrm{kin}]=\operatorname{InitParams01()}$

$\%$ Load paramaters - mean values from MCMC run $\operatorname{kin}=\operatorname{zeros}(13,1)$;

$\operatorname{kin}(1,1)=\log 10(4.2615 \mathrm{e}-5) ; \% \mathrm{~s} 1=10^{\wedge}$ params $(8,1) ; \% 5.0 \mathrm{e} 7 \%$ sec-1 IkBa-inducible mRNA synthesis fitting $\% \operatorname{kin}(2,1)=\log 10(1.0256 \mathrm{e}-11) ; \% \operatorname{cs} 1=10^{\wedge} \operatorname{params}(9,1) ; \% 0.0 \% \mathrm{mM}$ sec-1 IkBaconstitutive mRNA synthesis Assumption 
$\operatorname{kin}(2,1)=\log 10(0.6592) ; \% \mathrm{t} 1 \mathrm{IkBa}$ translation rate

$\operatorname{kin}(3,1)=\log 10(0.0967) ; \quad \% \mathrm{~s} 2=10^{\wedge} \operatorname{params}(14,1) ; \%$ sec-1 A20-inducible mRNA synthesis fitting

$\operatorname{kin}(4,1)=\log 10(8.634 \mathrm{e}-7) ; \% \operatorname{cs} 2=10^{\wedge} \operatorname{params}(15,1) ; \% 0.0 \% \mathrm{mM} \mathrm{sec}-1 \mathrm{~A} 20-$

constitutive mRNA synthesis Assumption

$\operatorname{kin}(5,1)=\log 10(0.0716) ; \% \mathrm{dm} 2=10^{\wedge} \operatorname{params}(16,1) ; \%$ sec-1 A20 mRNA

degradation fitting

$\operatorname{kin}(6,1)=\log 10(0.4138) ; \% \mathrm{t} 2=10^{\wedge} \operatorname{params}(17,1) ; \% 0.5 \%$ sec-1 A20 translation rate fitting

$\operatorname{kin}(7,1)=\log 10(0.0016) ; \% \mathrm{k} 1 \mathrm{sec}-1 \quad 0.0025 \mathrm{IKK}$ activation rate caused by TNF

Fitted

$\operatorname{kin}(8,1)=\log 10(0.2462) ; \quad \% \mathrm{k} 2 \mathrm{sec}-1 \quad$ IKK inactivation rate caused by A20 Fitted $\% \operatorname{kin}(10,1)=\log 10(3.2374 \mathrm{e}-10) ; \% \mathrm{k} 3 \mathrm{sec}-1 \quad$ IKK spontaneous inactivation rate

Fitted

$\operatorname{kin}(9,1)=\log 10(4.707 \mathrm{e}-4) ; \%$ kprod microM sec-1 IKKn production rate Fitted

$\operatorname{kin}(10,1)=\log 10(0.0031) ; \%$ kdeg sec-1 IKKa, IKKn and IKKi degradation Fitted

$\operatorname{kin}(11,1)=\log 10(1.3858 \mathrm{e}-4) ; \%$ e1a sec-1 IkBa nuclear export Assumption

\%0.0005 Lipniacki 2004, 0.005 Lipniacki 2006, 0.0002 Werner 2005

$\operatorname{kin}(12,1)=\log 10(4.3958 \mathrm{e}-4) ; \%$ i1 sec-1 NF-kB nuclear import Fitted

\%0.0025 Lipniacki 2004, 2006; 0.09 Werner 2005

$\operatorname{kin}(13,1)=\log 10(0.002) ; \%$ e2a sec-1 IkBa-NF-kB nuclear export Fitted

if $\operatorname{size}(\mathrm{kin}, 1)==1$

kin = kin'; \% convert $\mathrm{k}$ to a column vector instead of a row vector

end;

return;

function $[$ data $]=$ data_nfkb01

$\%$ Populate Propanil data array

$\%$ Initialization

data=struct('ppn', \{\} ,'tdata', \{\} ,'values', \{\}$)$; 
$\%$ Load data arrays

\%tdata $=[[0] ;[5] ;[7] ;[10] ;[11] ;[12] ;[15] ;[13] ;[16] ;[19] ;[22] ;[30-$

4.5];[28];[31];[33];[35];[39];[45-4.5];[42];[43];[45];[47];[49];[51];[53];[60-

4.5];[57];[59];[61];[63];[65];[67];[69];[75-4.5];[73];[75];[77];[79];[81];[83];[85];[90-

4.5];[87];[89];[91];[93];[95];[97];[99];[105-

4.5];[103];[105];[107];[109];[111];[113];[115];[120-

4.5];[116];[117];[119];[121];[123];[125];[127];[130];[132];[134];[136];[138];[140];[142] ;[150-

4.5];[147];[149];[152];[155];[157];[159];[161];[163];[165];[167];[169];[171];[173];[175] ;[180-

4.5];[177];[179];[182];[185];[187];[189];[192];[195];[197];[199];[201];[203];[204];[205]

;[210-4.5];[207];[210];[215];[220];[225];[230];[233];[240-

4.5];[237];[240];[245];[250];[255];[260];[263];[270-

4.5];[267];[270];[275];[280];[285];[290];[293];[300-

4.5];[297];[300];[305];[310];[315];[320];[325];[330-

4.5];[327];[330];[335];[340];[345];[350];[355];[360-4.5]];

$\%$ Experiment 1

$\%$ data(1).ppn $=0$;

$\%$ data( 1$) \cdot$ tdata $=$ tdata $. * 60+2000 * 60$;

\%data(1).values = [[1 1 1];[1.47 1];[3 0];[6.51 1];[7.5 0];[10 0];[9.71 1];[13 0];[19 0];[22

0];[16 0];[13.22 1];[28 0];[31 0];[33 0];[34.5 0];[39 0];[6.43 1];[42 0];[43 0];[45 0];[47

0];[49 0];[51 0];[53 0];[5.64 1];[57 0];[59 0];[61 0];[63 0];[65 0];[67 0];[69 0];[5.27

1];[73 0];[75 0];[77 0];[79 0];[81 0];[83 0];[85 0];[10.08 1];[73 0];[75 0];[77 0];[79

0];[81 0];[83 0];[85 0];[9.28 1];[73 0];[75 0];[77 0];[79 0];[81 0];[83 0];[85 0];[6.95

1];[73 0];[75 0];[77 0];[79 0];[81 0];[83 0];[85 0];[73 0];[75 0];[77 0];[79 0];[81 0];[83

0];[85 0];[5.67 1];[73 0];[75 0];[77 0];[79 0];[81 0];[83 0];[85 0];[73 0];[75 0];[77 0];[79

0];[81 0];[83 0];[85 0];[7.31 1];[73 0];[75 0];[77 0];[79 0];[81 0];[83 0];[85 0];[73 0];[75

0];[77 0];[79 0];[81 0];[83 0];[85 0];[7.51 0];[73 0];[75 0];[77 0];[79 0];[81 0];[83 0];[85

0];[6.88 0];[73 0];[75 0];[77 0];[79 0];[81 0];[83 0];[85 0];[6.77 0];[73 0];[75 0];[77

0];[79 0];[81 0];[83 0];[85 0];[7.84 0];[73 0];[75 0];[77 0];[79 0];[81 0];[83 0];[85

0];[7.47 0];[73 0];[75 0];[77 0];[79 0];[81 0];[83 0];[85 0];[8.23 0]]; 
$\%$ total cytoplasmic IkB

\%data(1).values = [[1 1];[1.47 1];;3 0];[6.51 1];[7.5 0];[10 0];[9.71 1];[13 0];[19 0];[22

0];[16 0];[13.22 1];[28 0];[31 0];[33 0];[34.5 0];[39 0];[6.43 1];[42 0];[43 0];[45 0];[47

0];[49 0];[51 0];[53 0];[5.64 1];[57 0];[59 0];[61 0];[63 0];[65 0];[67 0];[69 0];[5.27

1];[73 0];[75 0];[77 0];[79 0];[81 0];[83 0];[85 0];[10.08 1];[73 0];[75 0];[77 0];[79

0];[81 0];[83 0];[85 0];[9.28 1];[73 0];[75 0];[77 0];[79 0];[81 0];[83 0];[85 0];[6.95

1];[73 0];[75 0];[77 0];[79 0];[81 0];[83 0];[85 0];[73 0];[75 0];[77 0];[79 0];[81 0];[83

0];[85 0];[5.67 1];[73 0];[75 0];[77 0];[79 0];[81 0];[83 0];[85 0];[73 0];[75 0];[77 0];[79

0];[81 0];[83 0];[85 0];[7.31 1];[73 0];[75 0];[77 0];[79 0];[81 0];[83 0];[85 0];[73 0];[75

0];[77 0];[79 0];[81 0];[83 0];[85 0];[7.51 1];[73 0];[75 0];[77 0];[79 0];[81 0];[83 0];[85

0];[6.88 1];[73 0];[75 0];[77 0];[79 0];[81 0];[83 0];[85 0];[6.77 1];[73 0];[75 0];[77

0];[79 0];[81 0];[83 0];[85 0];[7.84 1];[73 0];[75 0];[77 0];[79 0];[81 0];[83 0];[85

0];[7.47 1];[73 0];[75 0];[77 0];[79 0];[81 0];[83 0];[85 0];[8.23 1]];

$\%$ Cyto. IkBa

$\% \operatorname{data}(3) \cdot \mathrm{ppn}=0$

$\%$ data(3).tdata $=$ tdata $* 60+2000 * 60$;

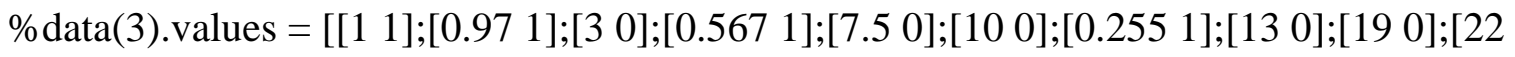

0];[16 0];[0.482 1];[28 0];[31 0];[33 0];[34.5 0];[39 0];[0.950 1];[42 0];[43 0];[45 0];[47

0];[49 0];[51 0];[53 0];[0.764 1];[57 0];[59 0];[61 0];[63 0];[65 0];[67 0];[69 0];[0.794

1];[73 0];[75 0];[77 0];[79 0];[81 0];[83 0];[85 0];[0.769 1];[73 0];[75 0];[77 0];[79

0];[81 0];[83 0];[85 0];[0.592 1];[73 0];[75 0];[77 0];[79 0];[81 0];[83 0];[85 0];[0.587

1];[73 0];[75 0];[77 0];[79 0];[81 0];[83 0];[85 0];[73 0];[75 0];[77 0];[79 0];[81 0];[83

0];[85 0];[0.663 1];[73 0];[75 0];[77 0];[79 0];[81 0];[83 0];[85 0];[73 0];[75 0];[77

0];[79 0];[81 0];[83 0];[85 0];[0.608 1];[73 0];[75 0];[77 0];[79 0];[81 0];[83 0];[85

0];[73 0];[75 0];[77 0];[79 0];[81 0];[83 0];[85 0];[0.733 0];[73 0];[75 0];[77 0];[79

0];[81 0];[83 0];[85 0];[0.688 0];[73 0];[75 0];[77 0];[79 0];[81 0];[83 0];[85 0];[0.849

0];[73 0];[75 0];[77 0];[79 0];[81 0];[83 0];[85 0];[0.693 0];[73 0];[75 0];[77 0];[79

0];[81 0];[83 0];[85 0];[0.869 0];[73 0];[75 0];[77 0];[79 0];[81 0];[83 0];[85 0];[0.608 0]];

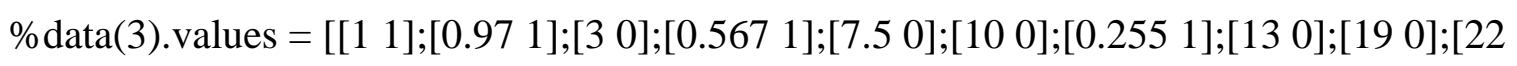

0];[16 0];[0.482 1];[28 0];[31 0];[33 0];[34.5 0];[39 0];[0.950 1];[42 0];[43 0];[45 0];[47

0];[49 0];[51 0];[53 0];[0.764 1];[57 0];[59 0];[61 0];[63 0];[65 0];[67 0];[69 0];[0.794 
1];[73 0];[75 0];[77 0];[79 0];[81 0];[83 0];[85 0];[0.769 1];[73 0];[75 0];[77 0];[79 0];[81 0];[83 0];[85 0];[0.592 1];[73 0];[75 0];[77 0];[79 0];[81 0];[83 0];[85 0];[0.587 1];[73 0];[75 0];[77 0];[79 0];[81 0];[83 0];[85 0];[73 0];[75 0];[77 0];[79 0];[81 0];[83 0];[85 0];[0.663 1];[73 0];[75 0];[77 0];[79 0];[81 0];[83 0];[85 0];[73 0];[75 0];[77 0];[79 0];[81 0];[83 0];[85 0];[0.608 1];[73 0];[75 0];[77 0];[79 0];[81 0];[83 0];[85 0];[73 0];[75 0];[77 0];[79 0];[81 0];[83 0];[85 0];[0.733 1];[73 0];[75 0];[77 0];[79 0];[81 0];[83 0];[85 0];[0.688 1];[73 0];[75 0];[77 0];[79 0];[81 0];[83 0];[85 0];[0.849 1];[73 0];[75 0];[77 0];[79 0];[81 0];[83 0];[85 0];[0.693 1];[73 0];[75 0];[77 0];[79 0];[81 0];[83 0];[85 0];[0.869 1];[73 0];[75 0];[77 0];[79 0];[81 0];[83 0];[85 0];[0.608 1]];

$\%$ Experiment 2

$\%$ data(2).ppn $=100$

$\%$ data $(2) \cdot$ tdata $=$ tdata. $* 60+2000 * 60$;

\%data(2).values = [[1 1 1];[1.41 1];[3 0];[5.60 1];[7.5 0];[10 0];[11.11 1];[13 0];[19 0];[22 0];[16 0];[10.77 1];[28 0];[31 0];[33 0];[34.5 0];[39 0];[6.01 1];[42 0];[43 0];[45 0];[47 0];[49 0];[51 0];[53 0];[6.21 1];[57 0];[59 0];[61 0];[63 0];[65 0];[67 0];[69 0];[7.93 1];[73 0];[75 0];[77 0];[79 0];[81 0];[83 0];[85 0];[9.29 1];[73 0];[75 0];[77 0];[79 0];[81 0];[83 0];[85 0];[7.49 1];[73 0];[75 0];[77 0];[79 0];[81 0];[83 0];[85 0];[5.72 1];[73 0];[75 0];[77 0];[79 0];[81 0];[83 0];[85 0];[73 0];[75 0];[77 0];[79 0];[81 0];[83 0];[85 0];[5.75 1];[73 0];[75 0];[77 0];[79 0];[81 0];[83 0];[85 0];[73 0];[75 0];[77 0];[79 0];[81 0];[83 0];[85 0];[8.80 1];[73 0];[75 0];[77 0];[79 0];[81 0];[83 0];[85 0];[73 0];[75 0];[77 0];[79 0];[81 0];[83 0];[85 0];[7.58 0];[73 0];[75 0];[77 0];[79 0];[81 0];[83 0];[85 0];[6.84 0];[73 0];[75 0];[77 0];[79 0];[81 0];[83 0];[85 0];[6.57 0];[73 0];[75 0];[77 0];[79 0];[81 0];[83 0];[85 0];[8.18 0];[73 0];[75 0];[77 0];[79 0];[81 0];[83 0];[85 0];[7.78 0];[73 0];[75 0];[77 0];[79 0];[81 0];[83 0];[85 0];[9.20 0]]; \%data(2).values = [[1 1 1];[1.41 1];[3 0];[5.60 1];[7.5 0];[10 0];[11.11 1];[13 0];[19 0];[22 0];[16 0];[10.77 1];[28 0];[31 0];[33 0];[34.5 0];[39 0];[6.01 1];[42 0];[43 0];[45 0];[47 0];[49 0];[51 0];[53 0];[6.21 1];[57 0];[59 0];[61 0];[63 0];[65 0];[67 0];[69 0];[7.93 1];[73 0];[75 0];[77 0];[79 0];[81 0];[83 0];[85 0];[9.29 1];[73 0];[75 0];[77 0];[79 0];[81 0];[83 0];[85 0];[7.49 1];[73 0];[75 0];[77 0];[79 0];[81 0];[83 0];[85 0];[5.72 1];[73 0];[75 0];[77 0];[79 0];[81 0];[83 0];[85 0];[73 0];[75 0];[77 0];[79 0];[81 0];[83 0];[85 
0];[5.75 1];[73 0];[75 0];[77 0];[79 0];[81 0];[83 0];[85 0];[73 0];[75 0];[77 0];[79 0];[81 0];[83 0];[85 0];[8.80 1];[73 0];[75 0];[77 0];[79 0];[81 0];[83 0];[85 0];[73 0];[75 0];[77 0];[79 0];[81 0];[83 0];[85 0];[7.58 1];[73 0];[75 0];[77 0];[79 0];[81 0];[83 0];[85 0];[6.84 1];[73 0];[75 0];[77 0];[79 0];[81 0];[83 0];[85 0];[6.57 1];[73 0];[75 0];[77 0];[79 0];[81 0];[83 0];[85 0];[8.18 1];[73 0];[75 0];[77 0];[79 0];[81 0];[83 0];[85 0];[7.78 1];[73 0];[75 0];[77 0];[79 0];[81 0];[83 0];[85 0];[9.20 1]]; $\%$ Cyto.IkBa

$\%$ total cytoplasmic IkB

$\%$ data(4).ppn $=100$

$\%$ data(4).tdata $=$ tdata $. * 60+2000 * 60$;

\%data(4).values = [[0.949 1];[0.864 1];[3 0];[0.376 1];[7.5 0];[10 0];[0.235 1];[13 0];[19

0];[22 0];[16 0];[0.430 1];[28 0];[31 0];[33 0];[34.5 0];[39 0];[0.928 1];[42 0];[43 0];[45 0];[47 0];[49 0];[51 0];[53 0];[0.726 1];[57 0];[59 0];[61 0];[63 0];[65 0];[67 0];[69 0];[0.897 1];[73 0];[75 0];[77 0];[79 0];[81 0];[83 0];[85 0];[0.630 1];[73 0];[75 0];[77 0];[79 0];[81 0];[83 0];[85 0];[0.559 1];[73 0];[75 0];[77 0];[79 0];[81 0];[83 0];[85 0];[0.544 1];[73 0];[75 0];[77 0];[79 0];[81 0];[83 0];[85 0];[73 0];[75 0];[77 0];[79 0];[81 0];[83 0];[85 0];[0.623 1];[73 0];[75 0];[77 0];[79 0];[81 0];[83 0];[85 0];[73 0];[75 0];[77 0];[79 0];[81 0];[83 0];[85 0];[0.552 1];[73 0];[75 0];[77 0];[79 0];[81 0];[83 0];[85 0];[73 0];[75 0];[77 0];[79 0];[81 0];[83 0];[85 0];[0.596 0];[73 0];[75 0];[77 0];[79 0];[81 0];[83 0];[85 0];[0.545 0];[73 0];[75 0];[77 0];[79 0];[81 0];[83 0];[85 0];[0.771 0];[73 0];[75 0];[77 0];[79 0];[81 0];[83 0];[85 0];[0.589 0];[73 0];[75 0];[77 0];[79 0];[81 0];[83 0];[85 0];[0.558 0];[73 0];[75 0];[77 0];[79 0];[81 0];[83 0];[85 0];[0.532 0]];

\%data(4).values = [[0.949 1];[0.864 1];[3 0];[0.376 1];[7.5 0];[10 0];[0.235 1];[13 0];[19 0];[22 0];[16 0];[0.430 1];[28 0];[31 0];[33 0];[34.5 0];[39 0];[0.928 1];[42 0];[43 0];[45 0];[47 0];[49 0];[51 0];[53 0];[0.726 1];[57 0];[59 0];[61 0];[63 0];[65 0];[67 0];[69 0];[0.897 1];[73 0];[75 0];[77 0];[79 0];[81 0];[83 0];[85 0];[0.630 1];[73 0];[75 0];[77 0];[79 0];[81 0];[83 0];[85 0];[0.559 1];[73 0];[75 0];[77 0];[79 0];[81 0];[83 0];[85 0];[0.544 1];[73 0];[75 0];[77 0];[79 0];[81 0];[83 0];[85 0];[73 0];[75 0];[77 0];[79 0];[81 0];[83 0];[85 0];[0.623 1];[73 0];[75 0];[77 0];[79 0];[81 0];[83 0];[85 0];[73 
0];[75 0];[77 0];[79 0];[81 0];[83 0];[85 0];[0.552 1];[73 0];[75 0];;77 0];[79 0];[81 0];[83 0];[85 0];[73 0];[75 0];[77 0];[79 0];[81 0];[83 0];[85 0];[0.596 1];[73 0];[75 0];[77 0];[79 0];[81 0];[83 0];[85 0];[0.545 1];[73 0];[75 0];[77 0];[79 0];[81 0];[83 0];[85 0];[0.771 1];[73 0];[75 0];[77 0];[79 0];[81 0];[83 0];[85 0];[0.589 1];[73 0];[75 0];[77 0];[79 0];[81 0];[83 0];[85 0];[0.558 1];[73 0];[75 0];[77 0];[79 0];[81 0];[83 0];[85 0];[0.532 1]];

tdata $=[[0] ;[1] ;[2] ;[4] ;[5] ;[7] ;[9] ;[10] ;[12] ;[14] ;[15] ;[17] ;[20] ;[24] ;[27] ;[30] ;$

[33];[36];[40];[42];[45];[47];[50];[53];[57];[60];[63];[67];[70];[72];[75];[77];[80];[83];[8 7];[90];[93];[97];[100];[102];[105];[108];[110];[113];[117];[119];[120];[125];[130];[135] ;[140];[145];[147];[150];[155];[160];[165];[170];[175];

[180];[185];[190];[195];[200];[205];[210];[215];[220];[225];[230];[235];[240];[245];[25 0];[255];[260];[265];[270];[275];[280];[285];[290];[295];[300];[305];[310];[315];[320];[ 323];[327];[329];[330];[335];[340];[343];[347];[350];[355];[360]];

data(1).ppn $=0$;

data(1).tdata $=$ tdata $* 60+2000 * 60$;

$\% \mathrm{NFkB}$ in the nucleas

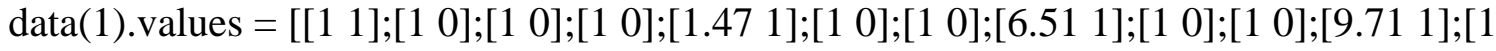
0];[1 0];[1 0];[1 0];[13.22 1];[1 0];[1 0];[1 0];[1 0];[6.43 1];[1 0];[1 0];[1 0];[1 0];[5.64

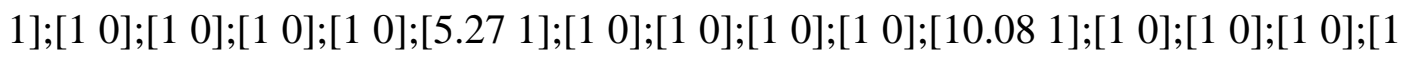

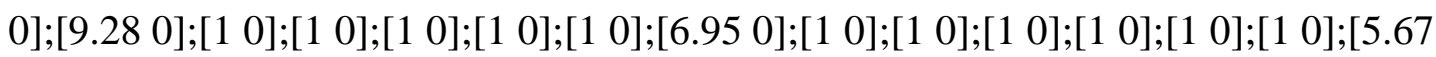

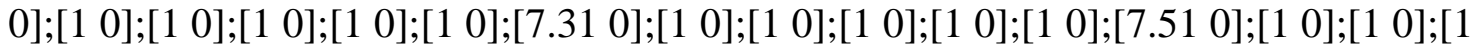

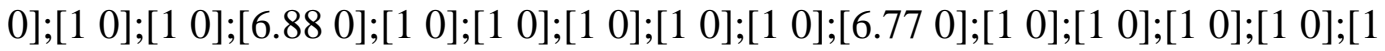

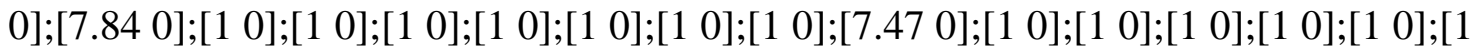
$0] ;[8.230]]$;

$\%$ total IkBa in the cytoplasm

$\operatorname{data}(3) \cdot p p n=0$;

data(3).tdata $=$ tdata $* 60+2000 * 60$; 


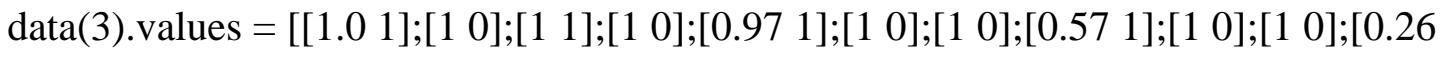

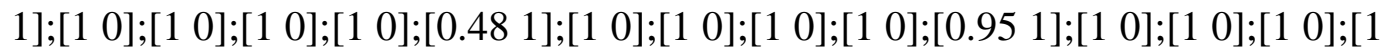

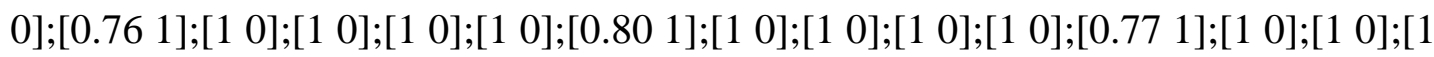

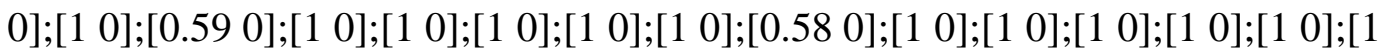

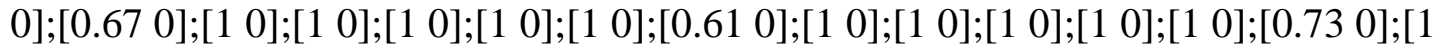

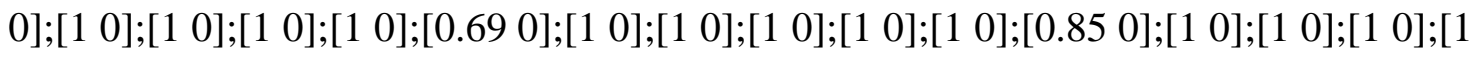

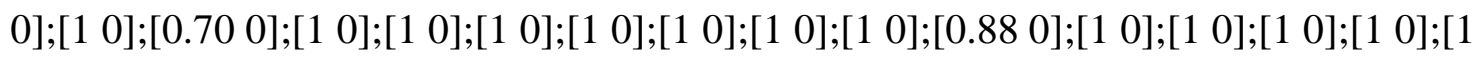
0];[1 0];[0.61 0]];

$\%$ total IkBb in the cytoplasm

data(5).ppn $=0$;

data(5).tdata $=$ tdata $* 60+2000 * 60$;

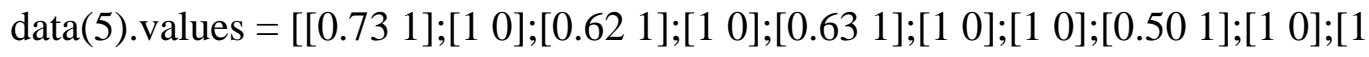

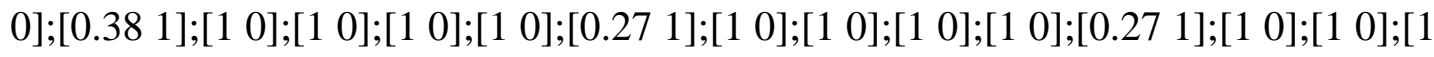

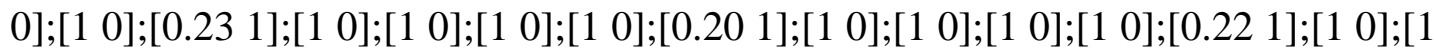

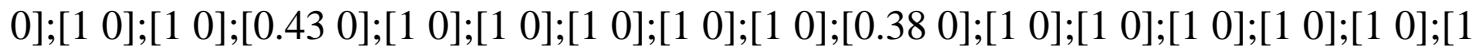

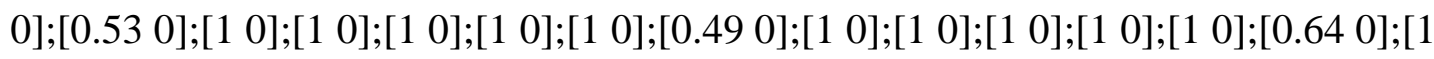

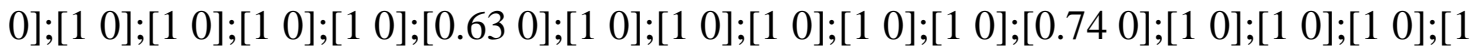

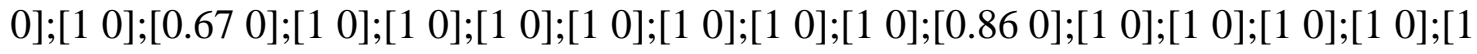
$0] ;[10] ;[0.700]]$;

\section{$\%$ Experiment 2}

$\% \mathrm{NFkB}$ in the nucleaus with DCPA treatment

$\%$

$\operatorname{data}(2) \cdot \mathrm{ppn}=100$;

data $(2)$. tdata $=$ tdata. $* 60+2000 * 60$;

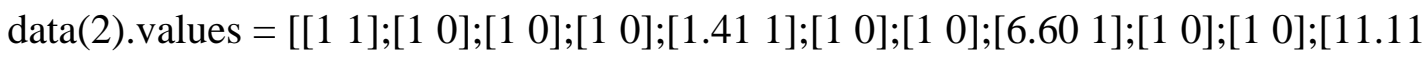

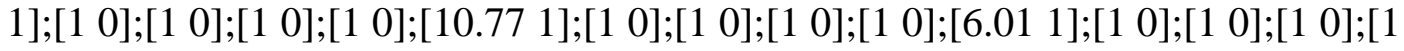

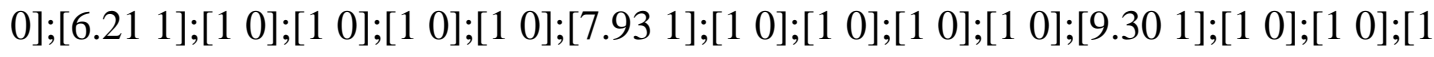

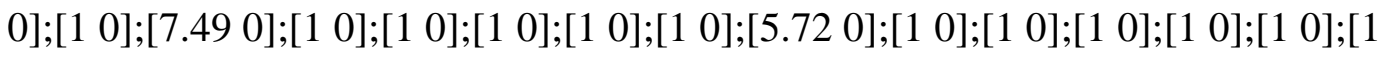

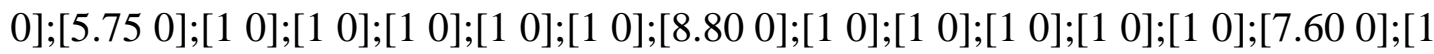

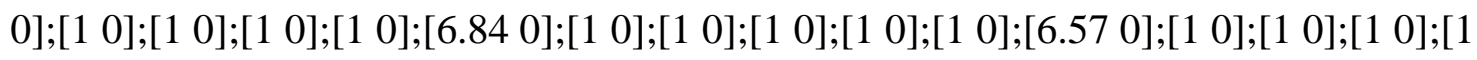




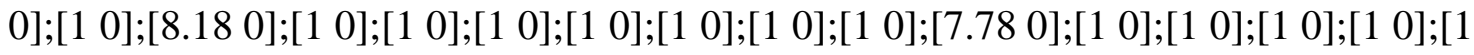
0];[1 0];[9.20 0]];

$\%$ total IkBa in the cytoplasm

$\%$ total IkBa in the cytoplasm

data(4).ppn = 100;

data(4).tdata $=$ tdata $* 60+2000 * 60 ;$

data(4).values = [[1.0 1];; 10$] ;\left[\begin{array}{lll}0.96 & 1\end{array}\right] ;\left[\begin{array}{ll}1 & 0\end{array}\right] ;\left[\begin{array}{lll}0.87 & 1\end{array}\right] ;\left[\begin{array}{ll}1 & 0\end{array}\right] ;\left[\begin{array}{ll}1 & 0\end{array}\right] ;\left[\begin{array}{lll}0.38 & 1\end{array}\right] ;\left[\begin{array}{ll}1 & 0\end{array}\right] ;\left[\begin{array}{ll}1 & 0\end{array}\right] ;\left[\begin{array}{ll}0.25\end{array}\right.$

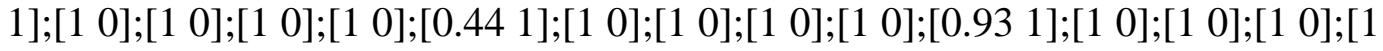

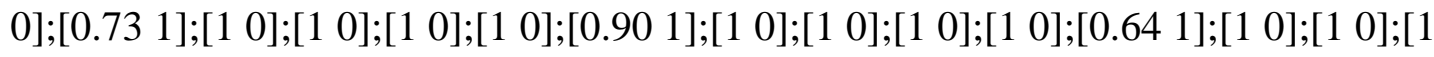

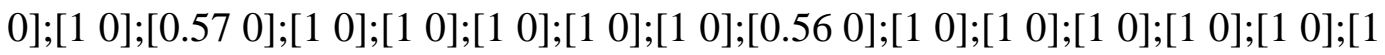

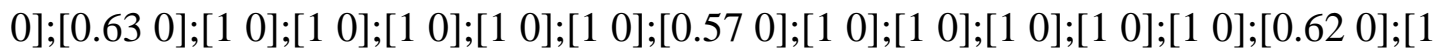

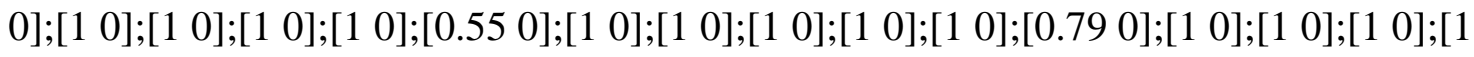

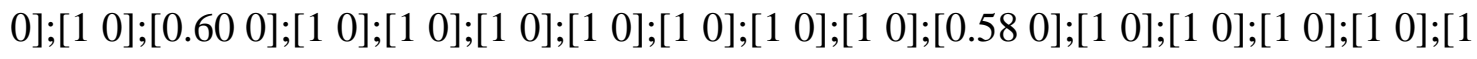

0];[1 0];[0.55 0]];

$\%$ total $\mathrm{IkBb}$ in the cytoplasm

$\%$ total $\mathrm{IkBb}$ in the cytoplasm

$\operatorname{data}(6) \cdot p p n=0$;

data(6).tdata $=$ tdata $* 60+2000 * 60 ;$

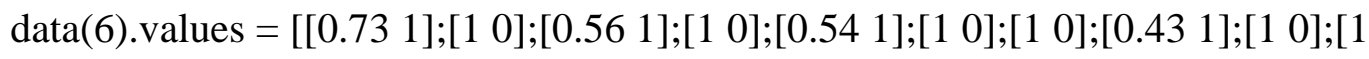

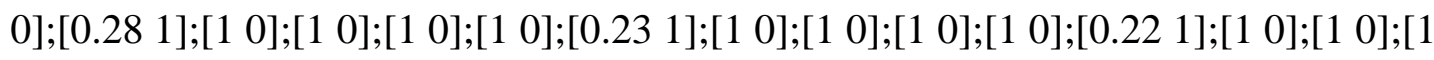

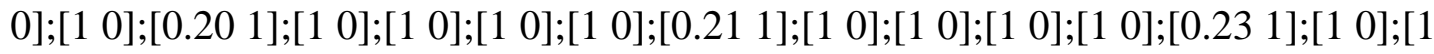

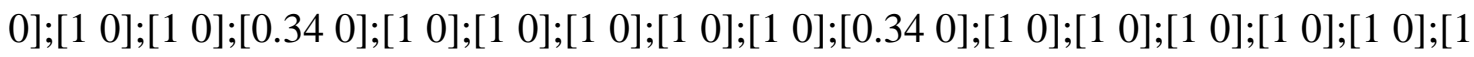

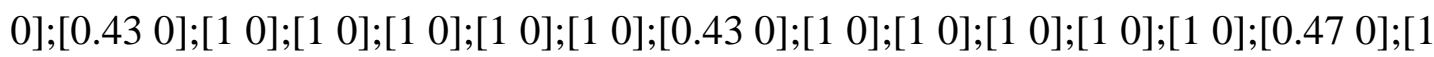

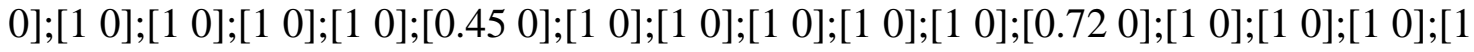

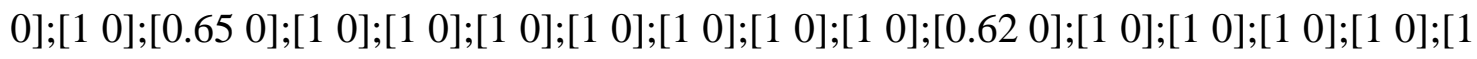

0];[1 0];[0.63 0]];

return; 
Supplement $3.1:$ Gel image for IאB $\alpha$ in the cytoplasm

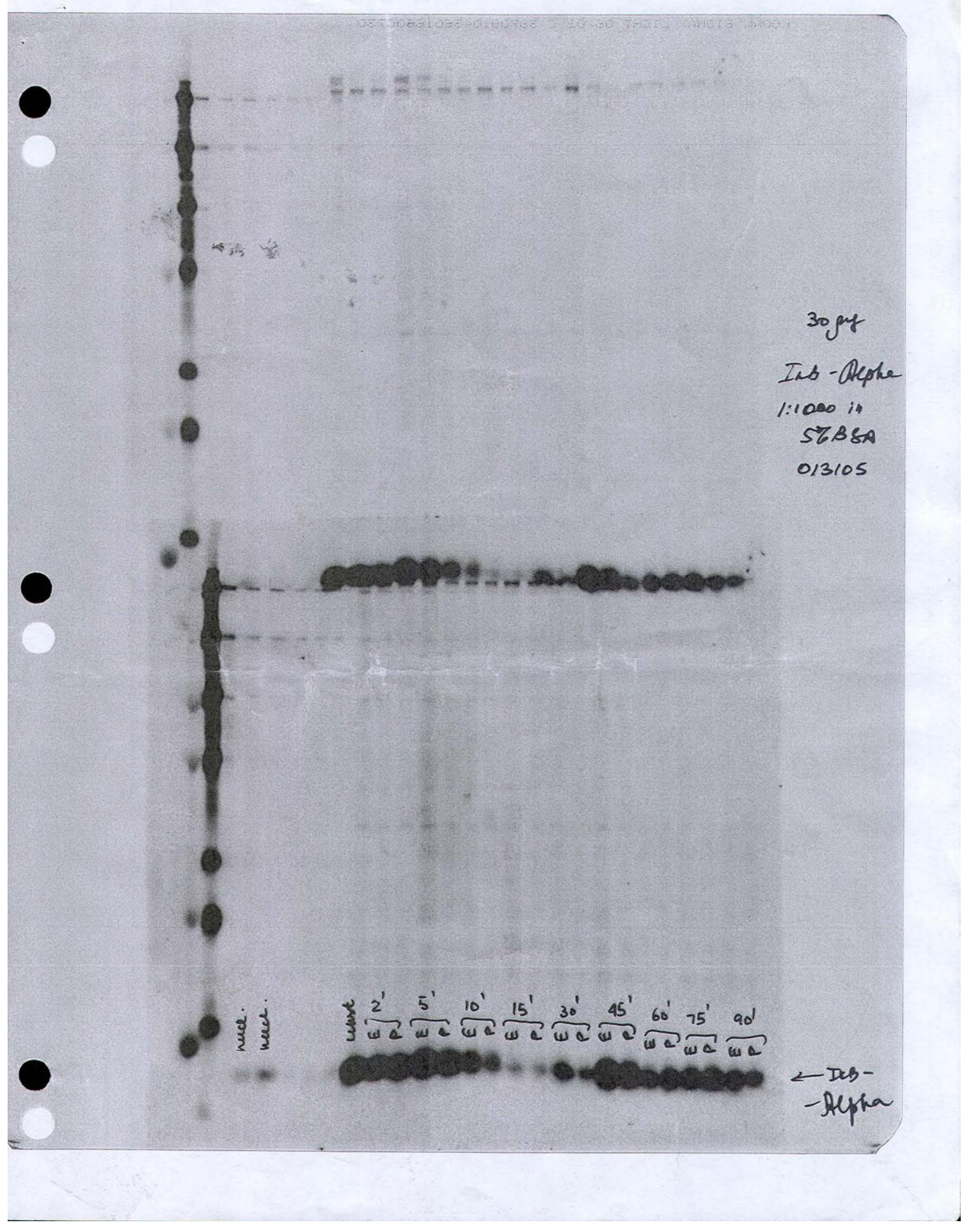




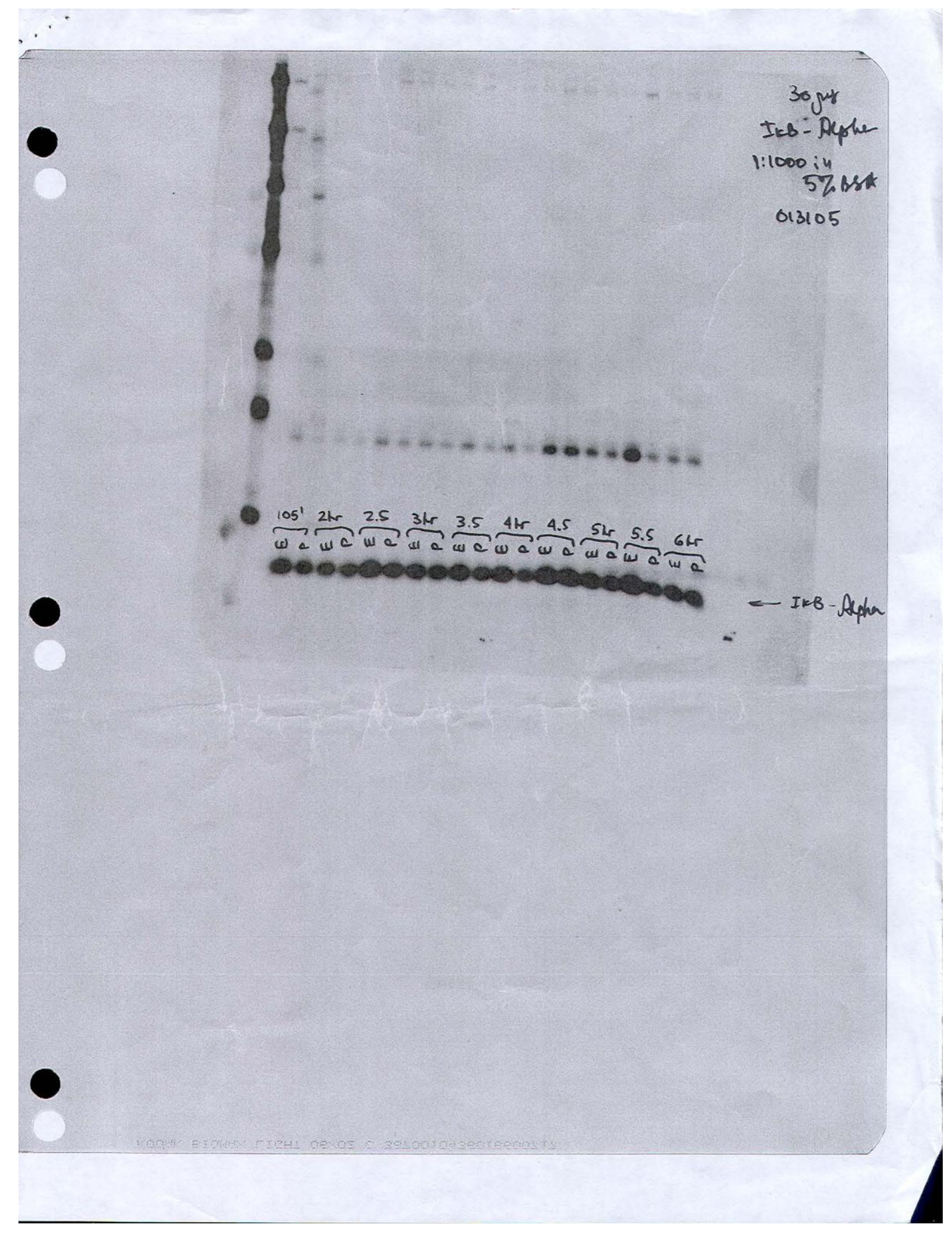


Supplement 3.2 : Gel image for $\beta$-actin

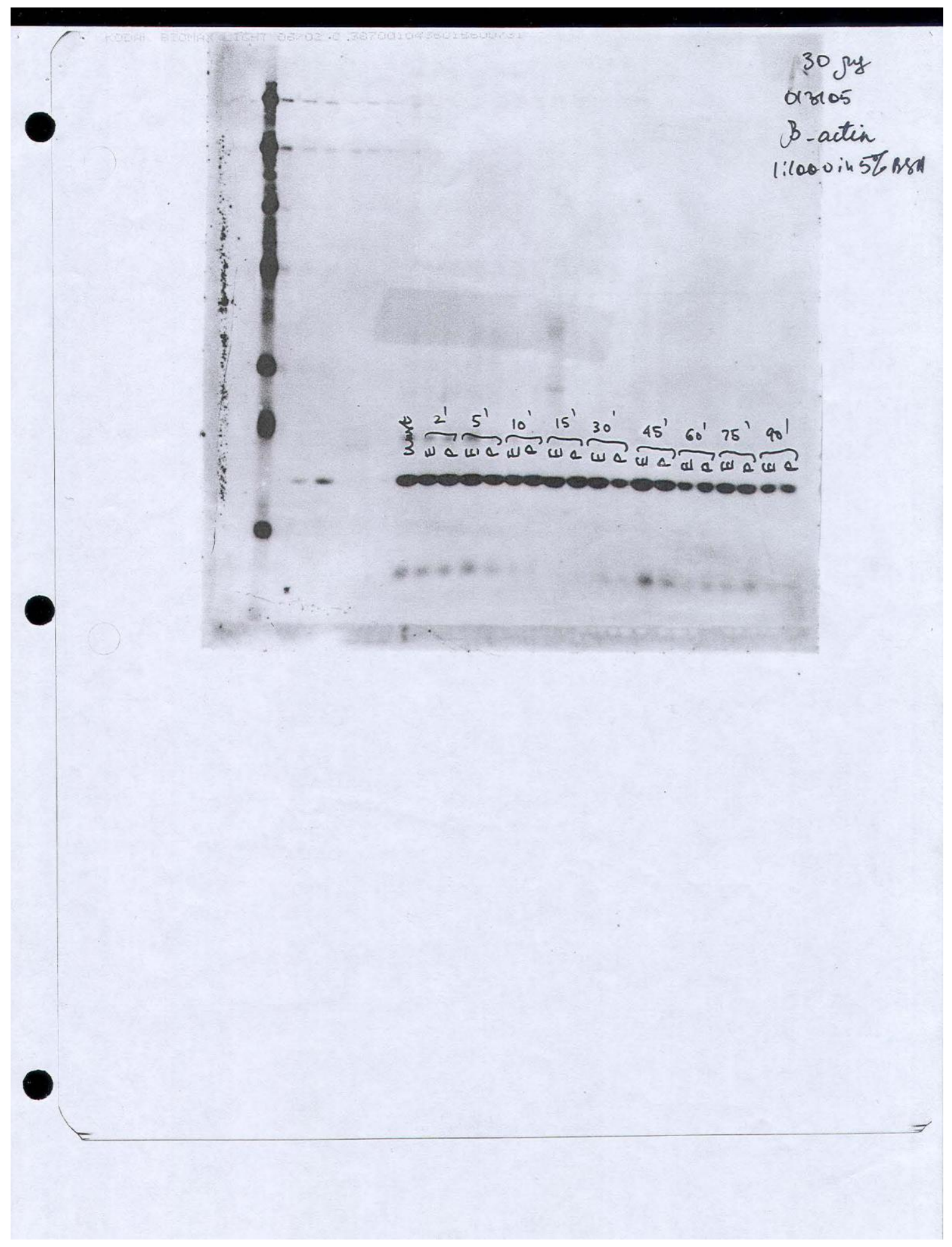




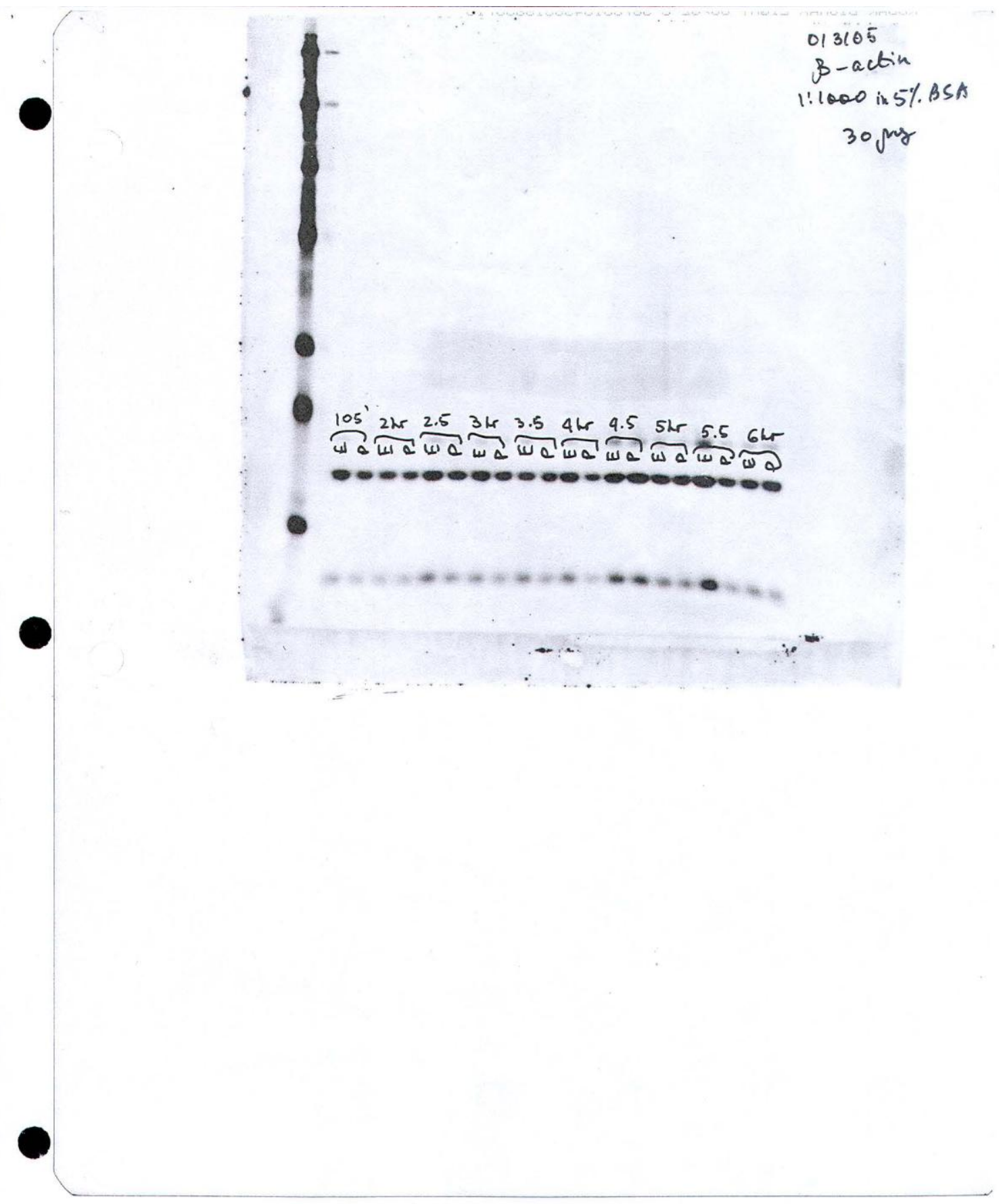


Supplement 3.3 : Gel image for IкB $\beta$ in the cytoplasm

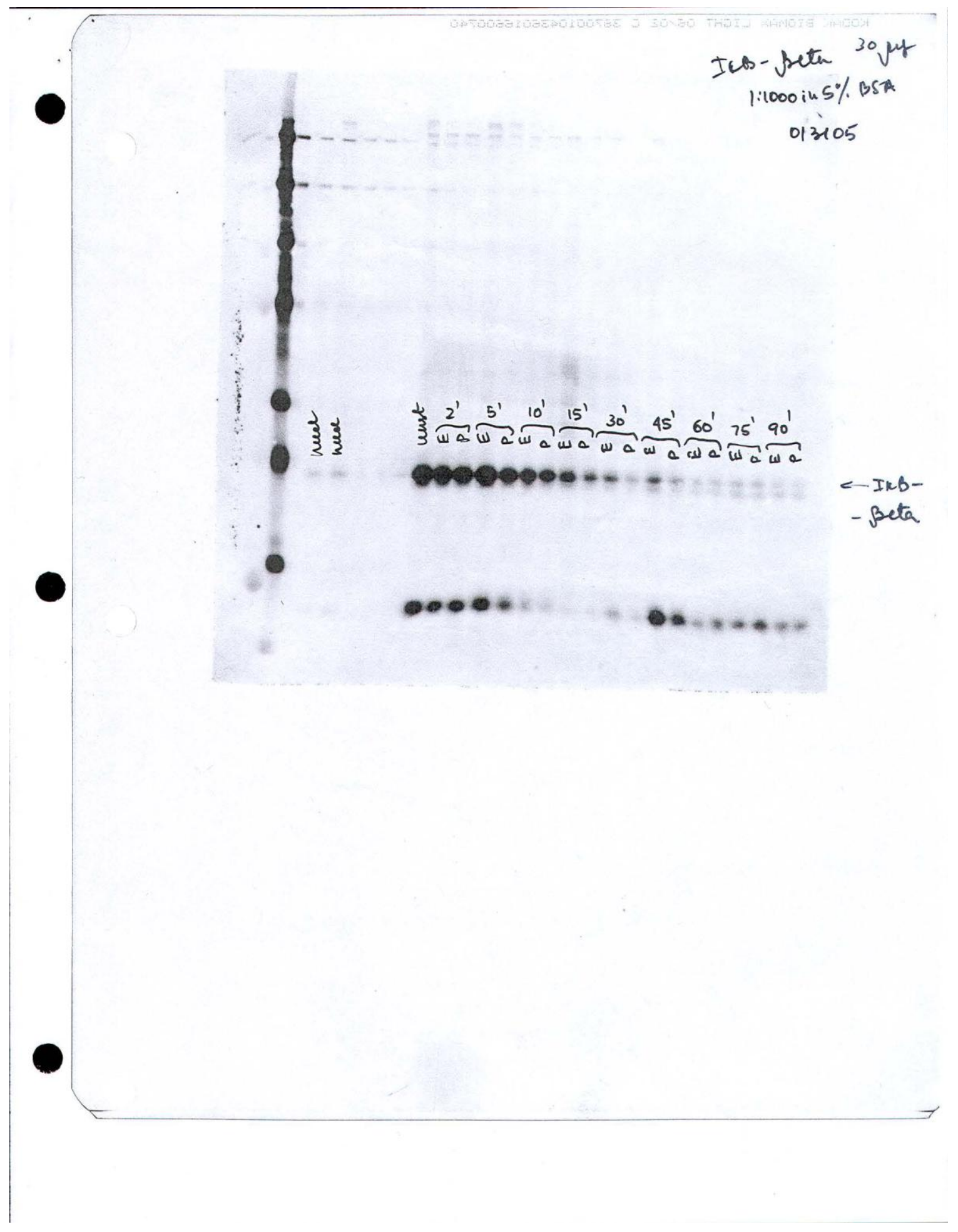




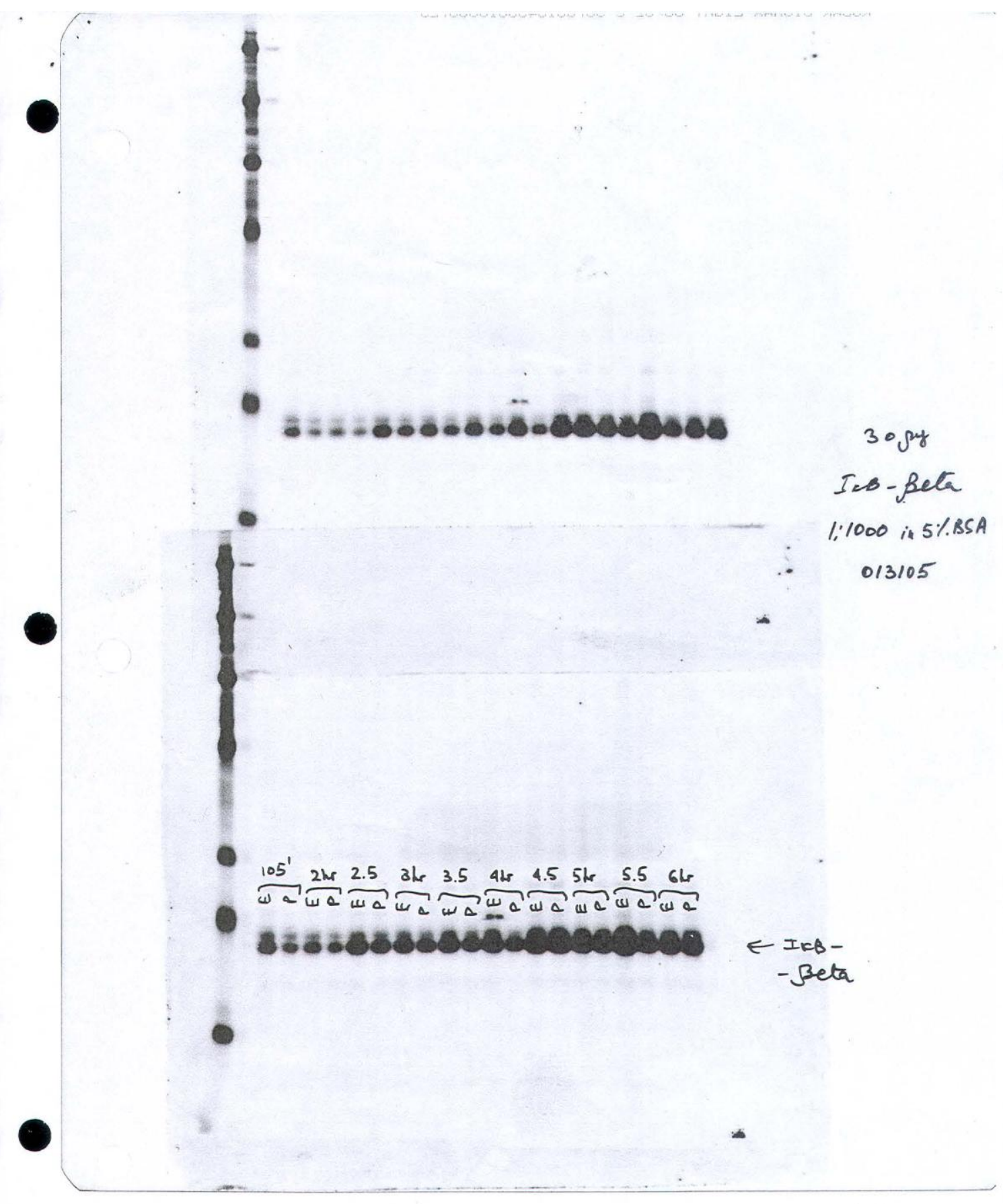


Supplement 3.4: Gel image for Free NFkB in the nucleus

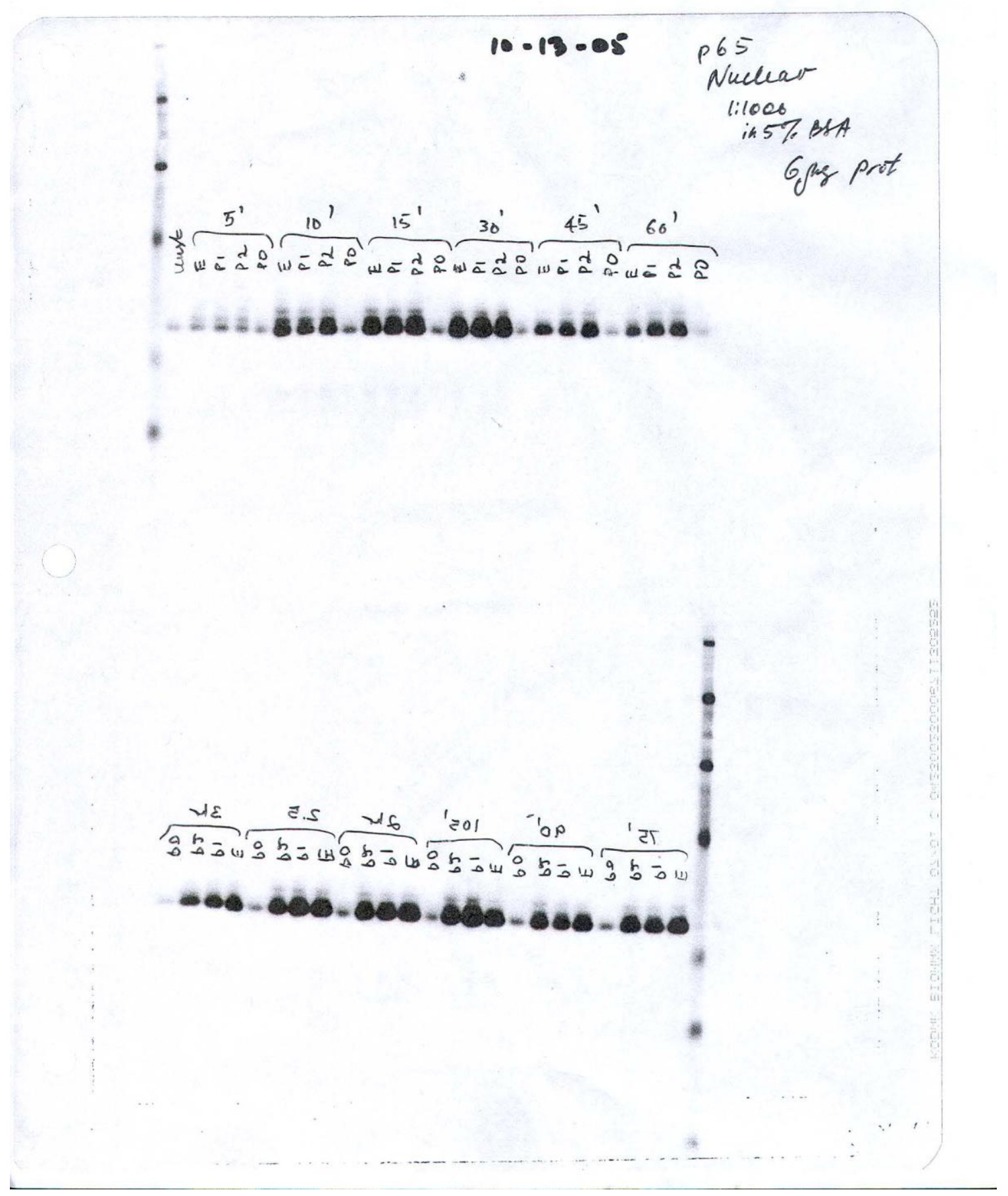




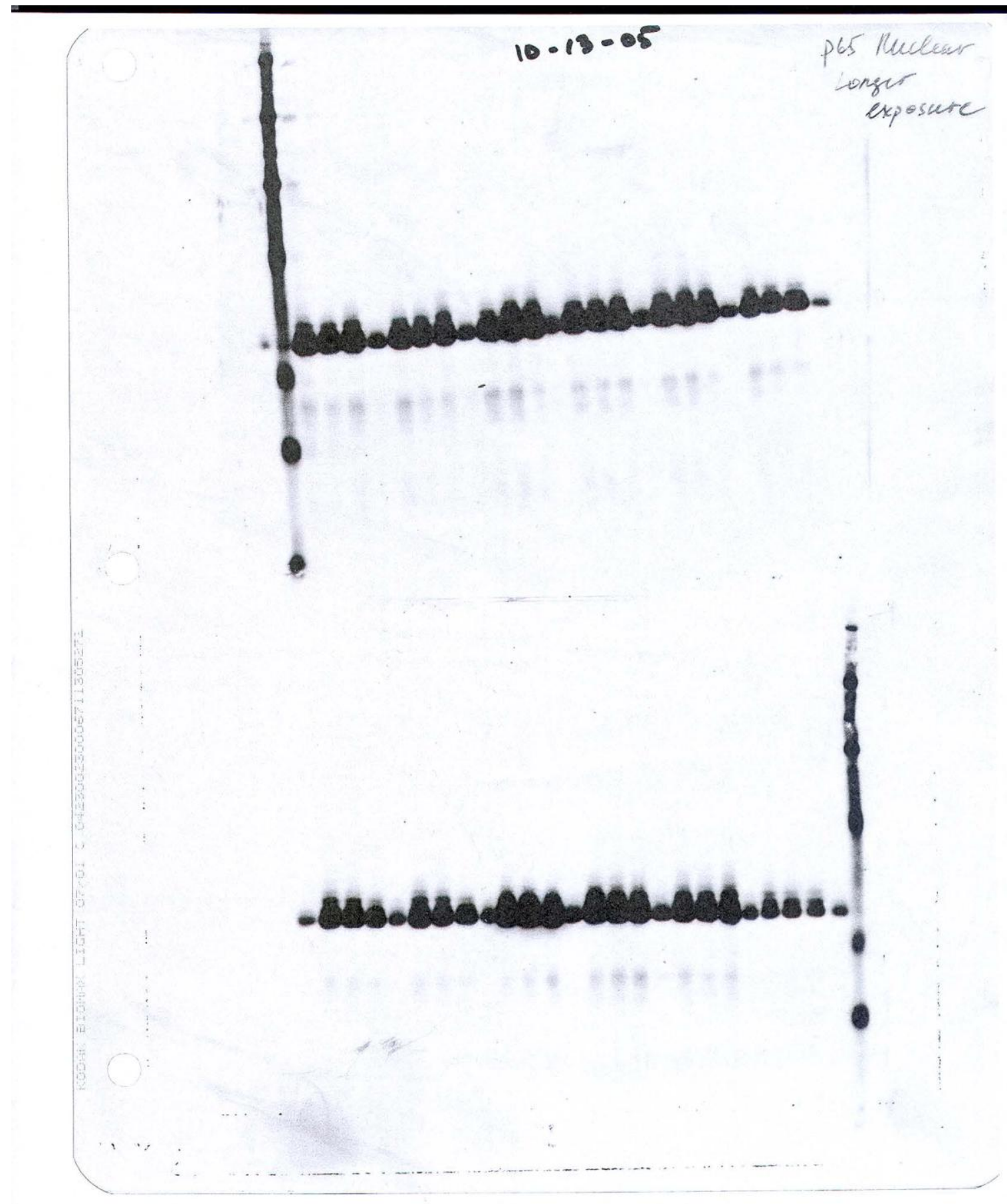

103 


\section{Huanling Liu}

\section{Copper Creek Court, Morgantown, WV, 26505, (304) 685-8115 huanlliu@gmail.com}

\section{QUALIFICATIONS}

Polymers evaluation, Solid catalyst development and characterization ability and mathematic modeling

\section{EDUCATION}

M.S., Chemical Engineering, West Virginia University, Morgantown, WV, 2008-2011 GPA: 3.6 Thesis: "Modulating Temporal Control of NF-кB Activation: Implications for Therapeutic Selection" Advisor: Dr. David J. Klinke II

M.S., Catalysis, Dalian Institute of Chemical Physics, CAS, Dalian, China, 2004-2007

GPA: 3.3

Thesis: "Studies on Ce Promoted $\mathrm{Pt} / \gamma-\mathrm{Al}_{2} \mathrm{O}_{3}$ Catalysts for Preferential CO Oxidation"

Advisor: Associate Professor Lei Ma

B.S., Applied Chemistry, Dalian University of Technology, Dalian, China, 2000-2004 GPA: 3.2 Graduate Project: "Catalytically Selective Hydrogenation of C=O bond by Raney Ruthenium"

Advisor: Dr. Xinqin Gao

\section{INDUSTRIAL EXPERIENCE}

Chemical Lab CO-OP, Cummins Filtration, Cookeville, TN

2010.05-2010.12

- Tested and evaluated polymer materials (including thermoset \& thermoplastic polymers, elastomers like gasket, seals, cellulose) by DSC and TGA

- Developed standard calibration procedure to keep DSC accurate and reliable

- Developed standard operating procedures for DSC and TGA

- Studied Filter Media Cellulose isotherm curing phenomena and kinetic theory

- Develop new and enhanced existing thermo analysis procedures for polymer characterization

- Cooperated with Research engineers in Cummins filtration and Coolant chemical groups

- Enhanced existing GC methods for glycol quantization

- Investigated filter media contaminant analysis by GC headspace

- Received 6 sigma overview training

- Supported VPI projects by DSC and TGA analysis

\section{RESEARCH EXPERIENCE}

Research Assistant, West Virginia University, Morgantown, WV

2008-2009

- Establish the confidence of parameters by Empirical Bayesian approach and Markov Chain Monte Carlo techniques

- Analyzed the correlation of parameters by Sensitivity Analysis and optimized them by Simulation Annealing program using MATLAB

- Developed an Ordinary Differential Equations-based mathematical model with 28 parameters based on biochemical reaction engineering to study dynamics of 14 variables by MATLAB

- Cooperated and coordinated with team workers from multiple disciplines including chemical engineering, immunology, medicine and clinic departments

Research Assistant, Dalian Institute of Chemical Physics, CAS, Dalian, China $\quad$ 2004-2007

- Designed a novel catalyst with high CO oxidation and selectivity for preferential CO oxidation in $\mathrm{H}_{2}$ rich atmosphere, lowing the conversional temperature from $160{ }^{\circ} \mathrm{C}$ to $60^{\circ} \mathrm{C}$

- Prepared and screened mixed and supported metal oxide with the methods of incipient wetness impregnation, co-precipitation and vacuum multi-step impregnation 
- Investigated the catalytic deactivation process of $\mathrm{Pt} / \gamma-\mathrm{Al}_{2} \mathrm{O}_{3}$ based catalysts by $\mathrm{GC}, \mathrm{ICP}, \mathrm{BET}$, $\mathrm{XRD}, \mathrm{H}_{2}$-TPR and In situ DRIFTS

- Illustrated the catalyst structure and reaction mechanism and observed that addition of Cerium changes one active site adsorption mechanism to double active sites adsorption mechanism

- Synthesized Mesoporous Molecular Sieves MCM-41 by hydrothermal methods and Characterized by XRD and SEM

Research Assistant, Dalian University of Technology, Dalian, China

2003-2004

- Optimized the selection of Raney Ruthenium Catalysts to $\mathrm{C}=\mathrm{O}$ hydrogenation in different solvents and at differential reaction temperatures

- Analyzed $\mathrm{CH} 3, \mathrm{CH} 2, \mathrm{C}=\mathrm{C}$ and $\mathrm{C}=\mathrm{O}$ organic functional groups by $\mathrm{H}-\mathrm{NMR}$, IR, and TLC

- Separated the products from batch reactions through extraction and rotary evaporation

\section{PUBLICATIONS and PRESENTATIONS}

1. Liu, Huanling, Irina V. Ustyugova, John B. Barnett, and Klinke, David J. II. Inferring the Impact of 3, 4-dichloropropionaniline on the Regulation of nuclear factor-кB Activation by ІкВ $\alpha$ and IкB $\beta$. American Chemical Society Chemistry Symposium, Morgantown, WV, 2009 April.

2. Liu, Huanling, Irina V. Ustyugova, John B. Barnett, and Klinke, David J. II. Inferring the Impact of 3, 4-dichloropropionaniline on the Regulation of nuclear factor-kappaB Activation by IkappaBalpha and IkappaBbeta. HSC Research Day \& Van Liere Convocation, Morgantown, WV, 2009 April.

3. Liu, Huanling, Ma, Lei, Shao, Saibing, Li, Zenghe, Wang, Aiqin, Huang, Yanqiang, and Zhang, Tao. Preferential CO Oxidation on Ce-Promoted Pt $/ \gamma-\mathrm{Al}_{2} \mathrm{O}_{3}$ Catalysts under $\mathrm{H}_{2}$-Rich Atmosphere. CHINESE JOURNAL OF CATALYSIS, 2007 Vol.28, No.12, P.1077-1082.

4. Liu, Huanling, Gao, Xinqin. Catalytically Selective Hydrogenation of $\mathrm{C}=\mathrm{O}$ bond by Raney Ruthenium. Graduate project competition. Dalian, China, 2004.

\section{COMPUTER SKILLS}

- High level : MATLAB, Microsoft World, Excel, PowerPoint

- Middle level: Origin, CHEMDRAW, CHEMCAD, R

\section{LANGUAGES}

- Good in English

- Excellent in Chinese 